Florida International University FIU Digital Commons

FIU Electronic Theses and Dissertations

University Graduate School

3-25-2009

\title{
The Mathematics Anxiety of Bilingual Community College Students
}

Laura Hillerbrand Iossi

Florida International University, lhillerb@hotmail.com

DOI: $10.25148 /$ etd.FI10022525

Follow this and additional works at: https://digitalcommons.fiu.edu/etd

\section{Recommended Citation}

Iossi, Laura Hillerbrand, "The Mathematics Anxiety of Bilingual Community College Students" (2009). FIU Electronic Theses and Dissertations. 198.

https://digitalcommons.fiu.edu/etd/198

This work is brought to you for free and open access by the University Graduate School at FIU Digital Commons. It has been accepted for inclusion in FIU Electronic Theses and Dissertations by an authorized administrator of FIU Digital Commons. For more information, please contact dcc@fiu.edu. 


\section{FLORIDA INTERNATIONAL UNIVERSITY \\ Miami, Florida}

\section{THE MATHEMATICS ANXIETY OF BILINGUAL COMMUNITY COLLEGE STUDENTS}

A dissertation submitted in partial fulfillment of the requirements for the degree of DOCTOR OF EDUCATION

in HIGHER EDUCATION

by

Laura Hillerbrand Iossi 
To: Interim Dean Kingsley Banya

College of Education

This dissertation, written by Laura Hillerbrand Iossi, and entitled The Mathematics Anxiety of Bilingual Community College Students, having been approved in respect to style and intellectual content, is referred to you for judgment.

We have read this dissertation and recommend that it be approved.

$\begin{array}{r}\hline \text { Janice R. Sandiford } \\ \hline \text { Glenda Musoba } \\ \hline \text { George O’Brien }\end{array}$

\section{Ann Nevin, Major Professor}

Date of Defense: March 25, 2009

The dissertation of Laura Hillerbrand Iossi is approved.

\begin{tabular}{r}
$\begin{array}{r}\text { Interim Dean Kingsley Banya } \\
\text { College of Education }\end{array}$ \\
\hline Dean George Walker \\
University Graduate School
\end{tabular}

Florida International University, 2009 
(C) Copyright 2009 by Laura Hillerbrand Iossi

All rights reserved. 


\section{DEDICATION}

I would like to dedicate this project to my students. I ventured forth on this journey with your stories at heart. Your perseverance in my classes, sometimes against great personal challenges, often reminded me to push on when I felt otherwise. I sincerely hope that the findings of this study may ultimately help you and all students succeed in their math classes and appreciate the beauty of mathematics. 


\section{ACKNOWLEDGMENTS}

Thank you to all those people who have surrounded me with support, love, and encouragement. I thank my husband, Rick, who has put up with my endless hours of research and frustration for years now. Thank you for sacrificing time together and for reading those drafts and offering your suggestions. I thank my parents who have always encouraged me to value my education. I especially thank my mother for her experience as a professor of English for speakers of other languages, which undoubtedly influenced my subject matter. I thank my father for his mastery of languages and example of being a true polyglot. I thank my grandmother, who looked down on me from heaven from the day I enrolled in the doctoral program. She constantly reminded me to find balance in my life; to eat, to play, and to not take myself too seriously during this journey. I also thank my cats, Frisco and Grindel, for their untiring devotion and dedication to lap sitting for the many hours I spent on my computer.

There are many individuals at Florida International University who have ensured that I completed this project. First, I thank my advisor, Dr. Nevin. You tirelessly offered your expertise at all times of the day and night. I still think that you have cloned yourself for you went well beyond my dreams for a supportive, mentoring, knowledgeable advisor. To the rest of my committee, Dr. Glenda Musoba, Dr. George O'Brien, and Dr. Janice Sandiford, thank you for professionalism, feedback, and support. I also thank Dr. Bryan Moseley, Dr. Cengiz Alacaci, Dr. Linda Bliss, Dr. Isadore Newman, and Dr. Maria Fernandez for the wisdom that they offered. Additionally, I thank those professionals who served the Office of Graduate Studies in the College of Education and the University Graduate School by providing feedback on my proposals and dissertation with the goal of 
ensuring that my dissertation meets the standard of excellence of Florida International University and the research community at large.

I thank all the faculty and student volunteers. Without you, this study could not exist. The opening of your minds, hearts, personal histories, and grade books offered insight into the personal experiences of mathematics anxiety.

Thank you, God, for bringing all these people into my life, for my ability to think, and for Your inspiration. 


\title{
ABSTRACT OF THE DISSERTATION \\ THE MATHEMATICS ANXIETY OF BILINGUAL COMMUNITY COLLEGE STUDENTS
}

\author{
by \\ Laura Hillerbrand Iossi \\ Florida International University, 2009 \\ Miami, Florida

\section{Professor Ann Nevin, Major Professor}

Math anxiety levels and performance outcomes were compared for bilingual and monolingual community college Intermediate Algebra students attending a culturally diverse urban commuter college. Participants $(N=618,250$ men, 368 women; 361 monolingual, 257 bilingual) completed the Abbreviated Math Anxiety Scale (AMAS) and a demographics instrument. Bilingual and monolingual students reported comparable mean AMAS scores (20.6 and 20.7, respectively) and comparable proportions of math anxious individuals (50\% and 48\%, respectively). Factor analysis of AMAS scores, using principal component analysis by varimax rotation, yielded similar two-factor structures for both populations -- assessment and learning content -- accounting for $65.6 \%$ of the trace for bilingual AMAS scores. Statistically significant predictor variables for levels of math anxiety for the bilingual participants included (a) preparatory course enrollment ( $\beta$ $=.236, p=.041)$ with those enrolled in prior preparatory courses scoring higher, (b) education major $(\beta=.285, p=.018)$ with education majors scoring higher, and (c) business major $(\beta=.252, p=.032)$ with business majors scoring higher. One statistically significant predictor variable emerged for monolingual students, gender $(\beta=-.085, p=$ 
.001) with females ranking higher. Age, income, race, ethnicity, U.S. origin, science or health science majors did not emerge as statistically significant predictor variables for either group.

Similarities between monolingual and bilingual participants included statistically significant negative linear correlations between AMAS scores and course grades for both bilingual $(r=-.178, p=.017)$ and monolingual participants $(r=-.203, p=.001)$.

Differences included a statistically significant linear correlation between AMAS scores and final exam grades for monolingual participants only $(r=-.253, p<.0009)$ despite no statistically significant difference in the strength the linear relationship of the AMAS scores and the final exam scores between groups, $z=1.35, p=.1756$.

The findings show that bilingual and monolingual students report math anxiety similarly and that math anxiety has similar associations with performance measures, despite differences between predictor variables. One of the first studies on the math anxiety of bilingual community college students, the results suggest recommendations for researchers and practitioners. 


\section{TABLE OF CONTENTS}

CHAPTER

PAGE

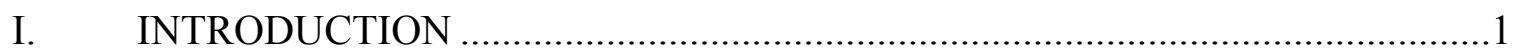

Background of the Study ..............................................................................

Theoretical Framework for Math Anxiety ........................................................2

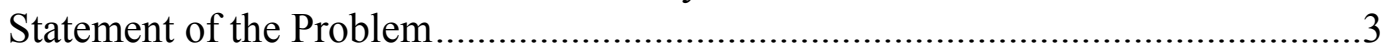

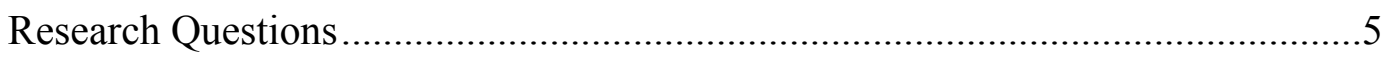

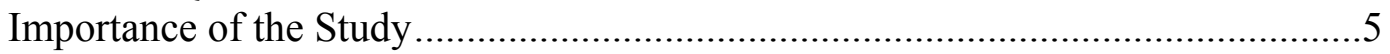

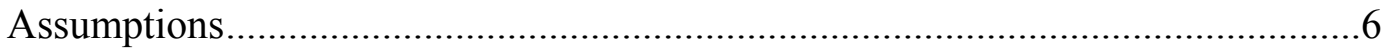

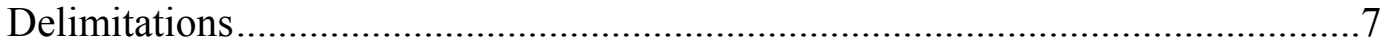

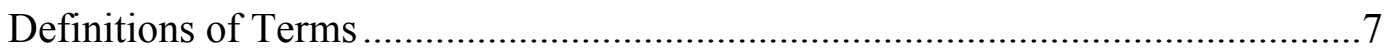

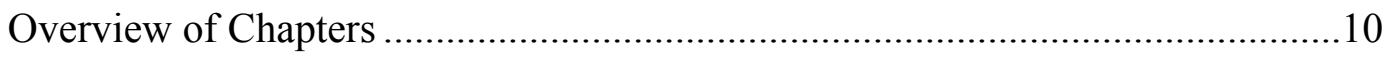

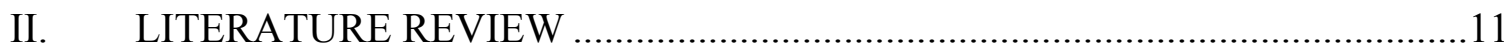

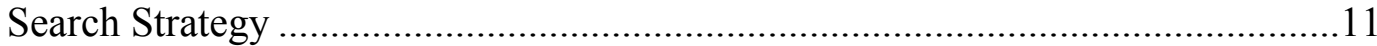

Criteria for Selecting Studies ......................................................................12

Explication and Critique of the Literature .........................................................13

Summary and Conclusion ...............................................................................40

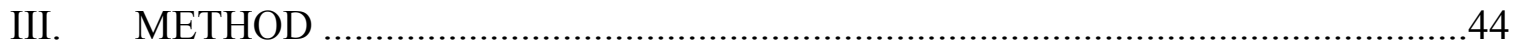

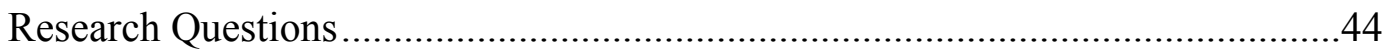

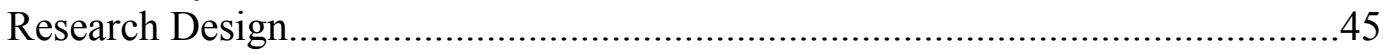

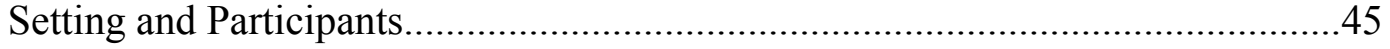

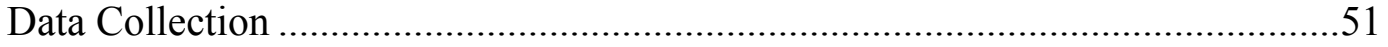

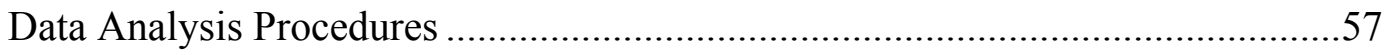

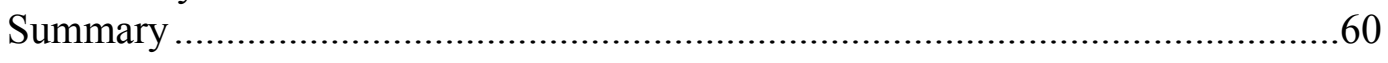

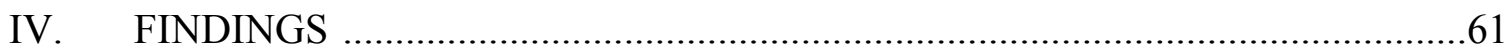

Research Question 1 ...............................................................................65

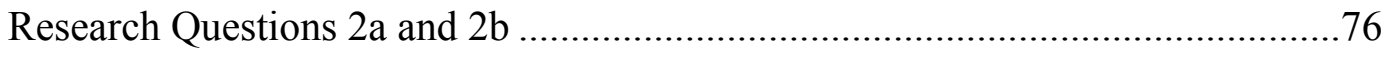

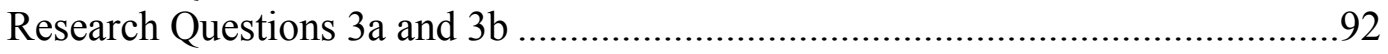

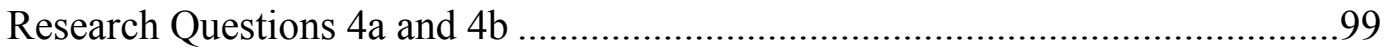

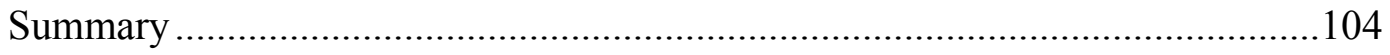

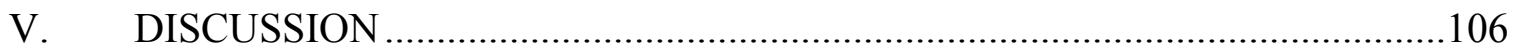

Summary of the Study and Overview of Significant Findings .............................106

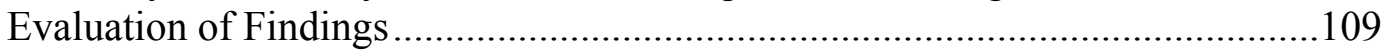

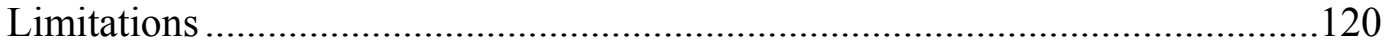

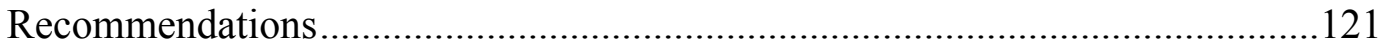

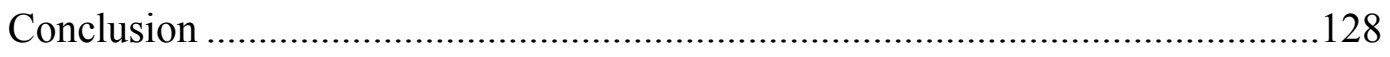




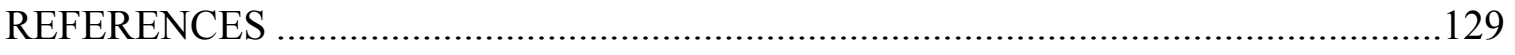

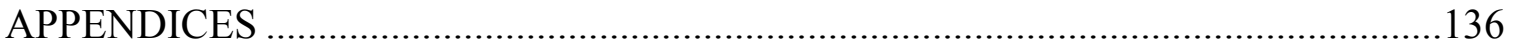

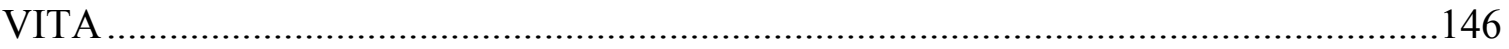




\section{LIST OF TABLES}

TABLE

PAGE

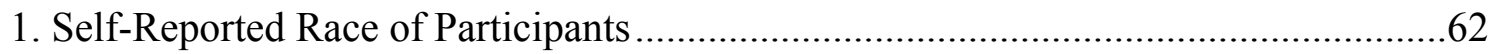

2. Self-Reported Ages of Participants..........................................................................63

3. Self-Reported Household Income Levels of Participants............................................63

4. AMAS Scores for Bilingual and Monolingual Participants ..........................................65

5. Principal Component Loadings...............................................................................66

6. Eigenvalues and Variance Explained for Principal Component Analysis...................67

7. Bilingual and Monolingual Rotated Factor Matrices....................................................69

8. Comparison of Mean Math Anxiety Frequency and Intensity According to

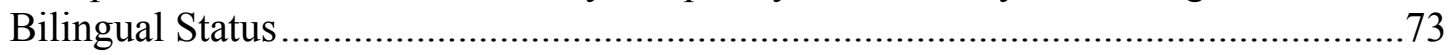

9. Mean Anxiety Frequency According to Bilingual Status ............................................74

10. Math Anxiety Intensity According to Bilingual Status...............................................75

11. AMAS Scores for Bilingual and Monolingual Participants by Gender.......................77

12. AMAS Scores for Bilingual and Monolingual Participants by Age.............................78

13. AMAS Scores for Bilingual and Monolingual Participants by Income ......................79

14. AMAS Scores for Bilingual and Monolingual Participants by Ethnicity …….............81

15. AMAS Scores for Bilingual and Monolingual Participants by U.S. Origin.................81

16. AMAS Scores for Bilingual and Monolingual Participants by Preparatory Course ...82

17. AMAS Scores for Bilingual and Monolingual Participants by Education Major ........83

18. Analysis of Variance for AMAS Scores by Bilingual Status and Education Major ...84

19. AMAS Scores for Bilingual and Monolingual Participants by Business Major ..........85

20. Analysis of Variance for AMAS scores by Bilingual Status and Business Major ......85 
21. AMAS Scores for Bilingual and Monolingual Participants by Health Sciences Major

22. Analysis of Variance for AMAS scores by Bilingual Status and Health Sciences Major.

23. AMAS Scores for Bilingual and Monolingual Participants by Science Major .88

24. Analysis of Variance for AMAS scores by Bilingual Status and Science Major........89

25. The $\beta$ and $p$-values for 11 Predictor Variables and Low/Middle/High Math Anxiety Classification.

26. The $\beta$ and $p$-values for 11 Predictor Variables and Low/Middle/High Math Anxiety Classification by Bilingual Status

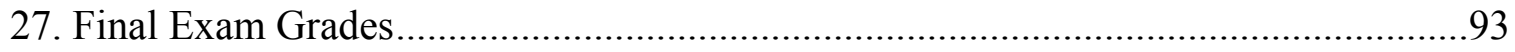

28. Final Exam Grades by Bilingual Status ................................................................96

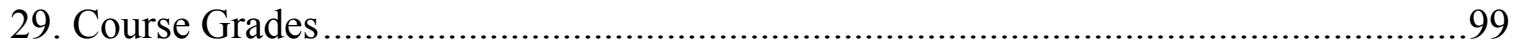

30. Course Grade Summary Statistics for All, Bilingual, and Monolingual

Participants.

31. Course Grades by Bilingual and Monolingual Status

101 


\section{LIST OF FIGURES}

FIGURE

PAGE

1. Sequence of First Few Mathematics Courses at Student Community College .48

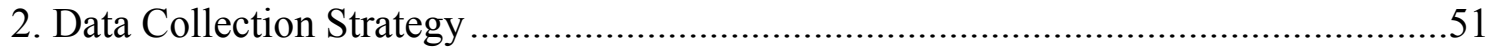

3. Histogram of AMAS Scores for 598 Intermediate Algebra Students.........................64

4. Scree Plot for Bilingual Participants.................................................................68

5. Scree Plot for Monolingual Participants .................................................................68

6. Histograms of Frequency of Math Anxiety and Intensity of Math Anxiety for

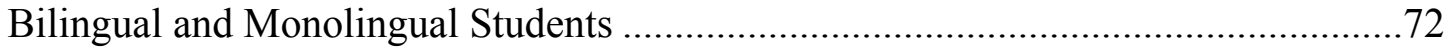

7. Scatterplot of AMAS Scores and Final Exam Scores.............................................95

8. Scatterplots of AMAS Scores and Final Exam Scores for Monolingual and

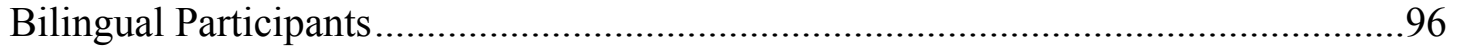

9. Scatterplot of AMAS Scores and Mean Course Grades .........................................100

10. Scatterplots of AMAS Scores and Mean Course Grades for Monolingual and Bilingual Participants. 


\section{LIST OF ACRONYMS}

ACRONYM

ACT

AMAS

ATMI

ATMS

EAP

ESL

FSMAS

MAQ

MARS

MAS

NCES

R-MARS

STABS

SPQ

TAI

\section{DEFINITION}

American College Test

Abbreviated Math Anxiety Scale

Attitudes Toward Mathematics Inventory

Anxiety Toward Mathematics Scale

English for Academic Purposes

English as a Second Language

Fennema-Sherman Mathematics Attitude Scale

Math Anxiety Questionnaire

Math Anxiety Rating Scale

Mathematics Anxiety Scale

National Center for Education Statistics

Revised Mathematics Anxiety Rating Scale

Suinn Test Anxiety Behavior Scale

Study Process Questionnaire

Test Anxiety Inventory 


\section{CHAPTER I}

\section{INTRODUCTION}

Many students experience math anxiety, defined as "feelings of tension and anxiety that interfere with the manipulation of numbers and the solving of mathematical problems in a wide variety of ordinary life and academic situations" (Richardson \& Suinn, 1972, p. 551). In her role as an instructor of mathematics at a community college, the researcher has taught intelligent, determined students who reported experiencing math anxiety and who repeatedly underperformed in their mathematics courses. Math anxiety has been associated with math avoidance, course selection, and mathematics performance (Hembree, 1990). Forms of math anxiety can range from moderate test anxiety to extreme anxiety (Perry, 2004). "Mathophobia may be compared with the loss of one of the primary senses" (Hilton, 1980a, p. 175). Extreme mathematics anxiety can lead to very debilitating states of mind (Akinsola, 2008).

\section{Background of the Study}

The pervasiveness of math anxiety has been reported. For example, Perry (2004) found that $85 \%$ of community college students in introductory math classes claimed to experience at least mild math anxiety. Jackson and Leffingwell (1999) found that 93\% of 157 elementary education students reported math anxiety in their math classes from kindergarten through college while only $7 \%$ did not report stressful experiences. The freshman year in college was the starting point of mathematics-related stress for $27 \%$ of their participants.

Students fail or drop out of college math courses, especially preparatory math classes, at very high rates (McCabe, 2003). In the fall 2000 semester, $22 \%$ of entering 
freshman enrolled in preparatory mathematics courses at institutions of higher education (Parsad \& Lewis, 2003), while the dropout rate in these courses was as high as $25 \%$ with only one of two students completing the courses (McCabe, 2003). Often, the passing rates in mathematics classes at this level can fall below 50\% (McCabe). Since math anxiety has been closely tied to performance in math courses (e.g., Chapell et al., 2005; Hembree, 1990; Ma, 1999), college success and career choices have also been influenced by high math anxiety. Students with high math anxiety tend to avoid educational paths and careers that require mathematics competence (Ashcraft \& Ridley, 2005).

\section{Theoretical Framework for Math Anxiety}

The construct of mathematics anxiety falls within the larger construct of anxiety (Hembree, 1990) where anxiety has been broadly defined to be a tense emotional response to the intellectual appraisal of a threatening stimulus. This emotional response has been described as disturbing and out of proportion to the threat (Beck \& Emery, 1985). Hembree (1990) described math anxiety as a domain specific expression of anxiety: "Anxiety is an omnibus construct, and under its rubric, there has appeared a host of subconstructs that relate to discrete situations" (p. 33). Hembree further defined math anxiety in this way: "The construct appears to comprise a general fear of contact with mathematics, including classes, homework, and tests" (p. 45).

The math anxiety literature evolved out of early studies in the 1950s on the effects of anxiety on scholastic performance. The earliest instrument to assess math anxiety can be traced to Dreger and Aiken (1957) who developed the Numerical Anxiety Scale, comprised of three questions. By the early 1970s, the lens narrowed from anxiety research in general to the construct of math anxiety. Richardson and Suinn (1972) 
brought the concept of math anxiety to the research forefront with the development of the Math Anxiety Rating Scale (MARS).

According to Selden and Selden (1993), the 1978 publication of Sheila Tobias's

book, Overcoming Math Anxiety, popularized the concept of math anxiety. In the 1980s, research on the effects of math anxiety on performance focused on gender differences and the relationship between math anxiety and other related anxieties. For example, Miller and Bichsel (2004) found that state anxiety, trait anxiety, and math anxiety were correlated, but math anxiety was the only type of anxiety that correlated with math performance. Recently, math anxiety literature has included studies on the cognitive impairments associated with math anxiety (Ashcraft, 2002; Ashcraft \& Kirk, 2001; Ashcraft \& Ridley, 2005).

\section{Statement of the Problem}

No research has been located regarding the success rates and math anxiety for bilingual community college students. At 2-year public colleges, approximately $23.2 \%$ of first and second year students enrolled in a remedial or preparatory course in $1999-2000$, with $75.6 \%$ of those students enrolled in a remedial math course (National Center for Education Statistics, NCES, 2000). Dropout rates in remedial or preparatory course were high and completion rates were low (McCabe, 2003). Bilingual students were included as part of the population sampled for these statistics, although results specific to this subpopulation were not described.

Despite the value that bilingual students bring to the community college, their educational experiences have not been well researched. In 2004, the United States population consisted of over $34,237,000$ foreign born individuals, of which $16,278,000$ 
were Hispanic foreign born (United States Census Bureau, 2004b). Moreover, an all time high of approximately 623,800 international students attended U.S. institutions in 20072008 (Institute of International Education, 2008). The majority of these students came from countries with primary languages other than English. International education can be considered the country’s fifth-largest export, contributing $\$ 13$ billion per year to the U.S. economy (Blair, Phinney, \& Phillippe, 2001).

The American Association of Community Colleges indicated that $82 \%$ of community colleges offered English as a Second Language (ESL) programs in 2000 (Blair et al, 2001). Blair et al. (2001) noted that cross-cultural differences were cited as a problem by $5 \%$ of institutions. All students must meet the mathematics requirement for graduation, despite varying math backgrounds and experiences with mathematics courses. Because math anxiety has been shown to affect performance (e.g., Chapell et al., 2005; Hembree, 1990; Ma, 1999), bilingual students may experience unique math anxiety challenges that might impact their success in the mathematics classroom. However, these students tend to be ignored once they are outside of structured ESL support programs or bilingual environments. The bilingual community college students' math anxiety may influence their math performance and success in math courses.

Due to the lack of knowledge about math anxiety for community college students who are bilingual (English/Spanish, English/Creole, English/Portuguese, etc.), this study examined the bilingual students' experiences of math anxiety. To date, no study had been found on the math anxiety of bilingual community college students in the United States. The present study expanded the existing literature on math anxiety to a population of students who, as of yet, had not been investigated. The researcher examined the math 
anxiety of bilingual community college students who were enrolled in an Intermediate Algebra course. The researcher hoped to inform the higher education community about the math anxiety experiences of these students so as to ultimately aid in the development of strategies for helping these students improve their rates of success in college mathematics.

\section{Research Questions}

Four questions were posed:

1. Are bilingual and monolingual students different in their self-reported levels of math anxiety?

2a. What are the variables that predict math anxiety levels?

$2 b$. Are the predictor variables for math anxiety levels different for bilingual students compared to monolingual students?

3a. How are final exam performance and self-reported levels of math anxiety related for bilingual students?

$3 b$. Is this relationship different from the relationship of final exam performance and self-reported math anxiety levels for monolingual students?

4a. How are course performance and self-reported levels of math anxiety related for bilingual students?

$4 \mathrm{~b}$. Is this relationship different from the relationship of course performance and self-reported math anxiety levels for monolingual students?

Importance of the Study

Information about bilingual community college students and their math anxiety had not been adequately addressed in the current literature. Additionally, information 
about the cultural influences on math anxiety was weak. The researcher hoped to fill a void in the literature about how math anxiety might be experienced by community college students who represented different cultural groups.

Many community college students enroll in preparatory mathematics courses, and many of these students fail or withdraw from these courses as well as subsequent college level math courses. Their pathway to success may be diverted by high math anxiety. The researcher hoped to improve the understanding of the cognitive and affective barriers to learning mathematics and the success of bilingual students so as to offer more career options.

The results from this study could provide useful information to instructors, counselors, student services personnel, and, most importantly, to the students themselves. Instructors may improve their student success by implementing math anxiety reduction techniques targeted for bilingual students as part of their instruction. Counselors might better assist frustrated students by better understanding the math anxiety of their students. Student services might provide more informed programs on math anxiety to target these students. Finally, students might make more informed decisions about the math anxiety they may be experiencing. Ultimately, the findings may encourage bilingual students to tackle the subject more freely, to explore careers that involve additional math courses, and to participate confidently in a math literate society.

\section{Assumptions}

The researcher made the following assumptions. First, math anxiety is a measurable construct. Second, the students were honest in their responses and accurately reported their experiences with math anxiety. Third, the participants reported their 
language ability accurately. Fourth, the instructors reported the correct final exam and course grades of participants.

\section{Delimitations}

The study participants were delimited to those students enrolled in Intermediate Algebra courses during one academic semester at one community college in a metropolitan area of the southeastern United States. The variables in the study were limited to number of languages spoken, math anxiety score, enrollment in a preparatory course, ethnicity, race, country of origin, household income, age, gender, major, final exam score, and course grade. Furthermore, the student demographics at the site may have represented or reflected a unique experience that may not be generalizable to other settings.

\section{Definitions of Terms}

The following terms were defined for use in this study. They appear in alphabetical order.

Bilingual. As used in the present study, self-reported claim of fluency in two or more languages.

Developmental education. The National Association for Developmental

Education (2007) has defined the term as follows:

Developmental education is a field of practice and research within higher education with a theoretical foundation in developmental psychology and learning theory. It promotes the cognitive and affective growth of all postsecondary learners, at all levels of the learning continuum. Developmental education is sensitive and responsive to individual differences and special needs among learners. Developmental education programs and services commonly address academic preparedness, diagnostic assessment and placement, development of general and discipline-specific learning strategies, and affective barriers to 
learning. (National Association for Developmental Education, 2007, Definition of Developmental Education section, $\uparrow 1$ and 2)

Math anxiety. Richardson and Suinn (1972) defined math anxiety in the following way. "Mathematics anxiety involves feelings of tension and anxiety that interfere with the manipulation of numbers and the solving of mathematical problems in a wide variety of ordinary life and academic situations" (p. 551). Related concepts that represent the same phenomenon include quantiphobia (Goldberg \& Waxman, 2003), mathophobia (Hilton, 1980a, 1980b), math phobia (Pan \& Tang, 2005), and mathematics-learning distress (The American Institute for the Improvement of Mathematics Learning and Instruction, 2005).

In this study, math anxiety was operationally defined as a score on AMAS (Hopko, Hunt, Armento, 2003). Participants were classified as "high math anxiety" based on scores that were more than one standard deviation above the mean, and they were classified as "low math anxiety" based on scores that were more than one standard deviation below the mean.

Math avoidance. Math avoidance involved steering clear of all that is mathematics related. This included not taking math classes, evading calculation and numbers, and making decisions based on the possibility of avoiding mathematics.

Performance anxiety. Performance anxiety was comprised of the "Experiences in which anxious responding occurs in the immediate context of a performance-based setting or possibly in anticipation of having to perform and the potential negative evaluation associated with this performance" (Hopko, Hunt, \& Armento, 2005, p.389). 
Performance anxiety has been operationally defined as a factor on the Math Anxiety Rating Scale (Bessant, 1995).

Performance measures. In the current study, there were two performance measures, operationally defined as course grades and final exam scores (see chapter $3, \mathrm{p}$. $55)$.

Preparatory courses. Preparatory courses (also known as remedial or developmental courses) were those courses that did not meet requirements towards graduation; students who were underprepared to enter college level courses were required to enroll in preparatory courses. These courses did not allow them to earn college level credit towards their programs of study. Math preparatory courses typically included content related to arithmetic, pre-algebra, and beginning algebra. The preparatory variable in this study is defined as prior enrollment in the Beginning Algebra course.

State anxiety. State anxiety has been defined as an unpleasant emotional arousal in the face of threatening demands or dangers (Schwarzer, 1997) and is considered to be a temporary condition (Spielberger, 2006). An example of how state anxiety has been operationally defined by researchers is the State Trait Anxiety Inventory (Hopko et al., 2005).

Test anxiety. Test anxiety has been defined as "The set of phenomenological, physiological, and behavioral responses that accompany concern about possible negative consequences or failure on an exam or similar evaluative situation" (Zeidner, 1998, p. 17). An example of how test anxiety has been operationally defined by researchers is the Test Anxiety Inventory (Dew, Galassi, \& Galassi, 1983). 
Trait anxiety. Trait anxiety has been defined as general anxiety (Zettle \& Raines, 2000) and was considered to be a general and long-standing condition (Spielberger, 2006). An example of how trait anxiety has been operationally defined by researchers is the Trait Anxiety Inventory (Spielburger, 2006).

\section{Overview of Chapters}

In this chapter, the researcher explained the background of the study, provided an overview of the theoretical framework for math anxiety, described the statement of the problem and purpose of the study, and posed the research questions. In addition, chapter 1 included a description of the importance of the study, the assumptions and delimitations of the study, and definitions of key terms used throughout the study. Included in chapter 2 is an explication and critique of the literature related to the research questions. In chapter 3 , the researcher provides a detailed description of the design and the methods used to address the research questions. The researcher presents a description of the data and comprehensive results of the data analysis related to the research questions in chapter

4. In chapter 5, the researcher includes a summary of the study, an overview of significant findings, an evaluation of findings with respect to prior research, a discussion of the limitations, and a discussion of recommendations for practice and research. 


\section{CHAPTER II}

\section{LITERATURE REVIEW}

This chapter includes a critical review of the recent empirical literature on math anxiety of college students. The review is structured in four sections: search strategy, criteria for selecting and evaluating studies, critique of the selected studies, and conclusions.

\section{Search Strategy}

The literature was collected by searching four electronic databases (Educational Resources Information Clearinghouse [ERIC], PsycInfo, WilsonWeb, and Journal Storage [JSTOR]) using the keywords "math" and "mathematics anxiety". ERIC listed 264 responses to the keyword search of math anxiety, of which 33 were published in peer reviewed journals. Among the hundreds of articles listed, those that focused on K-12 education or were over 25 years old were discarded. Reference lists from articles were utilized to expand the search. The researcher sought peer-reviewed articles that represented a cross-section of empirical studies. However, some suggestions were included from texts that the author viewed as contributing to a gap in the peer-reviewed literature. In addition, dissertation abstracts were searched with the intention of representing a new generation of researchers in the area of math anxiety. However, none

of the four abstracts that were located in Proquest using the key words "math anxiety" or "mathematics anxiety" and "bilingual" focused on bilingualism and mathematics anxiety in postsecondary education. Three of the four results were cross national comparisons involving math anxiety among high school students. Therefore, dissertations were excluded from this literature review. 
The researcher selected articles that focused on math anxiety for college students, looked for patterns in the research, and reported the results in five categories: (a) pervasiveness, (b) factors, (c) relationship to other constructs, (d) performance, and (e) subgroups. In the following sections, the researcher details the criteria for selecting studies and provides a critique of the math anxiety literature.

\section{Criteria for Selecting Studies}

Literature was included in this study if it met the criteria for (a) relevance, (b) scholarship, (c) empirical nature, and (d) quality. Relevance was represented by the degree to which the study focused on math anxiety in college students. The researcher focused on research that offered clarification on aspects of math anxiety (e.g., prevalence, factors that influence math anxiety, relationship of math anxiety to other constructs, effects of math anxiety, and extent to which populations of culturally diverse college students might experience math anxiety).

Studies were delimited to those published in the last 25 years $(1982$ - 2007). Although many valuable studies on math and testing anxiety were conducted before 1982, those studies were not included because they did not represent recent trends. Those studies that focused on intervention strategies were also dismissed because the researcher was not conducting an intervention study.

Studies that were scholarly in nature were selected, specifically those published in peer reviewed journals. In addition, studies that offered empirical evidence published in published in books and book chapters were included. Only research that was empirical in nature was selected, i.e., the studies offered quantitative or qualitative evidence for verifying knowledge claims. Works that focused on opinion or theory were excluded. 
Those studies that were deemed to meet the expectations for quality were included if the research design and analysis were (a) appropriately rigorous, (b) replicable, and (c) supported by valid and reliable measures.

The method for selecting studies inherently included some limitations. First, the findings listed in this review were selected from journals and books. Second, the studies were limited to recent research published in the last 25 years. Lastly, although the selected studies met the requirements of quality for inclusion, the quality varied and relevant shortcomings were noted in the critique.

Explication and Critique of the Literature

Pervasiveness of Math Anxiety

Despite the wealth of books and articles on math anxiety, there was limited research on the pervasiveness of math anxiety. A reliable estimate for the percentage of the college student population that experiences distractingly high levels of math anxiety was virtually unattainable. Jackson and Leffingwell (1999) found that only 7\% of the 157 elementary education majors enrolled in senior level math classes reported that they had positive experiences in the math classes they had taken from kindergarten through college. The remaining 93\% (146 students) reported that the events that produced the math anxiety occurred either at grades 3 - 4, grades 9 - 11, or college level. In fact, $27 \%$ of the participants reported that they began to experience mathematics-related stress during the freshman year in college. A limitation of the study was that only elementary education majors were studied and perhaps there was a unique relationship between those who majored in elementary education and math anxiety. 
In a study by Perry (2004), $85 \%$ of college students in introductory math classes claimed to experience at least mild math anxiety. Even though Perry did not mention the sample size, it is worth noting that Perry's results mirrored the experiences of the researcher's students. In summary, the studies related to pervasiveness of college students' math anxiety relied on descriptive methodologies, reporting simple percentages that may not be generalizable to other populations. Moreover, none of the pervasiveness studies focused on prevalence of math anxiety for bilingual college students.

\section{Factors that Contribute to Math Anxiety}

The factors that contribute to math anxiety were categorized into three areas: environmental, intellectual, and personality factors. Trujillo and Hadfield (1999) defined the factors as follows. The environmental factor included experiences in the classroom and at home; the intellectual factor included student self-efficacy, attitude, and learning styles in which the students' styles did not match the teachers' styles; and the personality factor included such traits as shyness and perfectionism.

Environmental factors. To learn more about the factors that contribute to math anxiety, Harper and Daane (1998) studied the math anxiety of 53 education majors before and after they completed an undergraduate elementary mathematics methods course. They collected data in four ways: (a) scores on the MARS; (b) ratings of the Factors Influencing Mathematics Anxiety (FIMA), a questionnaire constructed by Harper and Daane; (c) Methods Courses Reflections (MCR); and (d) interviews. They found a reduction in the level of math anxiety scores at the end of the methods course. Five factors contributed to the onset of math anxiety: (a) an emphasis on "right" methods and answers, (b) word problems, (c) fear of making mistakes, (d) timed tests, and (e) 
confidence levels. For $75 \%$ of the elementary majors in the study, word problems were reported as the factor that contributed to the onset of math anxiety. Eleven students were selected for interviews based on the greatest differences between their pre and post MARS scores-- six showed a large decrease, while five showed an increase. The responses to the student interview questions about past influences contributing to math anxiety yielded four topics: (a) specific math content, (b) teacher instruction and attitude, (c) specific episodes in math classes, and (d) aspects not directly related to the math classroom. Harper and Daane found that math anxiety often began in elementary school, possibly created by classroom teachers who exhibited math anxiety themselves and who developed rigid and structured classroom instructional practices which in turn caused anxiety in the students. Limitations of the Harper and Daane's study included (a) the exclusion of demographic characteristics of the sample and (b) lack of specificity about how the interviews were conducted.

Trujillo and Hadfield (1999) conducted a qualitative study on the mathematics anxiety of 50 elementary education majors. Based on Revised Mathematics Anxiety Rating Scale (R-MARS) scores, 5 students with the highest math anxiety scores were interviewed individually about their early school mathematics experiences. The results were organized into five categories: (a) self perceptions related to mathematics anxiety, (b) school experiences related to mathematics, (c) family influences on mathematics attitude, (d) mathematics test anxiety, and (e) future plans for teaching mathematics to children. Cross case analysis revealed that several negative experiences in the mathematics classroom and minimal positive support at home along with severe mathematics test anxiety contributed to mathematically anxious individuals. Five 
limitations of the study were noted: (a) no follow up interviews with the participants, (b) only one data source was used (the interviews), (c) only one 1-hour interview, (d) all of those interviewed were women, and (e) the gender or ethnic and linguistic demographics of the 50 students who completed the R-MARS were omitted. Also, the participants were limited to preservice teachers which may have resulted in a unique experience to that population that cannot be extended beyond that population.

Jackson and Leffingwell (1999) studied 157 elementary math education students. They focused on the instructor's role in math anxiety by analyzing the participants' responses to the question, "Describe your worst or most challenging mathematics classroom experience from kindergarten through college" (1999, p. 583). Jackson and Leffingwell categorized the responses that referred to instructors of the $27 \%$ of students whose anxiety began in the freshman year of college as follows: (a) communication and language barriers, (b) insensitive and uncaring attitude of instructors, (c) quality of instruction, (d) evaluation of instruction, (e) instructor dislike for level of class, (f) gender bias, and (g) age discrimination. They further classified the instructor behaviors into covert and overt behaviors, commenting that both have detrimental effects on math anxiety. Limitations of this study included: (a) data that consisted of written responses without elaboration as to data analysis, (b) participants who were seeking elementary school teaching certification, and (c) no mention of the gender breakdown of participants in this study. There could have been many more women in this study than men as is typical of elementary education majors. Furthermore, the researchers omitted any descriptions of ethnicity, race, or language skills of the participants. 
Caniglia and Duranczyk (1999) looked for common themes from the autobiographies of 96 college students from pre-algebra classes collected over a 2-year period by using the constant comparative method to analyze student responses to the instruction "Write what comes to your mind as you reflect on your math history?" Initial statements of attitude were categorized as negative for 30 participants, positive for 13 participants, and neutral for 53 participants. The high response in the neutral category was attributed to students wanting to give a safe response on the first or second day of class, when the question was posed. Most students attributed negative affective factors such as anxiety, fear, and panic to their poor performance in math classes. More negative comments focused on teachers who interfered with the learning process compared to any other single factor. Although Caniglia and Duranczyk's study did not solely focus on math anxiety, it provided a good example of a qualitative study with a revealing outcome of the way that many students connected their performance in math classes to math anxiety.

Intellectual factors. Bursal and Paznokas (2006) utilized a math anxiety rating scale, in this case the Revised Mathematics Anxiety Survey, to classify 65 pre service elementary education students into low, moderate, and high math anxiety groups so as to compare the students' scores on a teaching efficacy belief instrument. Those in the low math anxiety group were more confident about teaching mathematics than those with higher levels of math anxiety; a negative correlation $(r=-.638)$ was found between preservice teachers' math anxiety and their math teaching efficacy scores with only $48 \%$ of the highly math anxious group responding that they could teach math effectively. Once again, the results must be interpreted cautiously since the participants were mostly 
women with only 11 men and no descriptive data about their ethnicity or linguistic diversity was reported.

Personality factors. In his study, Bessant (1995) delved into the interrelatedness of math anxiety with attitudes toward mathematics, learning preferences, study motives, and strategies by collecting data from 173 university students who were enrolled in statistics courses. Students completed a math attitude scale, the MARS, and the Biggs's Study Process Questionnaire (SPQ) which helps identify their students' learning approaches. Factor analysis of MARS confirmed six factors of math anxiety: (a) general evaluation anxiety, (b) everyday numerical anxiety, (c) passive observation anxiety, (d) performance anxiety, (e) mathematics test anxiety, and (f) problem solving anxiety. The factor analysis of the attitudinal scale revealed five attitudinal factors and five factors related to learning and instructional preference. Bessant described how the six dimensions of the MARS correlated with the 10 attitudinal and learning preference factors while controlling for level of math anxiety by grouping participants into low, medium, and high math anxiety groups based on MARS scores. There was a negative linear relationship between mathematics enjoyment and general evaluation anxiety for all three levels of anxiety $(r=-.52,-.56,-.52, p<.05)$. Mathematics enjoyment was negatively related to math test anxiety among low $(r=-.26, p<.05)$ and moderately anxious students $(r=-.13, p<.05)$, but positively correlated within the high anxiety group $(r=.49, p<.05)$. Learner attitudes and approaches were correlated; i.e., deep processors and intrinsically motivated learners expressed less math anxiety $(r=.18, p<$ .05 ) and surface processors with their more superficial approach to learning experienced higher levels of evaluation anxiety $(r=.44, p<.01)$. Bessant concluded, "inquiries into 
learning orientations could form an important theoretical line between cognitive and affective explanation of mathematics anxiety" (p. 343). Three limitations were noted: (a) there were very few instrument questions to measure each factor, (b) more women than men participated, and (c) no demographic information about ethnic, linguistic, or cultural diversity was included.

Sloan, Daane, and Giesen (2002) conducted a correlational analysis of learning styles and mathematics anxiety for 72 elementary education majors at a university. The sample consisted of 66 women and 6 men, and only 3 of the participants were nonCaucasians. Math anxiety was measured using MARS and learning style was determined using the Style Analysis Survey (SAS). A low but statistically significant correlation ( $r=$ $.28, p<.05$ ) was found between global (right brain) dominant learning style and math anxiety. The right brain learners tended to "approach problems in an intuitive manner, whereas most mathematics courses are taught through systematic problem solving in a step-by-step linear fashion" (p. 86). A limitation of this study was the lack of diversity in the population.

In summary, the studies of factors related to math anxiety among college students mostly relied on qualitative or mixed method methodologies with some correlational methods. However, the qualitative designs tended to be quite weak, lacking triangulation and other validity measures with very brief and limited interview sessions. The results of the research on the factors contributing to math anxiety must be interpreted in light of several limitations. With the exception of Bessant's (1995) and Caniglia and Duranczyk's (1999) studies, the studies involved samples of preservice elementary education majors. Also, the samples consisted of high proportions of women. These results cannot be 
generalized to students majoring in other fields of studies or in programs with differing gender distributions. Also, students with varying ethnic and socioeconomic status may have quite different experiences.

Overall, the studies indicated a plethora of factors that contributed to math anxiety including an emphasis on being correct (i.e., right/wrong method/answers, fear of making mistakes ), math topics (i.e., word problems, specific math content), mathematics classroom and instruction (i.e., specific episodes in math classes, instructor pedagogy and attitude, communication and language barriers [i.e., not understanding the instructor], insensitive and uncaring attitudes of instructors, quality of instruction, evaluation of instruction, instructor dislike for level of class, gender bias, age discrimination, teachers interfering with the learning process, timed tests) and aspects not directly related to the math classroom (i.e., confidence levels, family influences). Several negative experiences in the mathematics classroom and minimal positive support at home along with severe mathematics test anxiety also were reported to influence math anxiety. The students attributed negative affective factors such as anxiety, fear, and panic to their poor performance in math classes.

\section{Relationship of Math Anxiety to Other Constructs}

Another domain of math anxiety research has focused on the relationship between math anxiety and other anxieties such as test anxiety, performance anxiety, trait anxiety, state anxiety, and the dimensionality of math anxiety. Two factors of math anxiety, mathematics test anxiety and numerical anxiety, were isolated (i.e., Brush, 1978; Rounds \& Hendel, 1980). Much later, Suinn and Winston (2003) confirmed the same two factors in a brief version of the MARS for 124 students in the introduction to psychology course. 
Performance anxiety occurred in the immediate context of a performance-based setting or possibly in anticipation of having to perform and the potential negative evaluation associated with this performance (Hopko et al., 2005). Defining features of performance anxieties generally included (a) physiological hyperarousal, (b) negative cognitions, (c) escape from and/or avoidance of, and (d) performance deficits (Hopko et al., 2005). Test anxiety had been considered a subset of performance anxiety. In its infancy, the study of math anxiety used the methods, procedures, and treatments already applied to test anxiety (Hembree, 1990). Hembree's meta-analysis focused on findings prior to 1990 that showed the relationship between math anxieties and other anxieties. Hembree found that math anxiety and test anxiety were correlated at a statistically significant level $(r=.52, p$ $<.01)$. However, since $r^{2}=.27$, the amount of shared variance was moderate, suggesting that math anxiety and test anxiety were separate constructs (Miller \& Bichsel, 2004). Hembree's 1990 meta-analysis found a statistically significant mean correlation between math anxiety and trait anxiety $(r=.38, p<.01)$, supported by Zettle and Raines (2000) who reported a correlation of $r=.49(p<.01)$.

In an earlier study, Dew, Galassi, and Galassi (1983) found that the math anxiety measures of three instruments (MARS, Math Anxiety Scale [MAS], Anxiety Toward Mathematics Scale $[\mathrm{ATMS}]$ ) were moderately related to each other, and that they were more closely related to each other than to test anxiety as measured by the Test Anxiety Inventory (TAI). Their study of 769 first and second year undergraduates (550 women and 209 men, where 10 did not specify gender) suggested that although math anxiety and test anxiety were related, the two constructs were not interchangeable. They only shared $11.6 \%-36 \%$ of the variance with each other. Women displayed more math anxiety at a 
statistically significant level compared to men on the MARS, $F(1,751)=6.85, p<.005$ and MAS $F(1,750)=4.86, p<.05$. However, the authors concluded that the differences were probably not as significant as stated in previous studies.

Ferguson (1986) found that abstraction anxiety, fear of more theoretical math concepts, was an important factor of mathematics anxiety in his study of 365 community college students. His inventory included 10 items that focused on mathematics test anxiety, 10 items that focused on numerical anxiety, and 10 items that focused on abstraction anxiety. Factor analysis found strong support that abstraction anxiety was indeed a third factor of math anxiety. Ferguson's study was noteworthy for including a large Hispanic population. A possible weakness in the study may be that the participants were selected from 18 classes that ran the gamut from elementary algebra to calculus. It could be possible that abstraction anxiety may vary according to skill level.

Hunsley (1987) conducted a study to explore the similarities and differences in the cognitive processes involved in mathematics anxiety and test anxiety of 96 second year psychology students (72 women and 24 men). Measures included (a) MARS, (b) the Debilitating Anxiety scale of the Anxiety Achievement Test, (c) pre exam cognitive assessment questions, (d) post exam questionnaires, and (e) a measure of negative internal dialogue, the Cognitive Interference Questionnaire (CIQ). Math anxiety and test anxiety were correlated at a statistically significant level $(r=.31, p=.001)$. No gender effects emerged for cognitive processes or examination grades using repeated measures one-way analysis of variance. Using a repeated measures hierarchical multiple regression analysis, both math anxiety and test anxiety accounted for unique variance in pre-exam appraisals $(p<.01)$, level of preparation $(p<.05)$, pre-and post exam anxiety levels $(p<$ 
$.01)$, and on cognitive interference $(p<.01)$. Only math anxiety contributed significantly to the students' self- estimated exam grade $(p<.01)$ and satisfaction with performance ( $p$ $<.01)$. However, only test anxiety accounted for variance in participants' actual examination performance $\left(r^{2}\right.$ change $\left.=.06, p<.05\right)$. Doubts about performance were apparent in math-anxious students' internal dialogue during the exams. So, this study supported that math anxiety and test anxiety were quite similar in several respects; however math anxiety was more related in the prediction of many cognitive processes and some of the cognitive processes differed qualitatively from those found in test anxiety. The following limitations indicate that the results should be interpreted cautiously. Participation was voluntary and final participants had to be present for several tests. The exclusion of students who dropped out of the course may have influenced the findings since that group may include high numbers of math anxious individuals. Many more women than men participated. Also, this study measured the impact of test anxiety and math anxiety on performance in a statistics course, which some students may perceive differently from a non-statistics course.

In 2000, Kazelskis et al. studied the relationship between mathematics anxiety and test anxiety for 177 women and 144 men enrolled in freshman college algebra courses where $21.7 \%$ were African American, $70.9 \%$ were White, and $1.5 \%$ were Native American. Three different instruments measured math anxiety: (a) the Revised Mathematics Anxiety Rating Scale (RMARS), (b) the Math Anxiety Questionnaire (MAQ), and (c) Mathematics Anxiety Scale (MAS; Fennema \& Sherman, 1976), and three instruments measured test anxiety, the Test Anxiety Inventory (TAI), the Achievement Anxiety Test, and the Suinn Test Anxiety Behavior Scale (STABS). 
Correlations between the measures of mathematics and test anxiety were nearly as high as those within the measures (averaging about .5), thus making it difficult to conclude that the two constructs were separate. Results for men and women were pretty similar on mean mathematics anxiety levels and the relationship between math anxiety and test anxiety measures. The results from that study did not provide support for a clear distinction between the measures of mathematics anxiety and test anxiety. However, the researchers found more support for a two factor model with the removal of the STABS data, supporting former research about STABS. This study illuminated the difficulty with math and test anxiety measures.

Zettle and Raines (2000) studied the relationship of test and trait anxiety with mathematics anxiety for 57 men and 134 women enrolled in college algebra and in college algebra preparatory courses using the following measures: (a) the Test Anxiety Inventory (TAI) by Spielberger (1980) measured test anxiety, (b) the trait portion of the State-Trait Anxiety Inventory measured trait anxiety, and (c) MARS measured math anxiety. Women reported significantly higher levels of test anxiety, $F(1,183)=10.47, p$ $=.001$, and math anxiety, $F(1,183)=4.05, p=.04$, than men. Also of note, women displayed a statistically significantly stronger relationship between MARS and test anxiety and between MARS and trait anxiety. The authors conducted comorbidity analysis of trait and test anxiety with math anxiety. Each participant was categorized as high anxiety or low anxiety for math, test, and trait anxieties. Women were more likely to exhibit comorbid test anxiety and men were more likely to exhibit comorbid trait anxiety. Through all of the correlational analyses, the relationship between math anxiety and test anxiety was stronger than that between math anxiety and trait anxiety. The researchers 
concluded that effective treatment of math anxiety may involve assessing and addressing test and trait anxiety. Although the study illuminated important differences between the genders, the response rates and poor gender representation rates of the population under study could have influenced the findings.

Hopko et al. (2005) found a statistically significant correlation $(r=.55, p<.01)$ between math anxiety and test anxiety as measured by the Abbreviated Math Anxiety Scale (AMAS) and the Test Anxiety Inventory (TAI) for 100 undergraduate students. Although the relationships were not as strong, statistically significant correlations were found between math anxiety and state anxiety $(r=.32)$, and math anxiety and trait anxiety $(r=.35)$ as measured by the State Trait Anxiety Inventory (STAI). The demographic uniformity of the sample was a limitation, especially the $89 \%$ Caucasian and overwhelming majority of $72 \%$ women demographics. Additionally, the authors did not indicate how the students were selected (i.e., no indication of they were enrolled in a course).

In summary, studies that linked math anxiety to other constructs involved correlational analyses. Math anxiety has been shown to be linked to test anxiety, trait anxiety, and state anxiety. Moreover, the relationship between math anxiety and other anxieties has been found to vary according to gender, and math anxiety has been shown to be an anxiety that is distinct from other types of anxieties.

\section{Impact of Math Anxiety on Achievement}

The consequences of math anxiety can include (a) the inability to do mathematics related tasks, (b) the decline in mathematics achievement, (c) the avoidance of math and math related tasks, (d) the selective omission of college majors and careers that involve 
mathematics, and (e) the growth of feelings related to guilt and shame (Ma, 1999). Ma's meta-analysis yielded a negative relationship between anxiety toward mathematics and achievement in mathematics of elementary and secondary students $(r=-.27)$. An earlier meta-analysis by Hembree (1990) found a mean correlation of $r=-.31$ between math anxiety and performance among postsecondary students.

Career choice. Hackett (1985) studied 117 undergraduate students enrolled in an introductory psychology course. Seven variables for a path analysis of math related career choice were identified, showing that math anxiety influenced math relatedness of choice of major both indirectly and directly.

Math performance. In 1984, Clute classified 81 students from two institutions (38 men and 43 women) who were enrolled in a mathematics survey course into low, medium, and high anxiety at the start of the quarter using the MARS instrument. Students with high levels of mathematics anxiety had statistically significantly lower achievement as measured by a mathematics achievement test constructed by the researcher compared to those with low levels of math anxiety, $F(2,69)=10.11, p<.01$. There was a statistically significant interaction between method of instruction and anxiety level, $F(2$, $69)=4.96, p<.01$. Groups with high levels of mathematics anxiety scored better with an expository method of teaching compared to the groups with low and medium levels of mathematics anxiety who scored higher with the discovery method. Although the study had many positive points such as using two performance measures at two institutions, limitations for this study included that the researcher was the instructor and that the only demographic information discussed was related to gender. 
Hackett and Betz (1989) studied 153 women and 109 men enrolled in an undergraduate introductory psychology course. Those individuals who reported lower levels of math anxiety on a subscale of the Fennema-Sherman Mathematics Attitude Scale (FSMAS) had higher scores on mathematics performance as measured by the performance subscale of the Dowling Mathematics Confidence Scale $(r=.40, p<.01)$ and American College Test (ACT) achievement measures $(r=.45, p<.01, n=181)$. However, mathematics anxiety variable did not contributed to the prediction of sciencemath college major. Limitations include (a) participation was voluntary, (b) ethnicity or linguistic diversity were not noted, and (c) the participants received course credit for participation.

Course performance. Green (1990) discussed the results of a study of 132 developmental mathematics students enrolled in a basic math course taught by three male instructors. Measures included (a) the Test Anxiety Scale, (b) the Mathematics Anxiety Scale, and (c) department examination grades. Test anxiety had a greater negative effect on the mathematics achievement of remedial mathematics students $(\beta=-.28, p<.01)$ compared to either math anxiety $(\beta=-.13 p>.05)$ or teacher comments $(\beta=.14, p>.01)$.

In a rare study on math anxiety outside of the U.S., Maqsud and Khalique (1991) studied 75 first year students (41 men and 34 women) enrolled in math courses of the University of Bophuthatswana (now North-West University in South Africa) as participants for a study on dogmatism, mathematics anxiety, and mathematics achievement. Measures included (a) the Rokeach Dogmatism scale of closedmindedness, (b) the Mathematics Anxiety Questionnaire (MAQ) by Wigfield and Meece (1988) for mathematics anxiety, (c) students' grades from university records for initial 
mathematics achievement (i.e., matriculation exam scores) and (d) a normal classroom test by the instructor of a first year math course MAT 105. In South Africa, matriculation referred to the final year of high school and the qualification received on graduating from high school, although strictly speaking it referred to the minimum university entrance requirements. Based on examinations conducted by the South African Joint Matriculation Board (JMB), successful candidates were awarded the matriculation certificate. The researchers found that the mean matriculation mathematics achievement scores (scores on an examination taken upon graduation from secondary school) for women were statistically significantly lower than for men $(t=2.1, p<.05)$. No statistically significant differences were found for gender and dogmatism, mathematics anxiety, or achievement. Mathematics anxiety showed a statistically significant negative linear relationship with matriculation mathematics scores $(r=-.53, p<.0001)$ and with math achievement $(r=-$ $.52, p<.0001)$, but not for dogmatism $(r=.19)$. These results indicated that students with high levels of math anxiety attained lower achievement in mathematics. Demographic information was limited in this study to gender and nationality (i.e., Botswana). The researchers did not mention controls for instructors. It would have been informative to know if there was a different correlation between math anxiety and achievement according to gender. This study allowed for the possibility that a relationship between math anxiety and performance exists in people from cultures other than the American culture.

Attitudes and anxiety that business students experience when they take an undergraduate business statistics course were studied by Zanakis and Valenzi (1997). A 45 item questionnaire that included such factors as interest-worth, help-interpretation, 
computer usefulness and experience, understanding, test anxiety, and math anxiety, was distributed at the start and end of business statistics courses to 166 students. Grades in the course were primarily influenced by initial math anxiety and computer experience. However, the greatest improvement at course end was in the reduction of test anxiety while math anxiety scores did not change. However, the results on math anxiety must be interpreted keeping in mind that only four items on the questionnaire measured math anxiety. Nonetheless, this study illuminated the possibility that math anxiety may influence student performance in statistics courses for business majors. In fact, a separate line of study in statistics anxiety has emerged. Researchers who have studied the related construct of statistics anxiety include, Onwuegbuzie and Whitcome (2004), and Pan and Tang $(2004,2005)$. As compiled from focus group interviews, Pan and Tang (2005) found that math phobia was one of the contributing factors to statistics anxiety.

Hembree (1990) found a statistically significant mean correlation $(r=-.31, p<$ $.01)$ between math anxiety and math achievement measures in his meta analysis of 58 postsecondary studies. Those individuals with higher math anxiety experience decreased math achievement. However, there was no statistically significant mean correlation $(r=-$ $.27, p>.01)$ between math anxiety and course performance in the 17 studies of postsecondary students that studied the relationship between these two variables. Years later, Eppler, Harju, Ironsmith, and Marva (2003) conducted a study with remedial math college students and found a statistically significant negative linear relationship between anxiety and the final course grade $(r=-.353, p<.01)$. Moreover, the correlation between math anxiety and the intent to take more math courses was statistically significant for college students $(r=-.32, p<.01)$ in eight of the studies used $(n=2,225)$. Hembree 
calculated several other correlations, which, however, combined K-12 studies with postsecondary studies and therefore were not relevant for this review of postsecondary research in math anxiety. Hembree found 13 studies which compared the test scores of students with high and low levels of mathematics anxiety. The mean effect size was 4.61, showing that students with low math anxiety scores consistently scored better than those who attained high math anxiety scores.

Two-factor model. Math anxiety has been shown to be a multidimensional construct (e.g., Bessant, 1995). Similar to phobias with cognitive, affective, and physiological components, Ho et al. (2000) described math anxiety to include (a) the cognitive component (i.e., worry, negative expectations, and self deprecatory thoughts) and (b) the affective emotionality impending doom (i.e., feelings of nervousness, tension, and dread). In this two-factor theoretical model, math related tasks trigger the physiological reaction to impending danger, even though no life threatening scenario may be present. The physiological reaction has been rarely studied in educational literature, possibly due to the techniques necessary to measure it. Similarly, in the present study, the researcher focused on the cognitive and affective components of math anxiety (as proposed by Liebert and Morris in 1967). The physiological component was combined with the affective similar to Ho et al. (2000) and Tryon (1980). Similar to the model for test anxiety, a two-factor model that tapped affective and cognitive dimensions had been found to be relevant for math anxiety (Bandalos, Yatese, \& Thorndike, 1995). Although the study did not include adults, Ho et al. (2000) found that their study of American, Chinese, and Taiwanese sixth graders supported the two-factor model with distinct 
affective and cognitive factors of math anxiety where the two factor structure was supported by the young students from all three nations.

Circular model. Pries and Biggs (2001) described a cycle of mathematics avoidance. In phase one, the person experiences negative reactions to mathematics situations as a result of past negative experiences with mathematics. In the second phase, the person avoids mathematics situations. Such avoidance leads to phase three, poor mathematics preparation, which brings them to phase four, poor mathematics performance. This generates more negative experiences with mathematics and brings the person back to phase one. In essence, people who go through this cycle over and over rarely rebound, and become convinced that they cannot do mathematics.

Interference and deficit models. Two theoretical models for math testing anxiety and the direction of effects have been posed in the literature: an interference model and a deficit model. Supporters of the interference model suggested that anxiety interferes with students' recall of prior learning while the deficit model implies that poor performance can be attributed to weak study habits or test taking skills and thus leads to high anxiety (Hembree, 1990; Sarason, 1972; Tobias, 1985; Wine, 1971). Although controversy regarding the direction of effects exists, Hembree (1988) concluded from a meta-analysis of 562 studies that test anxiety causes poor performance, thereby supporting the interference model. In addition, Hembree's (1990) meta-analysis also supported the interference model.

Demographic Variables that Relate to Math Anxiety

Field of study. Subpopulations of college students have been shown to experience math anxiety differently. For example, a study by Pozehl (1996) found that a sample of 
56 nursing students reported higher levels of math anxiety as measured by RMARS compared to the non-nursing sample with each group consisting of 54 women and 2 men, although the difference was not statistically significant using MANCOVA $(p>.05)$. However, the nursing students had statistically significantly lower mathematical skills test performance as measured by a computerized algebra test compared to the nonnursing students, $F(1,107)=11.89, p<.05$. Pozehl used the covariate controls of pretest state anxiety, computer anxiety, and the number of previous algebra courses taken. This study has several limitations such as (a) no male participants, (b) student enrollment in statistics for whom a statistics anxiety measure may be more relevant, (c) lack of personal importance of algebra test (i.e., no impact on grades), and (d) no demographic data on ethnic, cultural, or linguistic diversity of the population. Nevertheless, this was important because it was one of the rare studies where the researchers posed the possibility that levels of math anxiety may differ according to fields of study. These findings resonated with Hembree (1990) who found that preservice education majors reported the highest average math anxiety score on MARS as compared to other college majors.

Gender. Researchers have studied the differences in math anxiety between men and women. Generally, women reported higher levels of math anxiety compared to men (Zettle \& Raines, 2000). The research on the relationship between gender, math anxiety, and performance showed mixed results. In Hembree's (1990) meta-analysis of 47 studies at the college level, women reported higher math anxiety than men but there was no statistically significant difference in math performance between the genders. Miller and Bichsel (2004) found that women scored higher on math anxiety measures compared to men, but gender was not correlated with measures of math performance. Other 
researchers have found that levels of math anxiety were unrelated to gender (e.g., Moyr \& Taylor, 2001; Resnick, Segal, \& Viehe, 1982; Tapia \& Marsh, 2004).

Llabre and Suarez (1985) found that women $(N=112)$ reported statistically significantly higher levels of math anxiety compared to men $(N=72)$ on the Revised Math Anxiety Rating Scale (RMARS), $t(182)=17.63, p<.001$; yet, women received higher final course grades than men, $t(182)=2.27, p<.05$. Llabre and Suarez indicated that math anxiety was more strongly related to general anxiety in men than it was in women as measured by the General Anxiety Scale, which explained $24 \%$ of the variance on RMARS in men and only $4 \%$ of the variance in women. The researchers controlled for number of math courses in high school and for math aptitude. The implications for treatment may be that women were more likely to profit from treatment that focused upon mathematics situations whereas men might profit from treatment of general anxiety. Llabre and Suarez (1985) decided that math anxiety level did not improve prediction of college algebra grades for either men or women. They concluded that math anxiety may have led to avoidance of mathematics; however, once students were enrolled in a math course, the level of math anxiety they reported had little to do with the final grade they received.

Like other researchers, Llabre and Suarez (1985) did not address whether students who dropped the courses were included in the study even though those students may have had the highest MARS scores. Their sample had a $41 \%$ Hispanic composition and this could have influenced the overall outcome according to gender. Even though the authors acknowledged this limitation, it would have been informative if they had tested ethnicity as a variable to find out if the gender differences varied according to ethnic background. 
Hembree (1990) conducted a meta-analysis of 47 studies (out of the total of 151) that involved gender differences for college level students. In Hembree's results, women displayed higher levels of math anxiety than men with a mean effect size of .31, $p<.01$. He also found that, in 58 postsecondary studies, the correlations between math anxiety and achievement measures were not statistically different between genders, differing from results reported for K-12 populations. However, the higher levels did not seem to translate into more depressed performance or to greater mathematics avoidance on the part of women. Indeed, men in high school exhibited stronger negative behaviors in both regards. This apparent paradox may be explained in two ways. First, women may be more willing than men to admit their anxiety, in which case their higher levels are no more than a reflection of societal mores. Second, women may cope with anxiety better. Whatever the cause, at precollege levels, effects of mathematics anxiety seem more pronounced in men than women.

Zettle and Houghton (1998) found no statistically significant differences between men $(N=103)$ and women $(N=126)$ in reported levels of math anxiety as measured by MARS for undergraduates in an introductory psychology course. No gender differences were obtained on two measures of social desirability (Edwards Social Desirability Scale and the Marlowe-Crowne Social Desirability Scale). The MARS correlated significantly with the Edwards Scale $(r=-.36, p<.01)$ and with the Marlowe-Crowne Scale $(r=-.17$, $p<.01)$. However, when separated according to gender, the correlation between MarlowCrowne and MARS was statistically significant only for men $(r=-.19, p<.05)$. The results indicated that responses of men to MARS may have been affected by social desirability while the responses of women were not. The researchers concluded that 
scores on the MARS may underestimate levels of math anxiety for men and that different criteria may have to be used for men and women when using MARS for research and clinical purposes. The results of this study must be interpreted cautiously as the differences between the genders were not that large, and a similar study at an institution that has greater gender differences on math anxiety measures might show a different association with social desirability. The authors also suggest that math anxiety may be a local phenomenon and that it can even vary according to type of institution (i.e., public versus private).

To determine the relationship between math anxiety (MARS scores) and achievement (exit exam scores) and select demographics (i.e., gender and age), Woodward (2004) studied community college students ( $N=33$ men; $N=92$ women) enrolled in developmental (remedial or preparatory) mathematics courses. Woodward found a statistically significant negative linear relationship $(r=-.2013, p=.027)$ between math anxiety and exit exam scores where women reported significantly higher math anxiety scores compared to men $(t=-2.66, p=.009)$. In addition, Woodward found no significant difference in the math anxiety scores of students categorized as traditionalaged $(<25)$ and nontraditional-aged $(\geq 25)$. In other words, gender appeared to be related to math anxiety scores, but age did not seem to be related to math anxiety scores. However, the researchers failed to ask the question as to whether math anxiety scores were related to the performance scores differently according to gender. Moreover, there were many more women (92 women to 33 men) and they did not take into account the ethnicity or linguistic diversity of the participants. Also, there was no control for course 
level (3 levels of developmental courses were used) or whether this was the students' first time enrollment in college or first math course in college.

Tapia and Marsh (2004) studied undergraduate students ( $N=71$ men; 58 women) enrolled in mathematics classes comprised of $80 \%$ Caucasian and $20 \%$ African-American students. The students completed an Attitudes Toward Mathematics Inventory (ATMI) and a demographic questionnaire. The demographic questionnaire contained a question to determine the level of math anxiety (none, little, some, high). The researchers used gender and level of math anxiety as independent variables and four factors of the ATMI (self-confidence, value, enjoyment, and motivation) as dependent variables. With multiple analysis of variance the following results were found: (a) gender did not have an effect on attitudes towards mathematics; (b) different levels of math anxiety by gender classification had no effect on attitudes; (c) levels of math anxiety had an effect on attitudes toward math, independent of gender; and (d) levels of math anxiety had an effect on measures of self-confidence $\left(F[3,121]=31.158, p<.01, \eta^{2}=.44\right)$, enjoyment $\left(F[3,121]=9.614, p<.01, \eta^{2}=.19\right)$, and motivation $\left(F[3,121]=13.179, p<.01, \eta^{2}=\right.$ .25) (but not the factor of value). Pairwise comparisons showed that students with little or no math anxiety scored significantly higher in self-confidence and motivation compared to students with high math anxiety. Students with no math anxiety scored significantly higher in enjoyment than students with high math anxiety. In this sample of students, math anxiety was unrelated to gender. However, the students self-reported their math anxiety on a rather simplistic scale of none, little, some and high, which may have skewed the results, especially in light of the possibility that men might be less likely to 
report math anxiety. The findings of this study could be replicated with a more solid math anxiety measure in order to generate stronger conclusions.

Can math anxiety ratings predict performance according to gender? The research showed mixed results. For example, Miller and Bichsel (2004) showed that math anxiety was more predictive of performance in men than women for basic math performance, but not for applied math performance. They found that math anxiety accounted for $28 \%$ of the variance in basic math performance for men compared to $14 \%$ of the variance in basic math performance for women. Hence, the results supported the prediction that math anxiety was more predictive of performance in men than in women for basic math performance, but not for applied math performance. In a meta-analysis, Ma (1999) found a similar relationship between mathematics anxiety and mathematics achievement for men and women at the elementary and secondary school levels. Finally, Hackett (1985) studied 117 undergraduate students enrolled in an introductory psychology course and found the puzzling result that masculinity scores were unrelated to math anxiety in simple correlation analysis, but masculinity scores contributed significantly and negatively to the regression equation predicting math anxiety in the path analysis model $(r=-.28, p<$ $.001)$.

A possible reason for the mixed results regarding gender effects might be that the researchers did not further define the demographic variables. All women were amassed as a group and studied collectively. There were subpopulations of women, particularly by ethnicity or socioeconomic status, which could have influenced levels of math anxiety. Perhaps math anxiety and performance might be negatively correlated for Latin American women, but not for African American women, and so on. 
Ethnicity and race. Research on the differences of math anxiety between races and ethnicities has been rather sparse (Ma, 1999). Hembree (1990) located five studies where math anxiety scores of Black and White college students $(N=804)$ were compared; and only two studies were found that investigated math anxiety scores of Hispanic and White college students $(N=1489)$. The mean effect size in comparing the math anxiety of Blacks to Whites was not statistically significant. However, the mean effect size in comparing the math anxiety of Hispanics to White was statistically significant $($ mean effect size $=.82, p<.01)$. Therefore, the Hispanic student group seemed to be more math anxious. This could be related to bilingual issues, although the bilingual status of students was not described. Hembree concluded that the students in the Hispanic group had higher math anxiety scores compared to the other racial/ethnic groups.

Llabre and Suarez (1985) studied a sample which included 41\% Hispanic students. However, they did not study racial/ethnic differences, and they recommended replication with a less culturally diverse sample. Steele and Aronson (1995) found that stereotype threat increased Black participants' math anxiety scores. As noted by Steele (1998), "Negative group stereotypes can have powerful effects on important performances" (p. 681).

One study included persons of indigenous ancestry in Canada. McGregor, MacMillan, and Old (2005) studied 17 students in a college mathematics preparatory course, 5 of whom were aboriginals. Students completed a questionnaire and participated in focus groups with follow up interviews of a subset of 8 (4 aboriginals and 4 nonaboriginals). Overall, the aboriginal students mentioned beliefs that were similar to those 
mentioned by the non-aboriginal students about why they experienced math anxiety (i.e., fear of failure, fear of looking stupid in front of others). However, they mentioned two additional concerns: (a) anxiety about their unfamiliarity with an urban, college environment and (b) a lack of traditional family or cultural support at the college. The aboriginal students emphasized that the inclusion of aboriginal material in math instruction was helpful in reducing their anxiety. However, the results must be interpreted with caution for the lack of depth in data collection from such a small sample. Although the small sample alone was not a problem, it is the lack of depth due to no prolonged engagement given that the interview process only consisted of one interview with each student. Further research is needed to confirm the transferability of these findings. The strength of the study was the connection between ethnomathematics and math anxiety. Although the study dealt with bicultural issues, the language status of the participants was not mentioned.

Ma (1999) did not compare the relationships among racial/ethnic groups in his meta-analysis because of the sparse data on this issue. Nevertheless, he found that researchers who study participants of varied racial/ethnic backgrounds tended to find a relationship similar to that found by researchers who study participants with homogeneous racial/ethnic backgrounds. This may indicate that there may be no significant differences between ethnic groups and levels of math anxiety. However, more studies are needed to examine the relationship from the racial/ethnic perspective before one can conclude that measures of math anxiety may predict mathematics achievement equally well across racial/ethnic groups (Ma, 1999). Considering the diversity within the community college student population, this gap in the research should be filled. 


\section{Summary and Conclusion}

This chapter presented the key literature relevant to the research questions and methods for the current study of math anxiety of bilingual students. The intent of the literature review was to present the recent published empirical evidence on math anxiety, to clarify the methods utilized, and to critique the math anxiety literature.

\section{Knowledge Claims}

The researcher began the review of the literature with studies that included descriptive statistics on the pervasiveness of math anxiety. Although the studies indicate percentages upwards of $85 \%$ of the participants experience math anxiety, these numbers need to be replicated to confirm what percentage of the student population is dealing with math anxiety. Next, the environmental, intellectual, and personality factors that influence math anxiety were discussed. These qualitative and correlational studies included such factors as emphasis on being correct (i.e., right/wrong method/answers, fear of making mistakes), math topics (i.e., word problems, specific math content), mathematics classroom and instruction (i.e., specific episodes in math classes, instructor pedagogy and attitude, communication and language barriers [i.e., not understanding the instructor], insensitive and uncaring attitudes of instructors, quality of instruction, evaluation of instruction, instructor dislike for level of class, gender bias, age discrimination, teachers interfering with the learning process, timed tests) and aspects not directly related to the math classroom (i.e., confidence levels, family influences). The applicability of these factors to the bilingual student population should be addressed.

The review included correlational studies of the relationship between math anxiety and related constructs such as test, trait, and state anxieties. The researcher 
concluded, overall, that a significant relationship exists between math anxiety and related anxieties. However, there is still enough evidence to support that math anxiety is a separate construct. Subsequently, relevant literature on the impact of math anxiety on achievement was examined. Math anxiety has been shown to influence career choice, math achievement, and course performance. Additionally, the circular model and the interference or deficit model were evaluated for their relevance to the current study. Finally, several studies that included results on subpopulations of college students according to the demographic variables of field of study, gender, and race were found to be important to understanding math anxiety; similar demographic items were included in the current study.

\section{Methods}

The researcher noted a weakness of the math anxiety research with respect to the uniformity of research methods. Many of the studies used an instrument to measure anxiety and correlated it to performance or some other dependent variable(s). Qualitative and mixed methods studies on math anxiety were relatively sparse in the literature. For the ones that did exist, they were mostly seen when studying the factors that influenced math anxiety (e.g., Pan \& Tang, 2005; Trujillo \& Hadfield, 1999).

Many studies were conducted with education majors, leading to the question of whether the results were applicable to students who major in other subjects. Relatedly, many studies included uneven representation of both genders (generally including more women). Furthermore, race and ethnicity were rarely discussed. The language variable was absent in the literature. In summary, the findings in the literature point to a need for a study of the math anxiety of bilingual community college students. 


\section{Recency of the Literature}

Most of the studies included in this review were published over 5 years ago for several reasons. Much of the recent literature on math anxiety focused on intervention studies and therefore was not included in this review since the current study was not an intervention study. Furthermore, much of the math anxiety literature does not focus on the postsecondary population and the researcher excluded those studies that focused on K-12 populations. However, the paucity of recent research related to the math anxiety of bilingual community college students is an important finding in itself which the current study hoped to address.

\section{Critique of the Math Anxiety Literature}

There were several weaknesses in the literature that the current study was undertaken to address. First, there was insufficient research on bilingual students and their experience with mathematics. Moreover, the researcher did not locate a study that explicitly studied the math anxiety of the bilingual population. It was not known whether bilingualism may be associated with reduced or increased levels of math anxiety. Second, the homogeneity of populations in math anxiety studies constituted another weakness in the literature. Many of the studies were conducted at universities in the Midwestern United States that lacked cultural diversity among the students. Much of the research reported gender differences. However, research on how ethnicity, socioeconomic status, age, disabilities, and other factors influence math anxiety has been limited. Differences among White, Hispanic, and Black students have been rarely reported. Third, very few studies have targeted math anxiety in postsecondary students who have enrolled in 
remedial, preparatory, or developmental mathematics classes (e.g., Eppler et al., 2003;

Green, 1990; Mohr \& Taylor, 2001).

Based on the literature review, a need for more detailed information regarding math anxiety of bilingual college students was identified. In the current study, the researcher included bilingual community college students, which addressed the lack of studies on individuals of varying ethnicities and races. 


\section{CHAPTER III}

\section{METHOD}

The primary purpose of the study was to describe the math anxiety of bilingual college students at one community college campus. The researcher expected to discover the variables that influence mathematics anxiety in bilingual college students so as to aid in the future development of intervention strategies in addition to capturing any differences that bilingual students may have from monolingual students in reporting math anxiety. In this chapter, the researcher presents the research questions and the research design, describes the setting and participants, and delineates the data collection and data analysis procedures for each research question.

\section{Research Questions}

1. Are bilingual and monolingual students different in their self-reported levels of math anxiety?

2a. What are the variables that predict math anxiety levels?

2b. Are the predictor variables for math anxiety levels different for bilingual students compared to monolingual students?

3a. How are final exam performance and self-reported levels of math anxiety related for bilingual students?

3b. Is this relationship different from the relationship of final exam performance and self-reported math anxiety levels for monolingual students?

4a. How are course performance and self-reported levels of math anxiety related for bilingual students? 
4b. Is this relationship different from the relationship of course performance and self-reported math anxiety levels for monolingual students?

\section{Research Design}

In order to provide a better understanding of the math anxiety of bilingual students, the researcher utilized an ex post facto correlational design (Newman, Newman, Brown, \& McNeely, 2006) to address the research questions. The researcher collected the data in two phases. The first phase addressed the first two research questions and was conducted using data gathered at the beginning of the semester. To address the third and fourth research questions, the researcher examined the relationship between demographic variables, math anxiety measures gathered at the start of the semester, and performance measures gathered at the conclusion of the semester.

\section{Setting and Participants}

In this section, the researcher describes the setting, the participants, and a description of the intermediate algebra course. In addition, the researcher explains the procedures for assigning students to high and low math anxiety groups.

\section{Student Community College (SCC)}

This study was conducted on the main campus of a large urban public 2-year community college, henceforth named Student Community College (SCC). There were over 33,000 students, approximately 13,000 men and 20,000 women, enrolled in fall 2006 across three main campuses and three outreach centers (SCC, 2007). (Note: To protect the anonymity of the participants, all references and citations related to the research setting are referred to as SCC.) In Fall 2006, 37.3\% of the students at the main campus of SCC were white non-Hispanic, 28.6\% were Hispanic, 23.6\% were Black Non- 
Hispanic or African American, 4.2\% were Asian/Pacific Islander, 5.9\% were unspecified and $0.3 \%$ were American Indian/Alaska Native (SCC, 2007). These demographics were reflected in the community surrounding SCC which was ethnically and socioeconomically diverse.

This study took place at the main campus, which had an enrollment of almost 18,000 in fall 2006 (SCC, 2007). Classes typically consisted of students with various native languages. About $25 \%$ of the students at SCC were citizens of countries other than the United States, and the college enrolled students from approximately 150 different countries (SCC, 2007). At the main campus, the most frequently named countries of origin were Colombia, Jamaica, Haiti, Venezuela, Peru, and Brazil. The study included students with bilingual backgrounds in Spanish, Creole, Portuguese, and other languages. In the county where this study was conducted, about two thirds of the population spoke English only at home. Nearly $20 \%$ of the population reported speaking Spanish, and the rest reported speaking other languages (U.S. Census Bureau, 2004a).

The researcher chose SCC because the ethnic and linguistic diversity of its students and professors offered an opportunity to study the experiences of math anxiety across varied backgrounds. Moreover, the researcher had extensive familiarity with SCC which provided her with access to the student population. However, Polkinghorne (2005) advised that the researcher must remain vigilant to skewing the interpretations when conducting research in one's own backyard. Researching in a familiar setting may cause the researcher to limit the focus due to preconceived notions (Glesne, 1999). On the other hand, the researcher had the advantage of an established track record in teaching and 
service at SCC and enjoyed a rapport with the student population, the faculty, and the administration which aided in access to resources and support for the study.

The researcher guarded against possible weaknesses in several ways. She was on sabbatical and therefore did not teach the intermediate algebra course during the semester in which the data were gathered. She assured participants that all data would be reported in the aggregate, thus protecting the individual anonymity of each participant.

Additionally, while researcher bias was still possible, the quantitative nature of the data analysis provided less opportunity for bias.

\section{Participants}

The participants were purposefully selected to meet the goals of this research study. Participation was voluntary. Approval to conduct the study was obtained from Student Community College and the Institutional Review Board of Research Compliance of Florida International University. Informational cover letters and follow up letters were constructed in compliance with FIU's IRB procedures (see appendix A and B for IRB approvals). After obtaining consent, the survey instruments and cover letters were delivered by the researcher to the mailboxes of supporting faculty. All participants fulfilled the condition of being enrolled in Intermediate Algebra at Student Community College. The follow up informational letter about the collection of performance measures was distributed about midway through the semester in a similar manner (Appendix B).

\section{Intermediate Algebra Course Description}

Figure 1 illustrates where the intermediate algebra course fit into the sequence of the first few levels of mathematics courses at Student Community College. The course was a continuation of algebra. The course included topics such as (a) factoring; (b) 
operations with rational expressions; (c) absolute value, exponents, radicals, and roots; (d) complex numbers; (e) linear and quadratic equations and linear inequalities; (f) graphs; (g) systems of equations; and (h) functions. Throughout the course, applications were emphasized by instructors. The course met the requirement of 3 hours of elective credit for the A.A. degree. MAT 1033 was a course for which students received college elective credit. However, students did not receive credit towards the minimum math requirement for an A.A. degree.

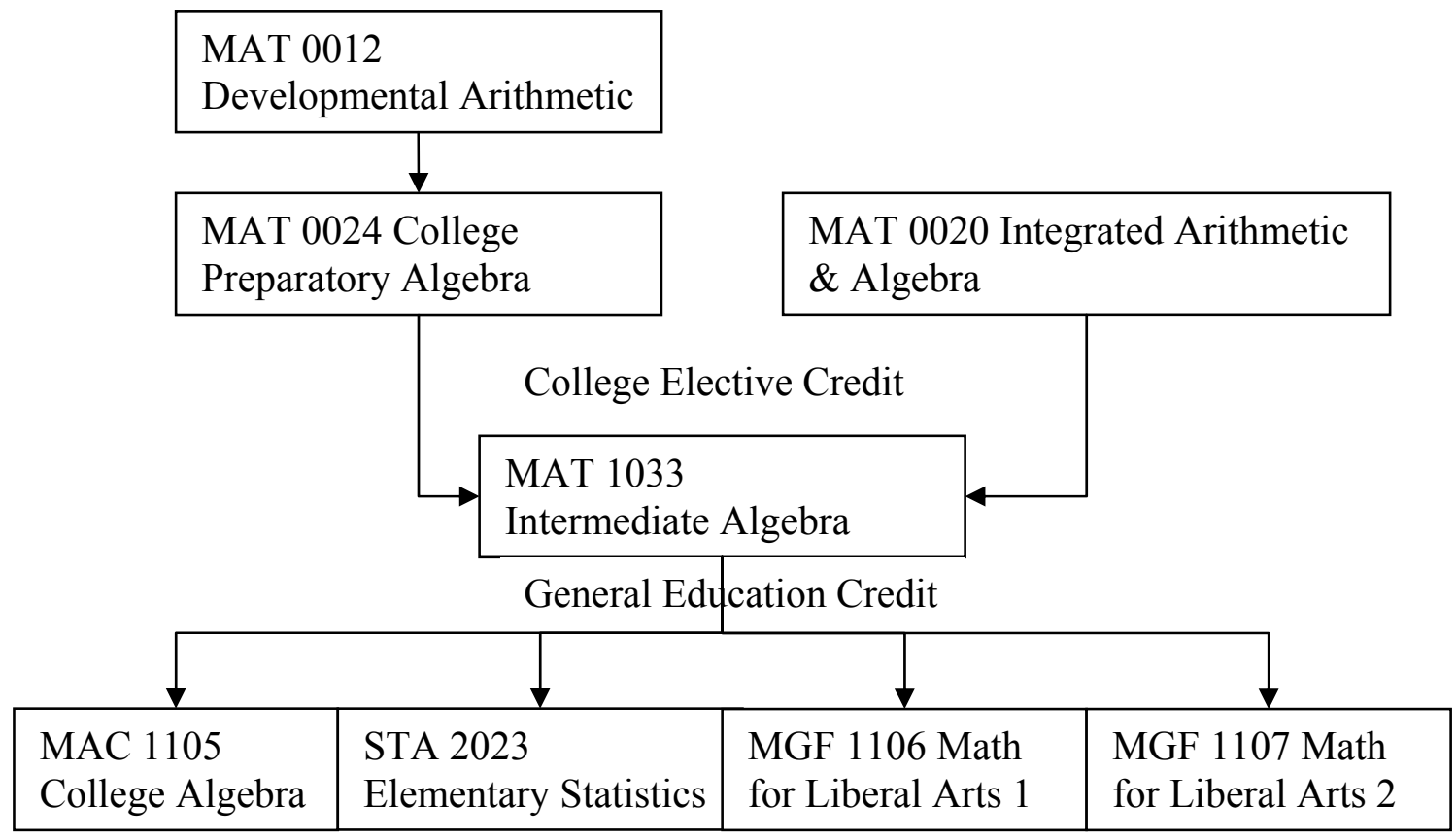

Figure 1. Sequence of first few mathematics courses at Student Community College.

\section{Procedures to Assign Students to High and Low Math Anxiety Groups}

Those students who elected to participate in the study received the informational letters and all human subject protection regulations, including protections to help ensure the privacy of subjects and the confidentiality of information was made clear to the 
participants and followed throughout the study. All students enrolled in MAT1033, Intermediate Algebra at Student Community College main campus, were invited to participate in the first part of the study by completing the demographic information form and the Abbreviated Math Anxiety Scale (AMAS). During the fall semester of the 2007/2008 academic year, MAT 1033 was the second most offered course at the college (behind English Composition 1101) with 3,384 students enrolled in the course collegewide (SCC, 2008). There were 36 sections of MAT 1033 offered on the main campus during the semester of the study. All 18 instructors of these courses were invited to participate in this study. Ultimately, there were 10 instructors who taught a total of 19 sections who volunteered to participate. Six hundred eighteen students from these instructors participated in this study. The estimated mean enrollment for each section was 38 students with a typical absenteeism rate of about 3 students per section during the first week of class. Therefore, the researcher estimates that approximately 665 surveys (35 students x 19 classes) were distributed, resulting in an estimated response rate of 93\%.

Based on the college and area demographics, approximately $25 \%-30 \%$ of the student population was bilingual. Therefore, the researcher expected that an acceptable number of participants would be bilingual. Individuals from the high AMAS scorers and the low AMAS scorers from the population of bilingual students were studied to address the second research question. Participants were classified as reporting high anxiety if AMAS scores were greater than one standard deviation above the mean and were classified as reporting low anxiety if AMAS scores were less than one standard deviation below the mean similarly to Bessant (1995). Cates and Rhymer (2003) used a similar 
selection method that grouped students into low and high math anxiety groups based on scores obtained from math anxiety instruments.

English proficiency of participants was determined by the admissions and registration office at SCC. Native speakers of English or those who had attended high schools in the U.S. were eligible to take the College Placement Test (CPT). All students who had not completed 2 years of American High School English and whose native language was not English were required to complete the Level of English Proficiency (LOEP) exam (SCC catalog, 2007). The LOEP consisted of a computer skills test that measured reading comprehension, vocabulary, grammar, language uses and sentence skills. Additionally, these students completed a 60 -minute proctored writing sample. Placement in English for Academic Purposes (EAP) grammar or composition courses depended on the evaluation of the writing sample. Finally, these students completed a listening test which determined levels of listening and speaking skills with subsequent requirement to complete an EAP phonetics course for those with low levels. According to the college advising recommendations, EAP students were not encouraged to enroll in Intermediate Algebra until they had completed Intermediate/Advanced EAP courses in grammar/composition, reading, and phonetics/communication. All of the researcher's prior experiences with teaching students in Intermediate Algebra at SCC had indicated that the students had the skills to read, write, and speak the English language. Therefore, students enrolled in Intermediate Algebra were presumed to possess adequate English language skills to complete the demographic questionnaire and the AMAS in English. 


\section{Data Collection}

As shown in Figure 2, the data collection procedures were completed in two phases. The two phases took place (a) at the beginning of the semester where students enrolled in intermediate algebra course section completed the AMAS and a demographic questionnaire, and (b) at the end of the semester where professors provided final exam scores and final course grades. Data were collected from the following sources: (a) two instruments (i.e., a demographic questionnaire and the AMAS), and (b) two performance measures (i.e., final exam scores and course grades).

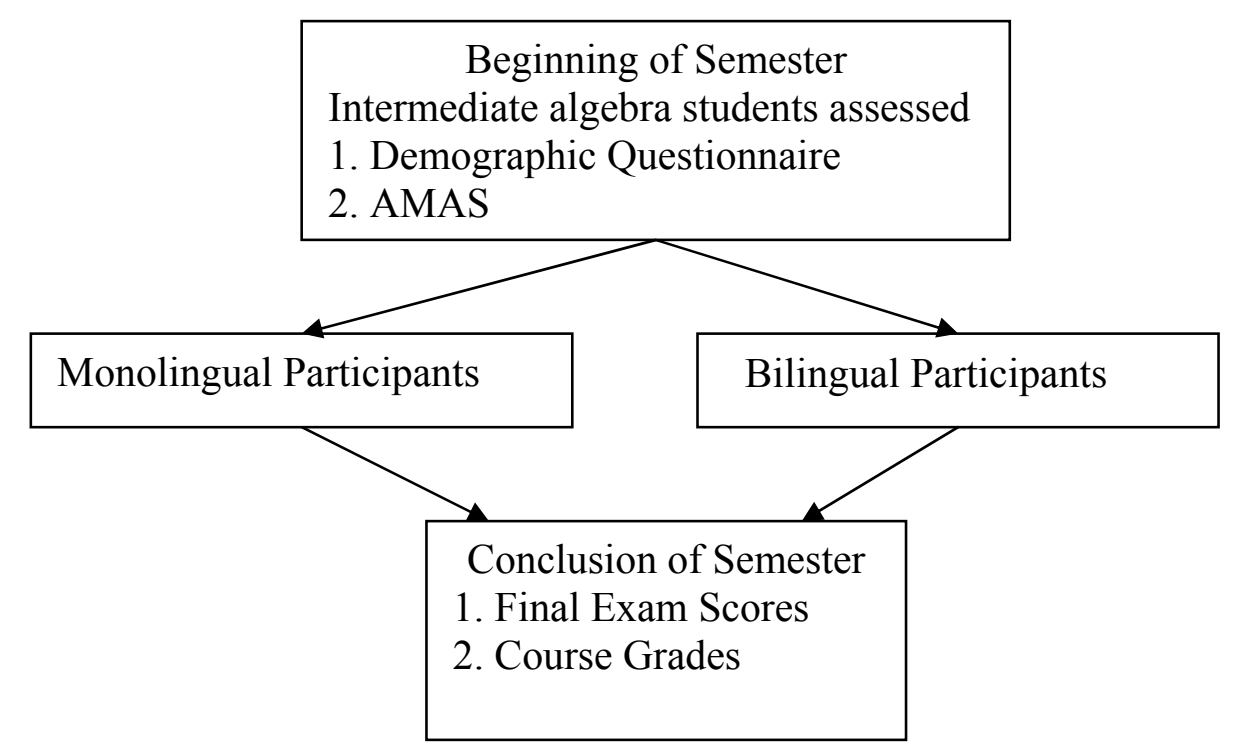

Figure 2. Data collection strategy.

\section{Instrumentation}

Two instruments were utilized in this study. Each is described below.

Demographic questionnaire. All participants completed a demographic questionnaire. The questionnaire consisted of two parts: (a) demographics revealed in the literature review and (b) three questions about the existence, level, and frequency of 
mathematics anxiety (see Appendix C for a copy of the questionnaire). The researcher posted these three questions to assess whether or not participants were aware of their math anxiety prior to completing the AMAS rating scale.

The questionnaires were included for two reasons. First, demographic characteristics helped in the identification of the bilingual participants. Second, the questionnaire responses operationally defined the predictive variables.

The questionnaire was administered during the first week of class by the students' instructors at the same time as the math anxiety instrument. A description of the study and the cover letters were included with the questionnaire. Students answered the questionnaires during class time. Based on the researcher's prior experiences as a community college instructor, if the students were asked to fill them out at home, many of the questionnaires would not be returned. However, many faculty had indicated their reluctance to use class time for surveys; so, the researcher emphasized the brevity of the instruments and requested their distribution in the first week of class, a time period in which many instructors had a few extra minutes after explaining course policies. In order to ensure that students did not feel that their grades would be affected by their responses, a student volunteer collected the surveys and returned them to the math department so that instructors would not see the results. Students were assured that their instructors would not see their responses.

The students responded to the questionnaire on the distributed forms. Students included the last four numbers of their student ID on the forms, answered all demographic questions on the forms, and answered the math anxiety questions in the space provided. Once all of the responses on the forms were collected, the researcher 
collated the responses. All responses in the category of other were manually reviewed and listed (i.e., those responses to the item "spoke a language other than those listed on the questionnaire"). All of the valid responses were recorded and organized using SPSS software.

Abbreviated Math Anxiety Scale (AMAS). The Abbreviated Math Anxiety Scale (AMAS) was used to measure levels of mathematics anxiety. All participating MAT1033 students completed the AMAS during the first week of class. The AMAS procedures were similar to procedures for the questionnaire and both were administered at the same sitting. It took the students approximately 10 minutes to complete the AMAS and the questionnaire on the distributed forms. The responses to each AMAS question were entered on an SPSS spreadsheet along with the data from the demographic questionnaire. All forms were kept and filed in a locked cabinet in the researcher's home office.

AMAS was constructed by Hopko, Mahadevan, Bare, and Hunt (2003) to provide a measure of math anxiety in an abbreviated version of the widely used MARS that was developed by Richardson and Suinn in 1972 for both students and non-students (see Appendix D for the AMAS instrument). AMAS was comprised of a 9-item Likert scale instrument where participants responded by rating their level of anxiety associated with various behavioral situations. Each item had 5 possible ratings, ranging from 1 (low anxiety) to 5 (high anxiety). The scores ranged from 9 (all ones) to 45 (all fives). In the normative study reported by Hopko et al. (2003), the mean score was 21.1 with a standard deviation of 7.0 for 1,239 undergraduate students. However, these normative values were not determined for a bilingual population. The results of the current study 
would be the first time for obtaining bilingual students' math anxiety levels using the AMAS.

The reliability of AMAS had been estimated by Hopko et al. (2003) who reported test-retest reliability $(r=0.85)$ and internal consistency (Cronbach $\alpha=.88)$. Moreover, convergent and divergent validity were estimated. Confirmatory factor analysis of a third (replication) sample provided support for the AMAS. Also, the findings replicated the results from other studies on gender differences with women who reported higher levels of math anxiety (Hopko et al., 2005).

The research with AMAS can be described as nascent (e.g., Hopko et al., 2005). However, the brevity of the instrument made it more appealing to administer than the MARS which is comprised of 98 questions. Hopko et al. (2003) suggested that AMAS was a superior measure to the Math Anxiety Rating Scale-Revised (R-MARS) and Ashcraft and Ridley (2005, p. 316) stated, "the AMAS appears to be the test of choice for future work on math anxiety." Researchers who have used the AMAS instrument include Hopko et al. (2005), Donelle, Arocha, and Hoffman-Goetz (2008), and Baylor, Shen, and Warren (n.d).

The researcher cautiously utilized the AMAS due to two warnings about MARS which she believed to be relevant to AMAS. It was possible that adults could score more similarly on math anxiety instruments than other age groups, resulting in lower score reliability (Capraro, Capraro, \& Henson, 2001). Zettle and Houghton (1998) cautioned against the use of MARS for screening the presence of math anxiety among male college students. Their study of 229 students focused on the correlation between MARS and two social desirability scales. Their findings may indicate that it was less socially acceptable 
for men to present themselves as being math anxious. They suggested that the gender of participants should be considered in using MARS for research and clinical purposes. Perhaps a lower math anxiety rating score may need to be used for screening men compared to women (Richardson \& Suinn, 1972), especially since the AMAS scores were used to identify the most math anxious and least math anxious students in the current study. Since Hopko et al. (2003) found similar differences in reported measures of math anxiety in AMAS, this warning was probably relevant to AMAS usage as well and was considered in the interpretations of math anxiety ratings.

\section{Performance Measures}

Final exam. The final exam for Intermediate Algebra was a uniformly constructed test at the college. Students enrolled in all sections of the course at all campuses of the college completed the same final exam. Several versions of the same exam were administered in order to prevent cheating. A committee of faculty members constructed the exam and modified it every few years. The exam was an example of a cumulative test and tested the material that was described in the college outline of course topics (see p. 48).

Course grade. The course grade was the grade the instructor assigned to each student in the course. The possible grades were A, B, C, D, F, W, WF, or X. A grade of W occurred when a student self withdrew from a course before the end of the withdrawal period. A grade of WF was assigned by the instructor when students received the equivalent of an F (failure) on their GPA due to excessive absences. When a student completed the requirements for an audit, a grade of $\mathrm{X}$ was assigned. 


\section{Procedure to Ensure Accuracy of Data Entry}

The researcher and the chair of the committee determined the accuracy of data entry (8/28/08). Four completed questionnaires were randomly selected from each of 8 of the 19 class sections for a total of 32 participants out of the 618 participants or 5.2\%. There were approximately 19.3 entries per participant for a total of 618 entries. No errors were found, representing $100 \%$ agreement. Later, the researcher met with another reviewer $(9 / 21 / 08)$ where four completed questionnaires were randomly selected from each of the remaining 11 class sessions. These 44 selected participants were combined with the previous 32 questionnaires for a total of 76 participants out of the study sample size of 618 or $12.3 \%$. The reviewer agreed with entries for 75 of the 76 participants, for a percentage of agreement of $98.7 \%$. No further reliability checks for data entry were deemed necessary.

\section{Data Coding Procedures}

In order to complete the data analysis, the data were coded within SPSS. Bilingual status was coded as 0 or $1(0=$ monolingual, $1=$ bilingual $)$. The information on the questionnaire was coded as 11 variables for the data calculations. Six of these variables did not relate to coursework or choice of major: (a) gender was coded as 0 or $1(0=$ female, $1=$ male); (b) age was coded as 1, 2, 3, 4, or $5(1=$ less than $19,2=19-23,3=$ $24-29,4=30-39,5=40$ or over); (c) income was coded as $1,2,3,4$, or $5(1=$ below $\$ 25,000,2=\$ 25,000-\$ 49,999,3=\$ 50,000-\$ 74,999,4=\$ 75,000-\$ 99,999,5=\$ 100,000$ or above); (d) U.S. origin was coded as 0 or $1(0=$ non-U.S. origin, $1=$ U.S. origin); (e) ethnicity was coded as 0 or $1(0=$ non-Hispanic, $1=$ Hispanic $)$; and (f) race was coded as 0 or $1(0=$ White, $1=$ Black $)$. There were seven participants who classified themselves as 
Black and White. For the regression analyses, these students were classified as Black based on the rationale that society often uses a $1 \%$ rule for Black classification and that these students identified themselves as Black. Participants who were a race entirely other than Black or White were not included in calculations with the race variable.

There were four variables related to choice of major that were coded as follows: (a) education major was coded as 0 or $1(0=$ all majors other than education, $1=$ education major); (b) business major was coded as 0 or $1(0=$ all majors other than business, $1=$ business major $)$; (c) health science major was coded as 0 or $1(0=$ all majors other than health science, 1 = health science major); and (d) science major was coded as 0 or $1(0=$ all majors other than science, $1=$ science major $)$. These majors were selected due to their relevance to the previous literature on math anxiety and due to the large number of participants that fit into these categories.

The variable, preparatory course, was coded as 0 or $1(0=$ no enrollment in preparatory course, $1=$ enrollment in preparatory course). AMAS responses resulted in a math anxiety classification that was coded as 0,1 , or $2(0=$ low math anxiety, $1=$ middle math anxiety, 2 = high math anxiety). The course grades from the second phase of the study were also coded as $0,1,2,3,4$, or $5(0=\mathrm{W}$ or $\mathrm{WF}, 1=\mathrm{F}, 2=\mathrm{D}, 3=\mathrm{C}, 4=\mathrm{B}$, $5=\mathrm{A}$ ). Grades of X (audit) were not included in the course grade data analyses.

\section{Data Analysis Procedures}

The data analysis was conducted in two phases. First, exploratory data analysis and factor analysis were conducted to address research questions 1 and 2. Then, correlational data analyses were conducted to address research questions 3 and 4 . 


\section{Research Question 1}

To address the first research question, the researcher conducted exploratory data analysis procedures including graphical displays such as frequency distributions. Descriptive statistics included means, medians, and standard deviations for all respondents who completed the AMAS survey as well as for the bilingual and monolingual participants. The purpose was to find patterns in the data that indicated differences between levels of math anxiety reported by bilingual and monolingual participants.

The researcher conducted a principal component by varimax rotation factor analysis of the AMAS scores for the monolingual participants and compared it to a factor analysis of AMAS scores for bilingual participants to see if the factor structures were similar and the AMAS scores comparable. Once the scores were determined to be comparable, the researcher conducted the following statistical tests: (a) a $t$-test to compare the mean AMAS score for bilingual students to the mean AMAS score for monolingual students, and (b) an $F$-test to compare the standard deviations of AMAS scores for bilingual and monolingual students. In addition, a $z$ test was conducted to compare the proportion of bilingual math anxious students to the proportion of monolingual math anxious students.

Research Questions $2 a$ and $2 b$

Upon identification of the high and low scorers (greater than one standard deviation above or below the mean), the researcher conducted a discriminant function analysis to predict group membership in low, middle, or high math anxiety groups using several predictor variables. The predictor variables, identified in the literature review, 
were comprised of the following: number of language spoken, prior enrollment in a preparatory math course, major, gender, age, racial category, ethnicity, and household income. The predictor variables were used to discriminate among the categories of low math anxiety, middle math anxiety, and high math anxiety as determined by AMAS scores. Finally, the researcher compared the predictor variables for the bilingual participants and the monolingual participants.

SPSS software was utilized for the statistical calculations. Descriptive statistics were calculated for the demographic variables on the responses to the AMAS. Frequencies and percentages were calculated for gender (men, women), age, ethnicity (Hispanic, non-Hispanic), race (Black, White), number of languages spoken, socioeconomic status, major (education, business, health sciences, and science), completion of preparatory courses in mathematics (yes, no), final exam scores, and course grades.

\section{Research Questions $3 a$ and $3 b$}

Correlational analyses were used to determine if different relationships existed between math anxiety level and final exam performance for bilingual and monolingual students. The correlation between AMAS scores and final exam performance for bilingual students was calculated and the correlation between AMAS scores and final exam performance for monolingual students was calculated. Both of these values of $r$ were tested for statistically significant relationships. Finally, the researcher analyzed the difference between the correlation coefficients of these two populations with a $z$ test (using a Fisher $r$ to $z$ transformation). 


\section{Research Questions $4 a$ and $4 b$}

Point biserial correlational analyses were conducted to determine if different relationships existed between math anxiety level and course performance for bilingual and monolingual students. The correlation between AMAS scores and course performance for bilingual students was calculated and the correlation between AMAS scores and course performance for monolingual students was calculated. Both of these values of $r$ were tested for statistically significant relationships and for a difference between the correlation coefficients of these two populations using the same methods described for research question $3 \mathrm{a}$ and $3 \mathrm{~b}$.

\section{Summary}

In chapter 3, the researcher described the methods that were utilized to investigate 4 research questions on the math anxiety of bilingual community college students. The research design, the setting, and the participants were described. Finally, the researcher explained the data collection and data analysis procedures. In the next chapter, the findings related to each research question are described. 


\section{CHAPTER IV}

\section{FINDINGS}

This chapter presents the findings and is organized into the following sections: description of the sample, findings related to Research Question 1, findings related to Research Questions 2a and 2b, findings related to Research Questions 3a and 3b, and findings related to Research Questions $4 \mathrm{a}$ and $4 \mathrm{~b}$. The chapter concludes with a summary.

Description of the Sample

This study gathered information from 618 students--368 women (59.5\%) and 250 men (40.5\%)--enrolled in 19 sections of Intermediate Algebra from 10 instructors. These participants were all enrolled at the same campus during the 16 week fall semester of 2008.

Of the 618 participants, 257 or $41.6 \%$ declared themselves as speaking more than one language fluently, with $35(5.7 \%)$ out of the 257 indicating that they spoke three or more languages fluently. There were 184 participants $(29.8 \%)$ who declared that they spoke Spanish fluently and 213 students (34.5\%) who declared themselves of Hispanic ethnicity, 362 students (58.6\%) were non-Hispanic (43 participants, or $7.0 \%$, did not respond to this question). It comes as no surprise that more than 1 in 3 students declared themselves as Hispanic since this institution was classified as a Hispanic Serving Institution.

As shown in Table 1, of the 472 survey participants, 299 (63.3\%) identified their race as White and 134 (28.4\%) identified their race as Black or African American. 
Table 1

Self-Reported Race of Participants

\begin{tabular}{lcc}
\hline Race & Frequency & Percent \\
\hline White & 299 & $63.3 \%$ \\
Black or African American & 134 & $28.4 \%$ \\
Asian & 33 & $7.0 \%$ \\
American Indian/Alaskan Native and & 7 & $1.5 \%$ \\
Native Hawaiian Pacific Islander & & \\
Other & 20 & $4.2 \%$
\end{tabular}

Note. The percents do not sum up to $100 \%$ since participants could respond to more than one category.

To explain the smaller response rate of 472 out of 618 to this question, many students selected "other" and wrote "Hispanic". The researcher did not include these as a separate racial category since Hispanic identity was included in a previous item on ethnicity.

Finally, there were 365 students who indicated that they were of U.S. origin. Although the researcher's intent with this question was to determine where students themselves were born, it is the researcher's impression, based on the written responses, that several of the participants indicated where the members of their families were from because they listed several countries under their country of origin.

The educational background and majors of the participants were reported. Of the 610 who responded, 265 or $42.9 \%$ had taken the preparatory course in elementary algebra at a state college. Of the 603 who described their major, 7.3\% were education majors, $18.4 \%$ were business majors, $16.9 \%$ were health science majors, and $11.9 \%$ were science majors. The distribution of the reported ages of participants is shown in Table 2 . 
Table 2

Self-Reported Ages of Participants

\begin{tabular}{lcr}
\hline Age in years & Frequency & Percent \\
\hline Less than 19 & 210 & $34.0 \%$ \\
$19-23$ & 328 & $53.1 \%$ \\
$24-29$ & 40 & $6.5 \%$ \\
$30-39$ & 30 & $4.9 \%$ \\
40 or over & 10 & $1.6 \%$ \\
\hline
\end{tabular}

The majority of the students that participated in this study were of traditional college age with over $87 \%$ of the participants aged 23 or younger.

The distribution of income categories of the participants who responded is presented in Table 3. Note that the percentage for each of the three lowest income levels was nearly $25 \%$ for each category.

Table 3

Self-Reported Household Income Levels of Participants

\begin{tabular}{lcr}
\hline Income level & Frequency & Percent \\
\hline Below $\$ 25,000$ & 134 & $24.6 \%$ \\
$\$ 25,000-\$ 49,999$ & 156 & $28.6 \%$ \\
$\$ 50,000-\$ 74,999$ & 139 & $25.5 \%$ \\
$\$ 75,000-\$ 99,999$ & 62 & $11.4 \%$ \\
$\$ 100,000$ or more & 54 & $9.9 \%$ \\
No Answer & 73 & --- \\
\hline
\end{tabular}




\section{Description of AMAS Responses}

A total of 598 participants completed the AMAS. Twenty participants (5

monolingual and 15 bilingual) did not complete the entire AMAS as instructed. Eleven of these 20 left the entire AMAS blank, 4 inserted some values to have scores below nine, and 5 had some blanks with overall scores over 9. Since the researcher recognized that these students did not follow the instructions provided by the authors of the instrument, all 20 scores were discarded.

For those students who completed the entire AMAS $(n=598)$, the measures of central tendency included a mean AMAS score of 20.7 and a median of 20.0. The standard deviation was 7.6 and the range was 36 with a minimum score of 9 and a maximum score of 45 . The distribution of scores can be seen in the histogram shown in Figure 3.

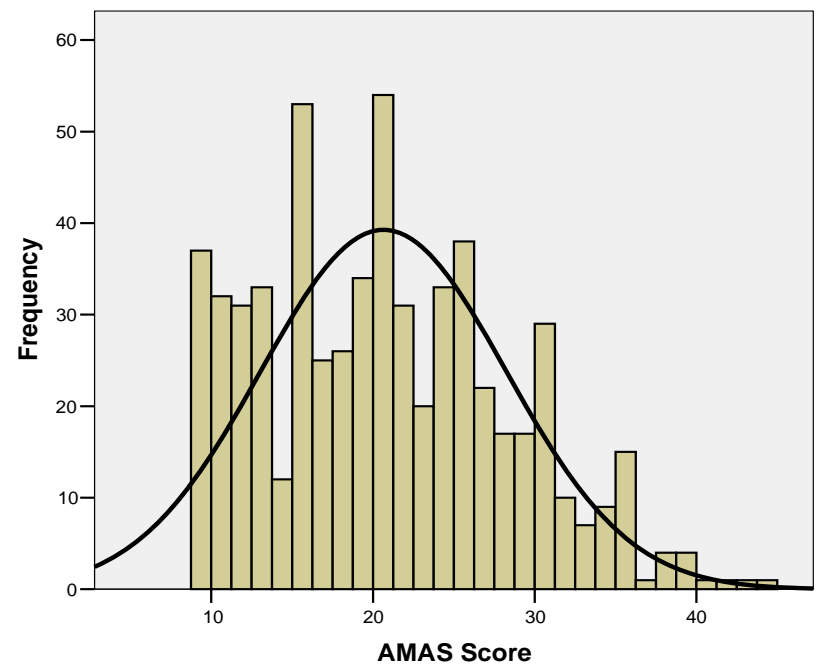

Figure 3. Histogram of AMAS scores for 598 intermediate algebra students. 


\section{Research Question 1}

This next section reports the data and analysis that addressed the first research question: Are bilingual and monolingual students different in their self-reported levels of math anxiety? First, summary data on the AMAS scores for these two groups are described. Then factor analyses of the AMAS are reported to compare the factor structure of the instrument for both the bilingual and monolingual participants. Finally, the results of statistical comparisons of math anxiety responses on the AMAS, self reported math anxiety classification, frequency, and intensity are summarized.

\section{Summary Statistics}

As shown in Table 4, of the 598 AMAS respondents, 242 participants (40.5\%) declared themselves as speaking two or more languages. The mean AMAS score for the bilingual group was 20.6 with a standard deviation of 7.5. Of the 598 AMAS respondents, 356 participants $(59.5 \%)$ declared themselves as monolingual. The mean AMAS score for the monolingual group was 20.7 with a standard deviation of 7.7.

Table 4

AMAS Scores for Bilingual and Monolingual Participants

\begin{tabular}{lcc}
\hline Statistic & Bilingual & Monolingual \\
\hline Mean & 20.6 & 20.7 \\
Standard deviation & 7.5 & 7.7 \\
Median & 20.0 & 20.0 \\
Range & 34.0 & 36.0 \\
\hline
\end{tabular}


Before tests of significance were conducted in order to address the first research question, the researcher conducted factor analyses to ensure that the AMAS adequately represented a similar measure of math anxiety for bilingual students as for monolingual students. The factor analysis is described in the next section.

Factor Analyses

A factor analysis was conducted on the nine items from AMAS to determine the factors for the bilingual participants and for the monolingual participants. The extraction values by principal component analysis are shown in Table 5 .

Table 5

Principal Component Loadings

\begin{tabular}{lcc}
\hline AMAS item & Bilingual & Monolingual \\
\hline Tables & .198 & .288 \\
Math test & .781 & .813 \\
Board & .668 & .725 \\
Exam & .788 & .821 \\
HW & .642 & .594 \\
Lecture & .772 & .746 \\
Formula & .665 & .718 \\
Pop quiz & .805 & .747 \\
Chapter & .582 & .670 \\
\hline
\end{tabular}


Furthermore, as shown in Table 6, two components with eigenvalues over 1 emerged for both the bilingual and monolingual populations. These factors were named assessment and learning content.

Two factors emerged in both factor analyses for two reasons. First, there were only two factors that had eigenvalues greater than 1 . Second, there were two components that were located within the steep descent of the scree plots of the eigenvalues.

Table 6

Eigenvalues and Variance Explained for Principal Component Analysis

\begin{tabular}{|c|c|c|c|c|}
\hline \multirow[b]{2}{*}{ Factor } & \multicolumn{2}{|c|}{ Bilingual } & \multicolumn{2}{|c|}{ Monolingual } \\
\hline & Eigenvalue & $\%$ of variance & Eigenvalue & $\%$ of variance \\
\hline 1 & 4.441 & 49.340 & 4.991 & 55.458 \\
\hline 2 & 1.460 & 16.222 & 1.131 & 12.565 \\
\hline 3 & .869 & 9.650 & .781 & 8.682 \\
\hline 4 & .556 & 6.182 & .514 & 5.716 \\
\hline 5 & .464 & 5.156 & .398 & 4.424 \\
\hline 6 & .409 & 4.549 & .357 & 3.971 \\
\hline 7 & .332 & 3.692 & .328 & 3.646 \\
\hline 8 & .267 & 2.962 & .299 & 3.324 \\
\hline 9 & .202 & 2.247 & .199 & 2.214 \\
\hline
\end{tabular}

Although the eigenvalues for components 1 and 2 differed slightly for the two groups, the scree plots indicated an overall similar pattern in eigenvalues for both groups. 
The scree plot for bilingual participants is shown in Figure 4 while the scree plot for monolingual participants is shown in Figure 5.

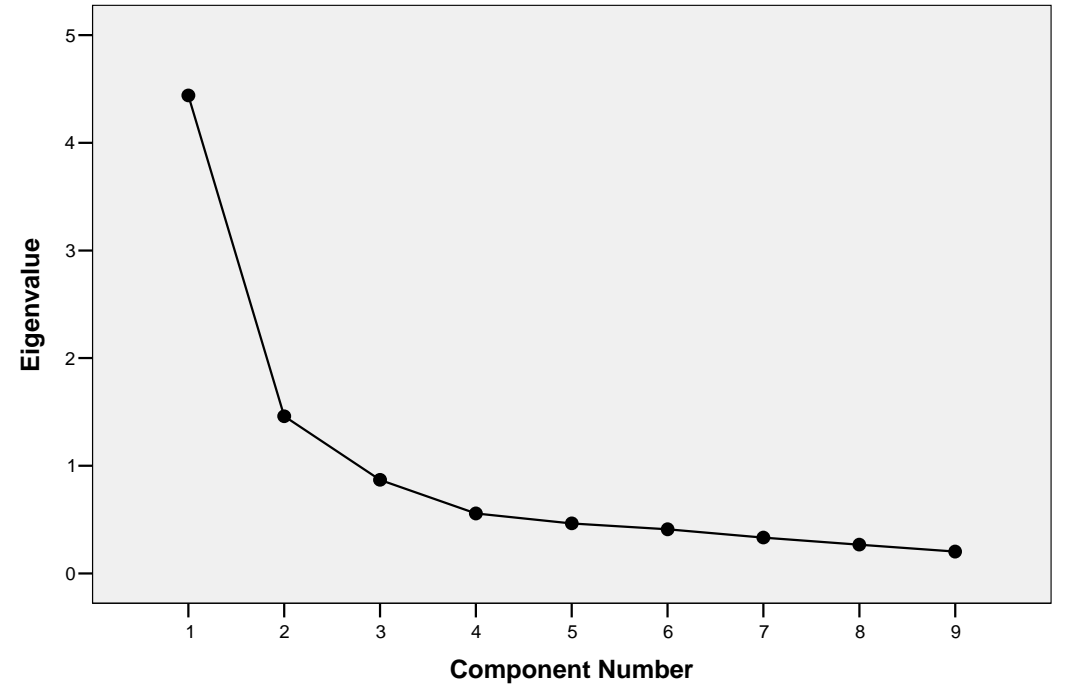

Figure 4. Scree plot for bilingual participants.

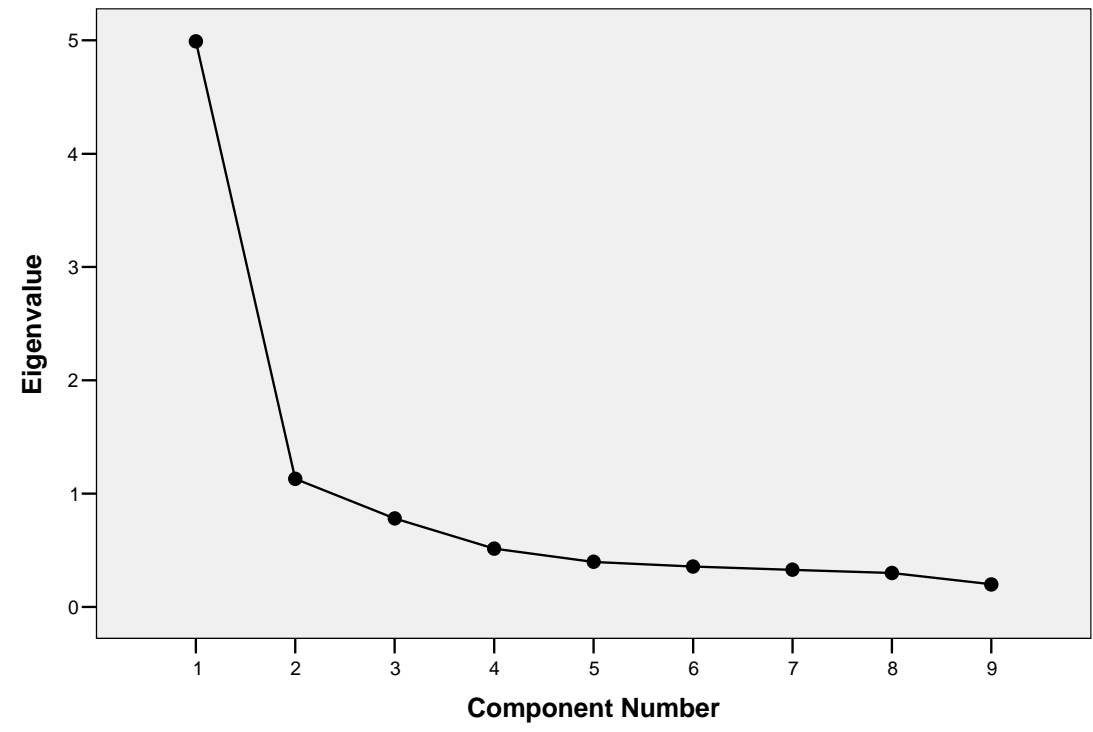

Figure 5. Scree plot for monolingual participants. 
The next question was whether the two factors were similar for both groups.

Factor rotation was utilized to address this question. As shown in Table 7, the comparison of items of the AMAS on the rotated factor matrices indicated that the two factors were indeed similar for both groups.

Table 7

Bilingual and Monolingual Rotated Factor Matrices

\begin{tabular}{|c|c|c|c|c|}
\hline \multirow[b]{2}{*}{ AMAS item } & \multicolumn{2}{|c|}{ Bilingual } & \multicolumn{2}{|c|}{ Monolingual } \\
\hline & Factor 1 & Factor 2 & Factor 1 & Factor 2 \\
\hline Exam & .847 & .213 & .858 & .235 \\
\hline Pop quiz & .847 & .139 & .715 & .335 \\
\hline Math test & .833 & .201 & .832 & .311 \\
\hline Home work & .650 & .349 & .541 & .448 \\
\hline Chapter & .455 & .523 & .414 & .655 \\
\hline Tables & .294 & .221 & .255 & .365 \\
\hline Board & .279 & .701 & .364 & .739 \\
\hline Lecture & .161 & .847 & .199 & .783 \\
\hline Formula & .139 & .671 & .232 & .750 \\
\hline
\end{tabular}

Note. Rotation converged in 3 iterations using the rotation method of Varimax with Kaiser normalization. Extraction method: maximum likelihood.

For factor 1 of the bilingual participants, high correlations above .5 were indicated for the Exam, Pop quiz, Math test, and Home work items. These items deal with evaluation; therefore, this factor was named assessment. For factor 2 of the bilingual participants, high correlations occurred for Lecture, Board, Formula, and Chapter items. 
These items focused on learning content, and this factor was summarized by the label learning content. These two factors accounted for $65.6 \%$ of the trace of bilingual AMAS scores.

Similar results occurred for the monolingual participant factor rotation. The Exam, Math test, Pop quiz, and Home work items had high correlations once again for a factor 1. So, it appeared that this factor for the monolingual students could be categorized as assessment. The Lecture, Formula, Board, and Chapter items contained high correlations for a factor for monolingual students. This factor for the monolingual students, categorized as the learning content factor, appeared to be similar to that of the bilingual students. In summary, factor analysis yielded the same factors on the AMAS for the monolingual and the bilingual populations, the factors of assessment and learning content. Overall, the factor structures were similar for both groups.

The researcher searched for some additional evidence that the factor structures were similar for both groups by conducting a point biserial correlation analysis and ANOVA with the above mentioned factors as independent variables and bilingual as the dependent variable. There were no statistically significant correlations $(n=598)$ between bilingual status and either the assessment $(r=-.037, p=.181)$ or learning content factors $(r=.049, p=.117)$. ANOVA indicated that there was no significant relationship between the factors and determination of bilingual status, $F(2,595)=2.75, p=.065$.

Furthermore, $t$ tests indicated that there were no significant differences in the mean learning content factor values between monolingual and bilingual participants, $t(596)=-1.193, p=.233$, and in the mean assessment factor values between monolingual 
and bilingual participants, $t(596)=.914, p=.361$. This further supported that the factor structure of the AMAS was comparable for bilingual and monolingual students.

Since the factor structures were similar for both groups, the researcher continued with tests of significance between the two groups.

Comparison of Bilingual and Monolingual Math Anxiety

Means. An independent samples $t$ test was used to compare the mean scores on the AMAS for bilingual $(M=20.6)$ and monolingual students $(M=20.7)$. Since Levine's test indicated that the equality of variance assumption holds $F(596)=.081, p=.776$, the $t$ test for means assuming equal variances yielded the results of $t(596)=.051, p=.96$. Therefore, the difference in mean AMAS scores between monolingual and bilingual participants was not statistically significant.

Standard deviations. As stated above, Levine's test indicated that the equality of variance holds, $F(596)=.081, p=.776$. Therefore, an equality of variance and hence standard deviation should be assumed.

Proportions of math anxious individuals. The researcher conducted a $z$ test to test whether there was a significant difference between the proportion of bilingual participants who declared themselves as math anxious individuals (125 out of 250 or $50 \%$ ) and the proportion of monolingual participants who declared themselves as math anxious individuals (168 out of 351 or $48 \%$ ). There was no significant difference in those proportions, $z=-0.52, p=.605$.

Frequency and intensity of math anxiety. Next, the responses to items 12 and 13 on the demographics questionnaire related to frequency of math anxiety and intensity of math anxiety intensity were studied (see Appendix C for questionnaire). The histograms 
shown in Figure 6 represent the responses to the math frequency and math intensity items on the questionnaire. The histogram at the top left hand side of the figure represents the frequency of math anxiety for bilingual students while the lower left histogram represents the frequency of math anxiety for monolingual students. The histogram at the top right hand side of the figure represents the intensity of math anxiety for bilingual students while the lower right histogram represents the intensity of math anxiety for monolingual students. Based on the histograms, both populations showed similar patterns in the frequency of occurrence of math anxiety and in the intensity of math anxiety.
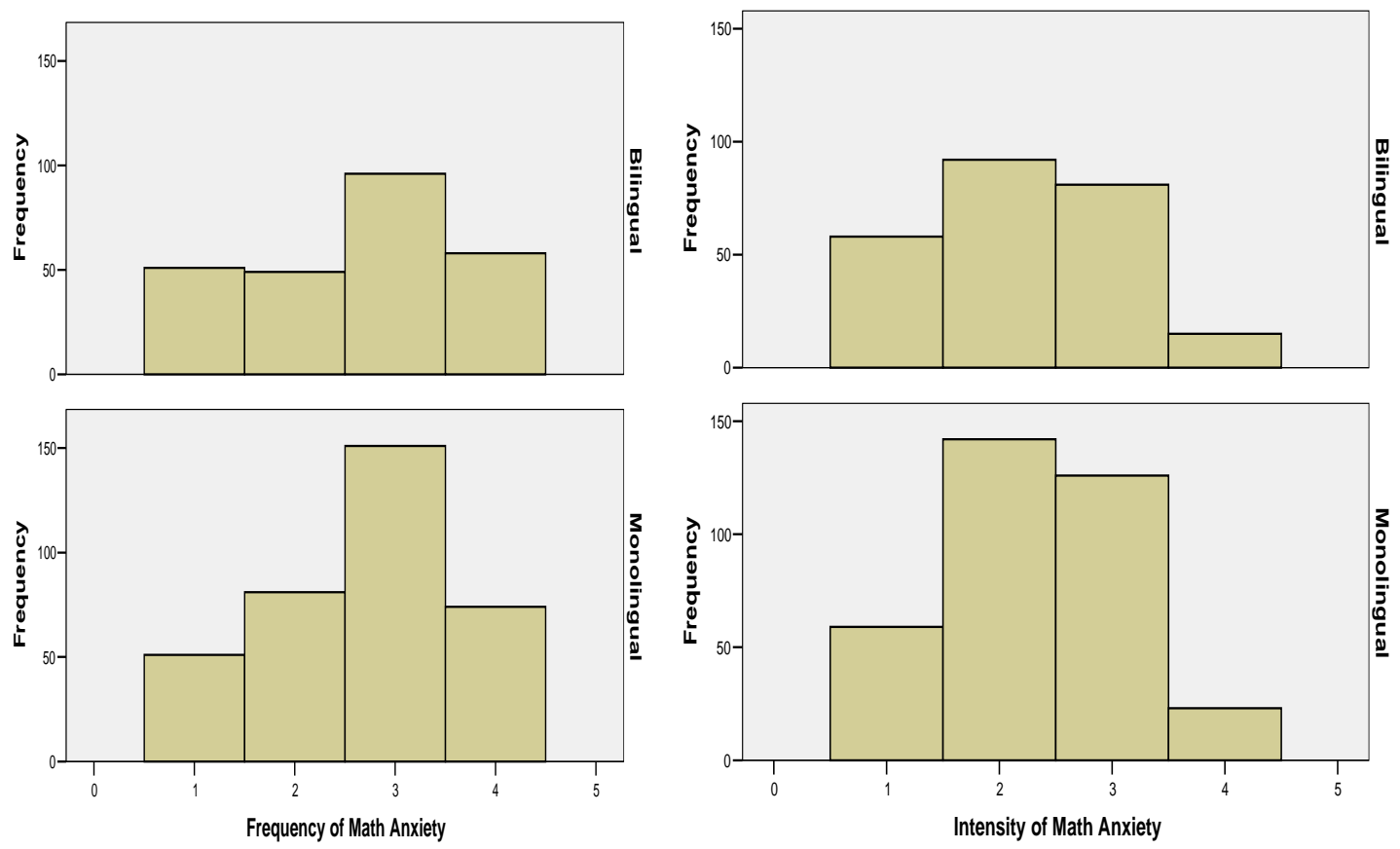

Figure 6. Histograms of frequency of math anxiety and intensity of math anxiety for bilingual and monolingual students.

Next, $t$ tests were conducted to compare the means of the responses to math anxiety frequency and math anxiety intensity. Neither of the $t$ tests yielded statistically significant differences. The $t$ test for the difference in mean scores for frequency between 
monolingual and bilingual students yielded a statistically non significant result of $t(609)$ $=.745, p=.457$. Similarly, the $t$ test for the difference in mean scores in math anxiety intensity between monolingual and bilingual students yielded a result of $t(594)=1.52, p=$ .129. The researcher conducted several measures to be as comprehensive as possible in the data analysis, thus increasing confidence in the results.

Although, none of the $t$ tests yielded statistically significant differences between the groups, the bilingual students classified themselves as math anxious more often than monolingual students. The mean reported value was higher for monolingual students than for bilingual students in both frequency and intensity. These differences indicated that perhaps further study (with a larger sample size) might provide evidence that monolingual students report a greater intensity and a higher frequency of math anxiety than bilingual students, despite declaring themselves as math anxious individuals less frequently.

Table 8

Comparison of Mean Math Anxiety Frequency and Intensity According to Bilingual Status

\begin{tabular}{lcccc}
\hline Measure of math anxiety & Bilingual $M$ & Monolingual $M$ & $t$ & $p$ \\
\hline Math anxiety frequency $^{\mathrm{a}}$ & $2.63(n=254)$ & $2.69(n=357)$ & .745 & .457 \\
Math anxiety intensity $^{\mathrm{b}}$ & $2.22(n=246)$ & $2.32(n=350)$ & -1.52 & .129
\end{tabular}

Note. ${ }^{\text {a }}$ Frequency was rated on a 4 -point scale ( $1=$ none, $2=$ rarely, $3=$ sometimes, $4=$ frequently).

${ }^{\mathrm{b}}$ Intensity was rated on a 4 -point scale $(1=$ none, $2=$ mild, $3=$ moderate, $4=$ severe $)$.

A two way contingency analysis was utilized to evaluate whether a statistical relationship existed between math anxiety frequency and bilingual status or whether the 
variables were independent. The counts for each rating are displayed in Table 9. Math anxiety frequency and bilingual status were independent, $\chi^{2}(3, N=611)=4.84, p=.184$. These results expanded upon the results of the $t$ test for mean frequency and provided evidence that the responses to level of frequency were similar for bilingual and monolingual students across all of the classifications of frequency (none, rarely, sometimes, and frequently).

Table 9

Math Anxiety Frequency According to Bilingual Status

\begin{tabular}{lcr}
\hline Measure of math anxiety frequency & Bilingual & Monolingual \\
\hline None & 51 & 51 \\
Rarely & 49 & 81 \\
Sometimes & 96 & 151 \\
Frequently & 58 & 74 \\
\hline
\end{tabular}

Fifty percent of bilingual and $48 \%$ of monolingual participants claimed to be math anxious. Only $21 \%$ of bilingual participants said that they did not experience math anxiety, and $63 \%$ of bilingual participants said they experienced it sometimes or frequently. In contrast, $14 \%$ of monolingual participants said that they did not experience math anxiety, and $63 \%$ of monolingual participants said that they experienced it sometimes or frequently.

A similar analysis was conducted to evaluate whether math anxiety intensity and bilingual status were independent. The counts for each category are shown in Table 10. Math anxiety intensity and bilingual status were independent as well, 
$\chi^{2}(3, N=596)=4.14, p=.247$. These results expanded upon the results of the $t$ test for mean intensity and provided evidence that the responses to level of math anxiety intensity were similar for bilingual and monolingual students across all measures of intensity. There were $76.4 \%$ of bilingual participants who said that they experienced math anxiety with some level of intensity. In comparison, $83.1 \%$ of monolingual participants said that they experienced math anxiety with some level of intensity.

Table 10

Math Anxiety Intensity According to Bilingual Status

\begin{tabular}{lcr}
\hline Measure of math anxiety intensity & Bilingual & Monolingual \\
\hline None & 58 & 59 \\
Mild & 92 & 142 \\
Moderate & 81 & 126 \\
Severe & 15 & 23 \\
\hline
\end{tabular}

Extreme math anxiety classification. Participants were categorized into low levels of math anxiety (more than one standard deviation below the mean) and high levels of math anxiety (more than one standard deviation above the mean). There were 133 participants (52 bilingual and 81 monolingual) who were classified into the low math anxiety group and 100 participants (38 bilingual and 62 monolingual) were classified into the high math anxiety group. Bilingual language status was not a significant predictor of participants into low or high anxiety classification $F(1,51)=.007, p=.935$. 


\section{Research Questions 2a and 2b}

This section presents the findings related to the second research question: (a) What are the variables that predict math anxiety levels? (b)Are the predictor variables for math anxiety levels different for bilingual students as compared to monolingual students? This section presents the comparison of mean AMAS scores according to each of the demographic variables and then according to the language variable. Then the results analyzing each predictor variable and low/middle/ high anxiety classification are presented. The linear model was used to identify the best prediction model for low and high anxiety groups. Finally, a comparison of the bilingual and monolingual models is described.

\section{Analysis According to Demographic Variables}

This next section begins by presenting the findings on the significance of different mean AMAS scores according to individual demographic variables. Several $t$ tests to compare means were conducted. Also, the results of interaction between each of these variables, bilingual status, and AMAS scores are explained. The independent variables described in this section include gender, age, income, race (Black, White), ethnicity (Hispanic, non-Hispanic), U.S. origin, preparatory course enrollment, major (education, business, health sciences, and science).

Gender. A $t$ test was conducted to see if there was a difference in the mean AMAS scores of men and women. There were 356 women yielding a mean AMAS score of 21.3 with a standard deviation of 7.4 and 242 men yielding a mean AMAS score of 19.7 and standard deviation of 7.7. There was a statistically significant difference in the mean scores between men and women with $t(596)=2.50, p=.013$. The bilingual women 
showed the highest mean AMAS scores. The bilingual women responded with higher mean AMAS scores than the monolingual women yet the bilingual men showed lower mean AMAS scores than monolingual men. Table 11 shows the AMAS scores for bilingual and monolingual participants by gender.

Table 11

AMAS Scores for Bilingual and Monolingual Participants by Gender

\begin{tabular}{|c|c|c|c|c|c|c|}
\hline \multirow[b]{2}{*}{ Gender } & \multicolumn{2}{|c|}{ Mean AMAS score } & \multicolumn{2}{|c|}{ Standard deviation } & \multicolumn{2}{|c|}{ Sample size } \\
\hline & $\begin{array}{c}\text { Bi- } \\
\text { lingual }\end{array}$ & $\begin{array}{l}\text { Mono- } \\
\text { lingual }\end{array}$ & $\begin{array}{c}\mathrm{Bi}^{-} \\
\text {lingual }\end{array}$ & $\begin{array}{l}\text { Mono- } \\
\text { lingual }\end{array}$ & $\begin{array}{c}\mathrm{Bi}- \\
\text { lingual }\end{array}$ & $\begin{array}{l}\text { Mono- } \\
\text { lingual }\end{array}$ \\
\hline Men & 19.5 & 19.9 & 7.4 & 8.0 & 105 & 137 \\
\hline Women & 21.5 & 21.1 & 7.4 & 7.5 & 137 & 219 \\
\hline
\end{tabular}

The researcher conducted a two-way ANOVA with AMAS as dependent variable and bilingual and gender as the independent variables to look for the interaction between these variables. However, no significant interaction was found between bilingual and gender, $F(1,594)=.46, p=.498$, partial $\eta^{2}=.001$, with no significant main effect for bilingual, $F(1,594)=.002, p=.963$, partial $\eta^{2}=.000$, and a significant main effect for gender, $F(1,594)=6.628, p=.010$, partial $\eta^{2}=.011$, with women scoring higher.

Age. Table 12 shows the AMAS scores for bilingual and monolingual participants by age. The results according to age must be interpreted with the caution that few participants appeared in the three older-age categories (24 -29, 30-39, 40 or over). From visual inspection of the data in Table 12, large difference can be seen in the mean AMAS score for bilingual $(M=17.8)$ and monolingual $(M=24.9)$ participants in the 30 - 
39 age bracket. In fact, this was a statistically significant difference with $t(23)=-2.202$, $p=.038$.

Table 12

AMAS Scores for Bilingual and Monolingual Participants by Age

\begin{tabular}{lrrrrrrrr}
\hline & \multicolumn{2}{c}{ Mean AMAS score } & & \multicolumn{2}{c}{ Standard deviation } & & \multicolumn{2}{c}{ Sample size } \\
\cline { 2 - 3 } \cline { 8 - 8 } \multicolumn{1}{c}{ Age } & $\begin{array}{c}\text { Bi- } \\
\text { lingual }\end{array}$ & $\begin{array}{c}\text { Mono- } \\
\text { lingual }\end{array}$ & & $\begin{array}{c}\text { Bi- } \\
\text { lingual }\end{array}$ & $\begin{array}{c}\text { Mono- } \\
\text { lingual }\end{array}$ & & $\begin{array}{c}\text { Bi- } \\
\text { lingual }\end{array}$ & $\begin{array}{c}\text { Mono- } \\
\text { lingual }\end{array}$ \\
\hline$<19$ & 20.2 & 19.5 & & 6.5 & 7.7 & & 80 & 125 \\
$19-23$ & 21.0 & 21.1 & & 7.9 & 7.4 & & 127 & 196 \\
$24-29$ & 21.5 & 20.3 & & 8.1 & 8.1 & & 22 & 16 \\
$30-39 *$ & 17.8 & 24.9 & & 7.6 & 8.3 & & 11 & 14 \\
$>40$ & 19.5 & 21.0 & & 12.0 & 11.1 & & 2 & 5 \\
\hline
\end{tabular}

*Statistically significant difference, $p=.038$

The researcher conducted a two-way ANOVA with AMAS as the dependent variable and bilingual and age as the independent variables to look for the interaction between these variables. No statistically significant interaction was found between bilingual participants and age, $F(4,588)=1.49, p=.202$, partial $\eta^{2}=.01$. There were no statistically significant main effects for bilingual, $F(1,588)=.782, p=.38$, partial $\eta^{2}=$ .001 , or age, $F(4,588)=.793, p=.530$, partial $\eta^{2}=.005$.

Income. The data on income are shown in Table 13. For the bilingual students, the math anxiety level generally climbed as the income level increased. For the bilingual participants, the highest math anxiety occurred with the participants who had an income greater than $\$ 100,000$. However, for the monolingual participants the highest mean AMAS score occurred among the participants in the lowest income bracket, that is, income below $\$ 25,000$. 
Table 13

AMAS Scores for Bilingual and Monolingual Participants by Income

\begin{tabular}{|c|c|c|c|c|c|c|}
\hline \multirow[b]{2}{*}{ Income } & \multicolumn{2}{|c|}{ Mean AMAS score } & \multicolumn{2}{|c|}{ Standard deviation } & \multicolumn{2}{|c|}{ Sample size } \\
\hline & $\begin{array}{c}\mathrm{Bi}^{-} \\
\text {lingual }\end{array}$ & $\begin{array}{l}\text { Mono- } \\
\text { lingual }\end{array}$ & $\begin{array}{c}\mathrm{Bi}^{-} \\
\text {lingual }\end{array}$ & $\begin{array}{l}\text { Mono- } \\
\text { lingual }\end{array}$ & $\begin{array}{c}\mathrm{Bi}^{-} \\
\text {lingual }\end{array}$ & $\begin{array}{l}\text { Mono- } \\
\text { lingual }\end{array}$ \\
\hline$<\$ 25,000$ & 19.3 & 22.0 & 7.1 & 9.2 & 55 & 71 \\
\hline$\$ 25,000-\$ 49,999$ & 20.6 & 20.0 & 7.7 & 7.2 & 67 & 85 \\
\hline$\$ 50,000-\$ 74,999$ & 20.1 & 21.1 & 6.6 & 7.1 & 49 & 87 \\
\hline$\$ 75,000-\$ 99,999$ & 21.0 & 18.7 & 7.9 & 7.2 & 24 & 38 \\
\hline$>\$ 100,000$ & 22.6 & 20.6 & 6.0 & 8.0 & 13 & 39 \\
\hline
\end{tabular}

The researcher conducted a two way ANOVA with AMAS as dependent variable and bilingual and income as the independent variables to look for the interaction between these variables. No statistically significant interaction was found between bilingual and income, $F(4,518)=1.72, p=.144$, partial $\eta^{2}=.013$. There were no significant main effects for bilingual, $F(1,518)=.101, p=.751$, partial $\eta^{2}=.000$, or income, $F(4,518)=$ $.367, p=.832$, partial $\eta^{2}=.003$.

Race. There were 128 Blacks and 295 Whites who completed the AMAS, with small counts in other racial groupings. Some of the participants were counted in both of these categories since participants could select more than one racial category. There was no significant difference in the mean scores between Black $(M=20.1, n=128)$ and nonBlack $(M=20.5, n=330)$ participants, $t(456)=.599, p=.549$. There was no statistically significant difference in the mean AMAS scores between White $(M=20.8, n=295)$ and non-White $(M=19.6 n=163)$ participants, $t(456)=-1.63, p=.103$. 
The researcher conducted a two-way ANOVA with AMAS score as the dependent variable and bilingual and Black/non-Black as the independent variables to look for the interaction between these variables. No significant interaction was found between bilingual and Black race, $F(1,454)=.831,, p=.362$, partial $\eta^{2}=.002$. There were no statistically significant main effects for bilingual status, $F(1,454)=.617, p=$ .433 , partial $\eta^{2}=.001$, or Black race, $F(1,454)=.013, p=.910$, partial $\eta^{2}=.000$.

The researcher conducted a two-way ANOVA with AMAS as the dependent variable and bilingual and White/non-White as the independent variables to look for the interaction between these variables. No significant interaction was found between bilingual and White race, $F(1,454)=.276,, p=.600$, partial $\eta^{2}=.001$. No significant main effects were found for bilingual participants, $F(1,454)=1.27 \cdot p=.260$, partial $\eta^{2}=$ .003 , or White race, $F(1,454)=1.33, p=.249$, partial $\eta^{2}=.003$.

Ethnicity (Hispanic, non-Hispanic). A $t$ test was conducted to determine whether there was a significant difference in the mean AMAS scores of Hispanic and nonHispanic participants (shown in Table 14). There was no statistically significant difference between mean AMAS scores for Hispanic and non-Hispanic participants, $t(556)=-.933, p=.351$.

The researcher conducted a two-way ANOVA with AMAS as dependent variable and bilingual and ethnicity as the independent variables to look for the interaction between these variables. No statistically significant interaction was found between bilingual and ethnicity, $F(1,554)=.185, p=.667$, partial $\eta^{2}=.000$, with no significant main effects for bilingual status, $F(1,554)=.374, p=.541$, partial $\eta^{2}=.001$, or ethnicity, $F(1,554)=1.24, p=.267$, partial $\eta^{2}=.002$ 
Table 14

AMAS Scores for Bilingual and Monolingual Participants by Ethnicity

\begin{tabular}{|c|c|c|c|c|c|c|}
\hline \multirow[b]{2}{*}{ Ethnicity } & \multicolumn{2}{|c|}{ Mean AMAS score } & \multicolumn{2}{|c|}{ Standard deviation } & \multicolumn{2}{|c|}{ Sample size } \\
\hline & $\begin{array}{c}\text { Bi- } \\
\text { lingual }\end{array}$ & $\begin{array}{l}\text { Mono- } \\
\text { lingual }\end{array}$ & $\begin{array}{c}\text { Bi- } \\
\text { lingual }\end{array}$ & $\begin{array}{l}\text { Mono- } \\
\text { lingual }\end{array}$ & $\begin{array}{c}\text { Bi- } \\
\text { lingual }\end{array}$ & $\begin{array}{l}\text { Mono- } \\
\text { lingual }\end{array}$ \\
\hline Hispanic & 21.1 & 21.2 & 7.6 & 8.6 & 165 & 39 \\
\hline $\begin{array}{l}\text { Non- } \\
\text { Hispanic }\end{array}$ & 19.7 & 20.6 & 7.5 & 7.7 & 67 & 287 \\
\hline
\end{tabular}

U.S. origin. A $t$ test was conducted to determine whether there was a significant difference in the mean AMAS scores of participants of U.S. origin and non-U.S. origin (shown in Table 15). There was no statistically significant difference between the mean AMAS scores of participants of U.S. origin and non U.S. origin, $t(604)=.537, p=.591$. Table 15 shows the mean AMAS scores, standard deviations, and sample sizes for bilingual and monolingual participants by U.S. origin.

Table 15

AMAS Scores for Bilingual and Monolingual Participants by U.S. Origin

\begin{tabular}{cccccccccc}
\hline & \multicolumn{2}{c}{ Mean AMAS score } & & \multicolumn{2}{c}{ Standard deviation } & & \multicolumn{2}{c}{ Sample size } \\
\cline { 2 - 4 } Origin & $\begin{array}{c}\text { Bi- } \\
\text { lingual }\end{array}$ & $\begin{array}{c}\text { Mono- } \\
\text { lingual }\end{array}$ & & $\begin{array}{c}\text { Bi- } \\
\text { lingual }\end{array}$ & $\begin{array}{c}\text { Mono- } \\
\text { lingual }\end{array}$ & & $\begin{array}{c}\text { Bi- } \\
\text { lingual }\end{array}$ & $\begin{array}{c}\text { Mono- } \\
\text { lingual }\end{array}$ \\
\hline U.S. & 20.51 & 20.48 & & 7.24 & 7.42 & & 82 & 277 \\
Non-U.S. & 20.70 & 21.29 & & 7.67 & 8.51 & & 158 & 79 \\
\hline
\end{tabular}

Preparatory course. A $t$ test was conducted to determine whether there was a significant difference in the mean AMAS scores between those students who completed a prep course and those students who had not taken a math prep course in college. There 
was a statistically significant difference in the mean AMAS scores between the two groups $t(586)=-2.99, p=.003$. There was also a significant difference in the variance between the two groups, $F(586)=5.88, p=.016$. Next, the researcher also addressed two more questions: (a) whether there was a significant difference in the AMAS scores between those bilingual students who had taken a math preparatory course and those who had not taken a preparatory course and (b) whether there was a significant difference in the AMAS scores between those monolingual students who had taken a preparatory course and those who had not taken a preparatory course. The mean AMAS scores, standard deviations, and sample sizes for bilingual and monolingual participants are shown in Table 16.

Table 16

AMAS Scores for Bilingual and Monolingual Participants by Preparatory Course

\begin{tabular}{lcccccccc}
\hline & \multicolumn{2}{c}{ Mean AMAS score } & & \multicolumn{2}{c}{ Standard deviation } & & \multicolumn{2}{c}{ Sample size } \\
\cline { 2 - 3 } $\begin{array}{l}\text { Preparatory } \\
\text { Enrollment }\end{array}$ & $\begin{array}{c}\text { Bi- } \\
\text { lingual }\end{array}$ & $\begin{array}{c}\text { Mono- } \\
\text { lingual }\end{array}$ & & $\begin{array}{c}\text { Bi- } \\
\text { lingual }\end{array}$ & $\begin{array}{c}\text { Mono- } \\
\text { lingual }\end{array}$ & & $\begin{array}{c}\text { Bi- } \\
\text { lingual }\end{array}$ & $\begin{array}{c}\text { Mono- } \\
\text { lingual }\end{array}$ \\
\hline Preparatory & 21.3 & 21.9 & & 8.1 & 8.2 & & 102 & 150 \\
$\begin{array}{l}\text { Non- } \\
\text { preparatory }\end{array}$ & 20.1 & 19.7 & & 6.9 & 7.1 & & 132 & 204 \\
\hline
\end{tabular}

The researcher conducted a two-way ANOVA with AMAS as the dependent variable and bilingual and preparatory course as the independent variables to look for the interaction between these variables. However, no significant interaction was found between preparatory course and bilingual participants, $F(1,584)=.65, p=.420$, partial $\eta^{2}=.001$. A significant main effect was found for preparatory course, $F(1,584)=7.65, p$ $=.006$, partial $\eta^{2}=.013$, which agreed with the findings from the $t$ test above. No 
significant main effect was found for bilingual status, $F(1,584)=.019, p=.890$, partial $\eta^{2}=.000$

Education major. A comparison of the reported AMAS scores between education and non-education majors was conducted. Participants who reported their major as education, early childhood education, teacher, or a field specific education major were categorized as education majors. A $t$ test was conducted to compare the mean AMAS scores of education majors and non-education majors. There were 44 students who declared themselves as education majors out of the 583 who completed the AMAS and stated their major. As shown in Table 17, the mean AMAS score for education majors was 24.7 with a standard deviation of 7.0, and the mean AMAS score for non-education majors was 20.3 with a standard deviation of 7.6. There was a statistically significant difference in the mean AMAS scores of education and non-education majors with $t(581)$ $=-3.68, p<0.0009$.

Table 17

AMAS Scores for Bilingual and Monolingual Participants by Education Major

\begin{tabular}{|c|c|c|c|c|c|c|}
\hline \multirow[b]{2}{*}{ Education Major } & \multicolumn{2}{|c|}{ Mean AMAS score } & \multicolumn{2}{|c|}{ Standard deviation } & \multicolumn{2}{|c|}{ Sample size } \\
\hline & $\begin{array}{c}\text { Bi- } \\
\text { lingual }\end{array}$ & $\begin{array}{l}\text { Mono- } \\
\text { lingual }\end{array}$ & $\begin{array}{c}\mathrm{Bi}- \\
\text { lingual }\end{array}$ & $\begin{array}{l}\text { Mono- } \\
\text { lingual }\end{array}$ & $\begin{array}{c}\mathrm{Bi}- \\
\text { lingual }\end{array}$ & $\begin{array}{l}\text { Mono- } \\
\text { lingual }\end{array}$ \\
\hline Yes* & 25.6 & 24.2 & 7.7 & 6.8 & 14 & 30 \\
\hline No & 20.4 & 20.3 & 7.4 & 7.7 & 225 & 314 \\
\hline
\end{tabular}

* Statistically significant differences in Mean AMAS scores, $p<0.00$

The researcher conducted a two-way ANOVA with AMAS as the dependent variable and bilingual and education major as the independent variables to look for the 
interaction between these variables. No statistically significant interaction was found between education major and bilingual status, $F(1,579)=.271, p=.603$, partial $\eta^{2}=$ .000 . There was a statistically significant main effect for education major, $F(1,579)=$ 13.172, $p<.0009$, partial $\eta^{2}=.022$, such that education majors scored higher, but no statistically significant main effect for bilingual status, $F(1,579)=.353, p=.553$, partial $\eta^{2}=.001$. The education major main effect indicated that education majors had higher math anxiety scores than non-education majors, as shown in Table 18.

Table 18

Analysis of Variance for AMAS Scores by Bilingual Status and Education Major

\begin{tabular}{lrrrr}
\hline \multicolumn{1}{c}{ Source } & $d f$ & $F$ & $\eta^{2}$ & $p$ \\
\hline Bilingual status (B) & 1 & 0.35 & .001 & .553 \\
Education major (E) & 1 & 13.17 & .022 & .000 \\
B x E & 1 & 0.27 & .00 & .603 \\
Within-group error & 579 & $(56.9)$ & & \\
\hline
\end{tabular}

Note: Bilingual status was coded as 0 or $1(0=$ monolingual, $1=$ bilingual $)$. Education major was coded as 0 or $1(0=$ all majors other than education, $1=$ education major $)$.Value enclosed in parentheses represents mean square error.

Business major. A $t$ test was conducted to see if there was a difference in the mean AMAS scores of business majors and non-business majors. Majors that were listed under the business administration department at the college were classified as business majors. Based on the responses, the majors that were classified as business included business administration, international business, human resources, hospitality, public administration, marketing, finance, advertising, accounting, travel and tourism management, and economics. 
There were 107 business majors who achieved a mean AMAS score of 20.5 with a standard deviation of 6.6. There were 476 non-business majors who achieved a mean AMAS score of 20.7 with a standard deviation of 7.8. There was no statistically significant difference in the mean scores between these two groups of participants with $t(581)=.28, p=.783$. Table 19 shows the mean AMAS scores, standard deviations, and sample sizes for bilingual and monolingual participants by business major.

Table 19

AMAS Scores for Bilingual and Monolingual Participants by Business Major

\begin{tabular}{|c|c|c|c|c|c|c|}
\hline \multirow[b]{2}{*}{$\begin{array}{c}\text { Business } \\
\text { major }\end{array}$} & \multicolumn{2}{|c|}{ Mean AMAS score } & \multicolumn{2}{|c|}{ Standard deviation } & \multicolumn{2}{|c|}{ Sample size } \\
\hline & $\begin{array}{c}\text { Bi- } \\
\text { lingual }\end{array}$ & $\begin{array}{l}\text { Mono- } \\
\text { lingual }\end{array}$ & $\begin{array}{c}\text { Bi- } \\
\text { lingual }\end{array}$ & $\begin{array}{l}\text { Mono- } \\
\text { lingual }\end{array}$ & $\begin{array}{c}\text { Bi- } \\
\text { lingual }\end{array}$ & $\begin{array}{l}\text { Mono- } \\
\text { lingual }\end{array}$ \\
\hline Yes & 21.7 & 19.7 & 5.9 & 6.8 & 42 & 65 \\
\hline No & 20.5 & 20.9 & 7.8 & 7.9 & 197 & 279 \\
\hline
\end{tabular}

The researcher conducted a two-way ANOVA with AMAS as the dependent variable and bilingual and business major as the independent variables to look for the interaction between these variables. The results are shown in Table 20.

Table 20

Analysis of Variance for AMAS Scores by Bilingual Status and Business Major

\begin{tabular}{lrrrr}
\hline \multicolumn{1}{c}{ Source } & $d f$ & $F$ & $\eta^{2}$ & $p$ \\
\hline Bilingual status (B) & 1 & 0.97 & .002 & .325 \\
Business major (M) & 1 & .001 & .000 & .975 \\
B x M & 1 & 2.08 & .004 & .150 \\
Within-group error & 579 & $(58.04)$ & & \\
\hline
\end{tabular}

Note: Bilingual status was coded as 0 or $1(0=$ monolingual, $1=$ bilingual $)$. Business major was coded as 0 or $1(0=$ all majors other than business majors, $1=$ business major $)$. Value enclosed in parentheses represents mean square error. 
However, no statistically significant interaction was found between business major and bilingual status, $F(1,579)=2.08, p=.15$, partial $\eta^{2}=.004$. Furthermore, there were no statistically significant main effects for business major, $F(1,579)=.001, p=$ .975 , partial $\eta^{2}=.000$, or bilingual, $F(1,579)=.971, p=.325$, partial $\eta^{2}=.002$

Health sciences major. The reported AMAS scores between health sciences and non-health sciences majors were compared. Participants who reported their major as nursing, dental, EMS, physical therapy, radiography, vision care, nuclear medicine, anesthesiology, chiropractic or pre-med were classified as health majors, according to the practice of the health sciences department at the college. A $t$ test was conducted to compare the mean AMAS scores of health science majors and non-health science majors. There were 99 students who declared themselves as health science majors out of the 583 who completed the AMAS and stated their major. As shown in Table 21, the mean AMAS score for health science majors was 19.6 with a standard deviation of 7.4 , and the mean AMAS score for non-health science majors was 20.9 with a standard deviation of 7.6. There was no statistically significant difference in the mean AMAS scores of health science and non-health science majors with $t(581)=1.54, p=.124$.

Table 21

AMAS Scores for Bilingual and Monolingual Participants by Health Sciences Major

\begin{tabular}{lccccccccc}
\hline & \multicolumn{2}{c}{ Mean AMAS score } & & \multicolumn{2}{c}{ Standard deviation } & & \multicolumn{2}{c}{ Sample size } \\
\cline { 2 - 3 } $\begin{array}{c}\text { Health Sciences } \\
\text { Major }\end{array}$ & $\begin{array}{c}\text { Bi- } \\
\text { lingual }\end{array}$ & $\begin{array}{c}\text { Mono- } \\
\text { lingual }\end{array}$ & & $\begin{array}{c}\text { Bi- } \\
\text { lingual }\end{array}$ & $\begin{array}{c}\text { Mono- } \\
\text { Lingual }\end{array}$ & & $\begin{array}{c}\text { Bi- } \\
\text { lingual }\end{array}$ & $\begin{array}{c}\text { Mono- } \\
\text { lingual }\end{array}$ \\
\hline Yes & 20.2 & 19.1 & & 7.8 & & 7.1 & & 44 & 55 \\
No & 20.8 & 20.9 & & 7.4 & 7.8 & & 195 & 289 \\
\hline
\end{tabular}


The researcher conducted a two-way ANOVA with AMAS as dependent variable and bilingual and health science major as the independent variables to look for the interaction between these variables. However, no statistically significant interaction was found between health science major and bilingual, $F(1,579)=.517, p=.472$, partial $\eta^{2}=$ .001 , with no statistically significant main effects for health science major, $F(1,579)=$ 2.07, $p=.150$, partial $\eta^{2}=.004$, and no statistically significant main effect for bilingual, $F(1,579)=.330, p=.566$, partial $\eta^{2}=.001$, shown in Table 22 .

Table 22

Analysis of Variance for AMAS Scores by Bilingual Status and Health Sciences Major

\begin{tabular}{lcccc}
\hline Source & $d f$ & $F$ & $\eta^{2}$ & $p$ \\
\hline Bilingual status (B) & 1 & 0.33 & .001 & .566 \\
Health science major (H) & 1 & 2.07 & .004 & .150 \\
B x H & 1 & .517 & .001 & .472 \\
Within-group error & 579 & $(58.0)$ & & \\
\hline
\end{tabular}

Note: Bilingual status was coded as 0 or $1(0=$ monolingual, $1=$ bilingual $)$. Health science major was coded as 0 or $1(0=$ all majors other than health science, $1=$ health science major $)$.Value enclosed in parentheses represents mean square error.

Science major. The reported AMAS scores between science and non-science majors were compared. Participants who reported their major as biology, marine biology, chemistry, environmental science, meteorology, pharmacy, nutritional science, horticultural science, exercise science, and zoology were classified as science majors because they fall under the natural sciences and biological sciences departments at the college. A $t$ test was conducted to compare the mean AMAS scores of science majors and non-science majors. There were 68 students who declared themselves as science majors 
out of the 583 who completed the AMAS and stated their major. The mean AMAS score for science majors was 19.7 with a standard deviation of 7.5, and the mean AMAS score for non-science majors was 20.8 with a standard deviation of 7.6. There was no statistically significant difference in the mean AMAS scores of science and non-science majors with $t(581)=1.08, p=.282$. The mean AMAS scores, standard deviations, and sample sizes are shown in Table 23.

Table 23

AMAS Scores for Bilingual and Monolingual Participants by Science Major

\begin{tabular}{lcccccccc}
\hline & \multicolumn{2}{c}{ Mean AMAS score } & & \multicolumn{2}{c}{ Standard deviation } & & \multicolumn{2}{c}{ Sample size } \\
\cline { 2 - 3 } $\begin{array}{c}\text { Science } \\
\text { Major }\end{array}$ & $\begin{array}{c}\text { Bi- } \\
\text { lingual }\end{array}$ & $\begin{array}{c}\text { Mono- } \\
\text { lingual }\end{array}$ & & $\begin{array}{c}\text { Bi- } \\
\text { lingual }\end{array}$ & $\begin{array}{c}\text { Mono- } \\
\text { lingual }\end{array}$ & & $\begin{array}{c}\text { Bi- } \\
\text { lingual }\end{array}$ & $\begin{array}{c}\text { Mono- } \\
\text { lingual }\end{array}$ \\
\hline Yes & 18.9 & 20.2 & & 7.0 & 7.9 & & 26 & 42 \\
No & 20.9 & 20.7 & & 7.6 & 7.7 & & 213 & 302 \\
\hline
\end{tabular}

The researcher conducted a two-way ANOVA with AMAS as dependent variable and bilingual and science major as the independent variables to look for the interaction between these variables. However, no statistically significant interaction was found between science major and bilingual, $F(1,579)=.576, p=.448$, partial $\eta^{2}=.001$, with no statistically significant main effects for science major, $F(1,579)=1.48, p=.224$, partial $\eta^{2}=.003$, and no statistically significant main effect for bilingual, $F(1,579)=$ $.295, p=.587$, partial $\eta^{2}=.001$, as shown in Table 24 . 
Table 24

Analysis of Variance for AMAS Scores by Bilingual Status and Science Major

\begin{tabular}{lrrrr}
\hline Source & $d f$ & $F$ & $\eta^{2}$ & $p$ \\
\hline Bilingual status (B) & 1 & 0.30 & .001 & .587 \\
Science major (S) & 1 & 1.48 & .003 & .224 \\
B x S & 1 & .576 & .001 & .448 \\
Within-group error & 579 & $(58.1)$ & & \\
\hline
\end{tabular}

Note.: Bilingual status was coded as 0 or $1(0=$ monolingual, $1=$ bilingual $)$. Science major was coded as 0 or $1(0=$ all majors other than science, $1=$ science major $)$. Value enclosed in parentheses represents mean square error.

Summary of mean AMAS scores according to major. There was a statistically significant difference in the mean AMAS scores between education and non-education majors. There were no statistically significant differences in the AMAS scores between (a) business and non-business majors, (b) health science and non-health science majors, and (c) science and non-science majors.

Regression Analysis

Discriminant analysis was used to address the second research question: $2 a$. What are the variables that predict math anxiety levels? and $2 b$. Are the predictor variables for math anxiety levels different for bilingual students as compared to monolingual students? The independent variables of gender, age, income, race (Black vs. White), ethnicity (Hispanic, non-Hispanic), U.S. origin, preparatory course enrollment, major (education, business, health science, and science) were used to discriminate between low levels of math anxiety (more than one standard deviation below the mean), middle levels of math anxiety (within one standard deviation of the mean), and high levels of math anxiety (more than one standard deviation above the mean). 
The corresponding model $(n=346)$ resulted in a multiple correlation coefficient of $R=.281$, indicating that these 11 variables accounted for about $7.9 \%$ of the variance in math anxiety classification. The values for the standardized beta weights and the associated probabilities for each predictor variable are indicated in Table 25.

Table 25

The $\beta$ and p-values for 11 Predictor Variables and Low/Middle/High Math Anxiety Classification

\begin{tabular}{lrc}
\hline Predictor variable & Standardized $\beta$ & $p$-value \\
\hline Gender* & -.167 & .003 \\
Age & .035 & .549 \\
Income & .027 & .622 \\
Race (Black, White) & -.071 & .208 \\
Ethnicity (Hispanic, non-Hispanic) & -.038 & .499 \\
U.S. origin & -.011 & .843 \\
Preparatory course* & .120 & .039 \\
Education major* & .128 & .024 \\
Business major & -.036 & .520 \\
Health science major & -.056 & .344 \\
Science major & -.033 & .553 \\
\hline
\end{tabular}

\footnotetext{
*Statistically significant

Note: Bilingual status was coded as 0 or $1(0=$ monolingual, $1=$ bilingual $)$. Gender was coded as 0 or $1(0$ $=$ female, $1=$ male $)$. Age was coded as 1, 2, 3, 4, or $5(1=$ less than 19, $2=19-23,3=24-29,4=30-39,5$

$=40$ or over). Income was coded as $1,2,3,4$, or $5(1=$ below $\$ 25,000,2=\$ 25,000-\$ 49,999,3=\$ 50,000$ $\$ 74,999,4=\$ 75,000-\$ 99,999,5=\$ 100,000$ or above $)$. Race was coded as 0 or $1(0=$ White, $1=$ Black $)$. Ethnicity was coded as 0 or $1(0=$ non-Hispanic, $1=$ Hispanic $)$. U.S. origin was coded as 0 or $1(0=$ nonU.S. origin, $1=$ U.S. origin). Preparatory course was coded as 0 or $1(0=$ no enrollment in preparatory course, $1=$ enrollment in preparatory course $)$. Education major was coded as 0 or $1(0=$ all majors other than education, $1=$ education major $)$. Business major was coded as 0 or $1(0=$ all majors other than business, $1=$ business major $)$. Health science major was coded as 0 or $1(0=$ all majors other than health science, $1=$ health science major $)$. Science major was coded as 0 or $1(0=$ all majors other than science, 1 $=$ science major $)$. Math anxiety classification was coded as 0,1 , or $2(0=$ low math anxiety, $1=$ middle math anxiety, 2 = high math anxiety).
} 
A similar analysis was conducted for the bilingual participants and then for the monolingual students to determine whether the models differed between these two groups. Using the same 11 predictor variables, the fit of the model was stronger for math anxiety classification for the bilingual participants $(n=87), R=.425$ compared to the monolingual participants $(n=259), R=.329$. Table 26 indicates the values for the standardized beta weights and the associated probabilities for each predictor variable.

The 11 variables predicted low/middle/high anxiety classifications by bilingual status. The 11 variables accounted for about $18 \%$ of the variance in math anxiety classification level for bilingual participants and $10.8 \%$ of the variance for monolingual participants. Analysis of variance indicated no statistically significant relationship between the 11 predictor variables and the dependent variable of math anxiety classification, $F(11,90)=1.46, p=.160$ for the bilingual participants.

However, those same predictor variables showed a significant relationship with math anxiety classification for the monolingual participants, $F(11,247)=2.723, p=.002$. Table 26 indicates the significance levels of each predictor variable within the model for bilingual and monolingual participants.

The statistically significant predictor variables for the bilingual participants were the preparatory course variable $(\beta=.236 p=.041)$ with those enrolled in prior preparatory courses scoring higher, the education major variable $(\beta=.285 p=.018)$ with education majors scoring higher, and the business major variable $(\beta=.252 p=.032)$ with business majors scoring higher. The model for the monolingual participants included one statistically significant predictor variables, gender with $\beta=-.085$ and $p=.001$ such that women ranked higher in math anxiety classification. 
Table 26

The $\beta$ and p-values for 11 Predictor Variables and Low/Middle/High Math Anxiety Classification by Bilingual Status

\begin{tabular}{|c|c|c|c|c|}
\hline \multirow[b]{2}{*}{ Predictor variable } & \multicolumn{2}{|c|}{ Standardized $\beta$} & \multicolumn{2}{|c|}{$p$-value } \\
\hline & Bilingual & Monolingual & Bilingual & Monolingual \\
\hline Gender* & -.089 & -.217 & .423 & .001 \\
\hline Age & -.142 & .105 & .221 & .126 \\
\hline Income & .138 & -.015 & .246 & .808 \\
\hline Race (Black, non-Black) & -.028 & -.074 & .827 & .248 \\
\hline Ethnicity (Hispanic, non- & -.099 & .037 & .424 & .552 \\
\hline \multicolumn{5}{|l|}{ Hispanic) } \\
\hline U.S. origin & -.073 & -.040 & .519 & .526 \\
\hline Preparatory course ${ }^{* *}$ & .236 & .077 & .041 & .259 \\
\hline Education major** & .285 & .075 & .018 & .252 \\
\hline Business major** & .252 & -.125 & .032 & .054 \\
\hline Health science major & .166 & -.134 & .155 & .055 \\
\hline Science major & .083 & .014 & .464 & .835 \\
\hline
\end{tabular}

*Statistically significant for monolingual participants only.

**Statistically significant for bilingual participants only.

Note: Bilingual status was coded as 0 or $1(0=$ monolingual, $1=$ bilingual $)$. Gender was coded as 0 or $1(0$ $=$ female, $1=$ male $)$. Age was coded as 1, 2, 3, 4, or $5(1=$ less than 19, $2=19-23,3=24-29,4=30-39,5$

$=40$ or over). Income was coded as $1,2,3,4$, or $5(1=$ below $\$ 25,000,2=\$ 25,000-\$ 49,999,3=\$ 50,000$ $\$ 74,999,4=\$ 75,000-\$ 99,999,5=\$ 100,000$ or above $)$. Race was coded as 0 or $1(0=$ White, $1=$ Black $)$. Ethnicity was coded as 0 or $1(0=$ non-Hispanic, $1=$ Hispanic $)$. U.S. origin was coded as 0 or $1(0=$ nonU.S. origin, $1=$ U.S. origin). Preparatory course was coded as 0 or $1(0=$ no enrollment in preparatory course, $1=$ enrollment in preparatory course $)$. Education major was coded as 0 or $1(0=$ all majors other than education, 1 = education major). Business major was coded as 0 or $1(0=$ all majors other than business, 1 = business major). Health science major was coded as 0 or $1(0=$ all majors other than health science, $1=$ health science major $)$. Science major was coded as 0 or $1(0=$ all majors other than science, 1 $=$ science major $)$. Math anxiety classification was coded as 0,1 , or $2(0=$ low math anxiety, $1=$ middle math anxiety, 2 = high math anxiety).

\section{Research Questions 3a and 3b}

This section presents the findings related to the third research question: $3 \mathrm{a}$. How are final exam performance and self-reported levels of math anxiety related for bilingual 
students? (b) Is this relationship different from the relationship of final exam performance and self-reported math anxiety levels for monolingual students? First, this section presents the results of correlational analyses of math anxiety and final exam performance scores for bilingual students and of math anxiety and final exam performance scores for monolingual students. Then, the results of these analyses are presented.

Grades on the departmental Intermediate Algebra final exam were gathered from 294 students enrolled in 19 sections of Intermediate Algebra from 10 instructors. The distribution of final exam grades can be seen in Table 27. The performance results mirrored typical results at the college, with $39.2 \%$ of the participants receiving a passing grade of $\mathrm{A}, \mathrm{B}$ or $\mathrm{C}$ ( $70 \%$ or higher) on the final exam and the majority $(60.9 \%)$ receiving failing grades. There were several reasons that grades and final course grades were not available for all participants in Phase 1 of the study. First, some ID numbers that students supplied at the beginning of the semester did not match any of the ID numbers supplied by professors at the end of the semester.

Table 27

Final Exam Grades

\begin{tabular}{lrr}
\hline Final exam grade & Frequency & Percent \\
\hline $90-100$ & 19 & $6.5 \%$ \\
$80-89$ & 52 & $17.7 \%$ \\
$70-79$ & 44 & $15.0 \%$ \\
$60-69$ & 58 & $19.7 \%$ \\
$0-59$ & 121 & $41.2 \%$ \\
\hline
\end{tabular}


This could have occurred for several reasons: the students incorrectly indicated their ID number on the survey sheet, the professors incorrectly entered the ID numbers at the end of the semester, or the students dropped the class within the first week of class (add/drop) week and therefore, professors had no record of those students on the final grade sheet. Some ID numbers supplied by professors at the end of the semester did not match any of the ID numbers indicated on the surveys. This could be due to students who added the course during add/drop week, but after the surveys were distributed. Some students might have been absent/tardy on the day that the survey was administered. Several students did not supply ID numbers at the start of the semester (for whom the researcher assigned ID values of 0001,0002 , etc.). These students would probably match several of the IDs that professors supplied at the end of the semester with grades, had their ID numbers been entered. In regards to the unaccounted Phase I and II data, the researcher used several strategies to reduce the possibility of researcher error. She checked the grade sheets supplied by the professors with the original surveys. Several mistakes were found and corrected (e.g., mistaking a 4 for a 9). Additionally, the researcher honored the requests from six students who did not want to have their grades included in the study.

Figure 7 shows a weak linear pattern for the scatterplot of the AMAS scores and the final exam grades for all the participants. The plot indicates that there is a slight negative relationship between AMAS scores and final exam grade. Since a linear model appeared to fit the data, the researcher continued with correlational analysis. There was a statistically significant negative linear correlation between AMAS scores and final exam 
grades, $r=-.191, p=.001$. This indicated that students with higher AMAS scores earned lower final grades.

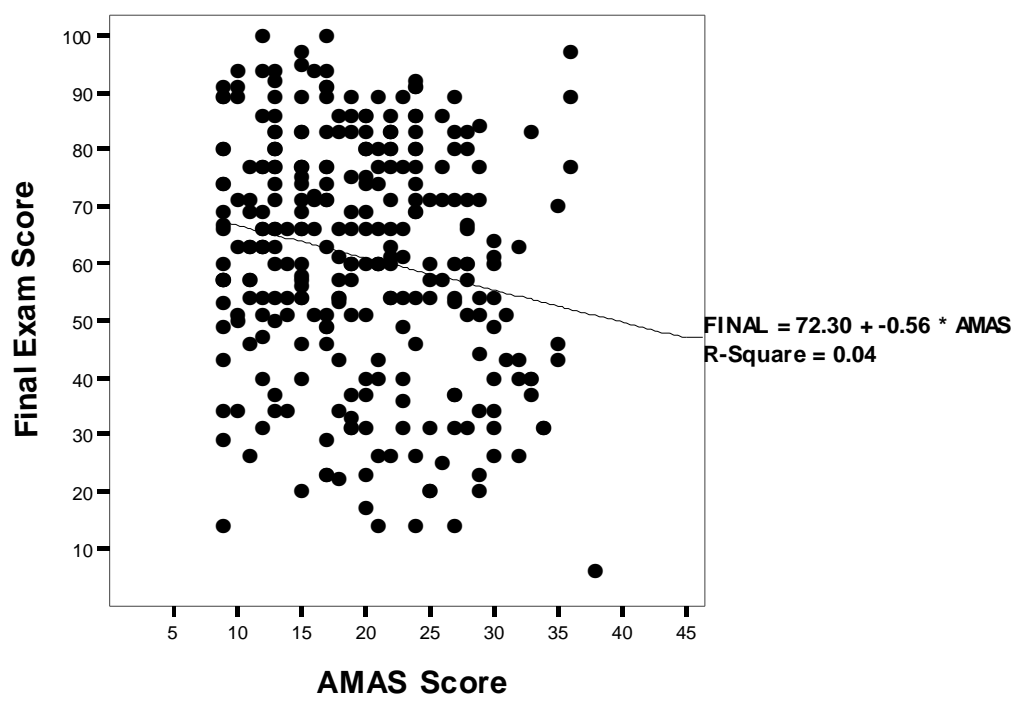

Figure 7. Scatterplot of AMAS scores and final exam scores.

Next, the data were studied taking into account the bilingual or monolingual status of participants. The distribution of final exam grades can be seen in Table 28 . There was no statistically significant difference between the mean final exam scores for the bilingual participants $(M=62.89)$ and for monolingual participants $(M=60.32)$ with $t(303)=-1.069$ and $p=.286$.

The final course grades matched the low passing profile for the college with $41.9 \%$ of bilingual participants earning course grades of $\mathrm{A}, \mathrm{B}$, or $\mathrm{C}$ (70 or above) on the final exam and $58.1 \%$ earning grades of D or F. The monolingual students performed similarly with $38.3 \%$ earning course grades of $\mathrm{A}$, B, or C, on the final exam and $61.7 \%$ earning grades of D or F. Table 28 describes the distribution of final exam grades. 
Table 28

Final Exam Grades by Bilingual Status

\begin{tabular}{|c|c|c|c|c|}
\hline \multirow[b]{2}{*}{ Final exam grade } & \multicolumn{2}{|c|}{ Frequency } & \multicolumn{2}{|c|}{ Percent } \\
\hline & Bilingual & Monolingual & Bilingual & Monolingual \\
\hline $90-100$ & 9 & 9 & $7.7 \%$ & $5.2 \%$ \\
\hline $80-89$ & 26 & 30 & $22.2 \%$ & $17.4 \%$ \\
\hline $70-79$ & 14 & 27 & $12.0 \%$ & $15.7 \%$ \\
\hline $60-69$ & 28 & 28 & $23.9 \%$ & $16.3 \%$ \\
\hline $0-59$ & 40 & 78 & $34.2 \%$ & $45.3 \%$ \\
\hline Total $^{\mathrm{a}}$ & 117 & 172 & $100 \%$ & $99.9 \%$ \\
\hline
\end{tabular}

Figure 8 displays a scatterplot of the AMAS scores and the final exam grades for the monolingual participants (indicated by no) and bilingual participants (indicated by yes). The plot indicates a slight negative relationship between exam and AMAS scores.
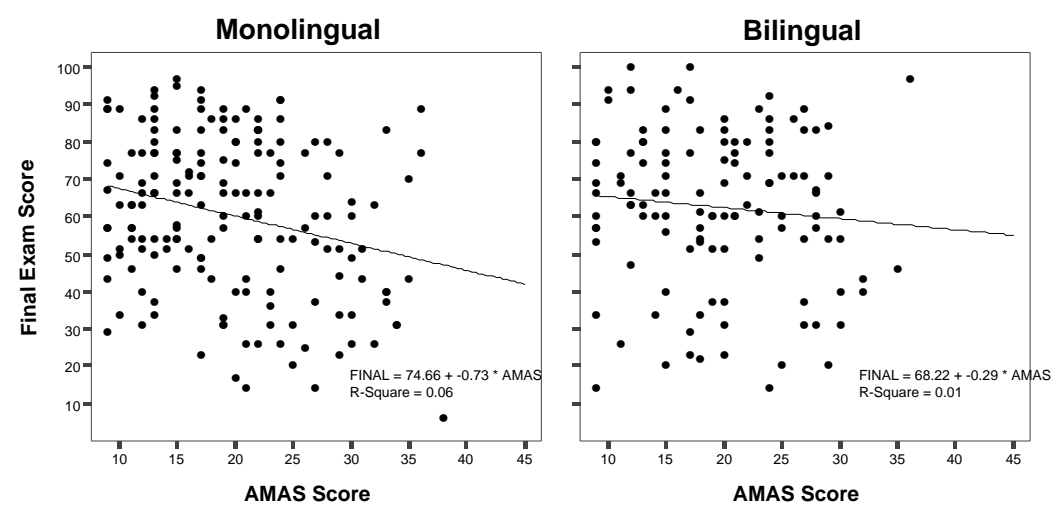

Figure 8. Scatterplots of AMAS scores and final exam scores for monolingual and bilingual participants. 
Since a linear model appeared to fit the data for bilingual participants, the researcher continued with correlational analysis. There was no statistically significant linear correlation between AMAS scores and final exam scores for bilingual participants, $r=-.096, p=.147$. This addressed the first part of the third research question. The final exam scores were not related to the AMAS scores for bilingual students.

Next, the researcher studied the results for monolingual students in a similar fashion with the hopes of addressing a comparison with the results for bilingual students. Figure 8 shows a scatterplot of the AMAS scores and the final exam grades for the monolingual participants. The plot indicates a negative relationship between AMAS scores and final exam grade for monolingual students. Since a linear model appeared to fit the data, the researcher continued with a correlational analysis. There was a statistically significant linear correlation between AMAS scores and final exam grades for monolingual participants, $r=-.253, p<.0009$. There was a statistically significant relationship between final exam scores and reported levels of math anxiety for monolingual students. There was no statistically significant relationship between final exam scores and reported levels of math anxiety for bilingual students.

Next, the researcher studied whether the relationships between AMAS scores and final exam scores was different for bilingual students compared to monolingual students. There was no statistically significant difference in strength the linear relationship of the AMAS scores and the final exam scores between the bilingual participants and monolingual participants, $z=1.35, p=.1756$.

Finally, the researcher studied those predictor variables that were statistically significantly predictors of math anxiety classification to see if those same variables were 
related to final exam performance. There was a statistically significant difference in the mean final exam scores between those who took a math preparatory course $(M=55.5)$ and those who did not take a math preparatory course $(M=64.41)$, with $t(300)=3.61$ and $p<.0009$. There was no statistically significant difference in the mean final exam scores between women $(M=60.8)$ and men $(M=62.3)$, with $t(303)=-.604$ and $p=.546$. There was not a statistically significant difference in the mean final exam scores between education majors $(M=53.25)$ and non-education majors $(M=61.76)$, with $t(297)=1.78$ and $p=.076$. However, there were only 20 education majors in the sample. Since the data produced a $p$-value that was close to $5 \%$, perhaps further study with a greater proportion of education majors would yield significant results at the $5 \%$ significance level.

Since preparatory course was the only variable found to be both a statistically significant predictor of math anxiety classification for bilingual students and a predictor variable that resulted in statistically different final exam scores, a regression analysis was conducted to determine the strength of a relationship between anxiety classification of low, middle, or high, preparatory course enrollment, and final exam scores. Anxiety classification and preparatory enrollment, predicted $6 \%(R=.245, n=120)$ of the final exam scores for bilingual participants. The model with these predictor variables formed a statistically significant relationship with final exam score, $F(2,117)=3.72, p=.027$. However, only preparatory course enrollment was a statistically significant variable in the model with $\beta=-.183$ and $p=.043$. Anxiety classification was not statistically significant at the $5 \%$ level, $\beta=-.165, p=.069$. These results indicate that further study on the relationships between math anxiety, preparatory course enrollment, and final exam performance for bilingual students is recommended. 


\section{Research Questions 4a and 4b}

This section presents findings related to the fourth research question: $4 a$. How are course performance and self-reported levels of math anxiety related for bilingual students? (b) Is this relationship different from the relationship of course performance and self-reported math anxiety levels for monolingual students? First, this section presents descriptive statistics on course performance and the results of correlational analyses of math anxiety and course performance for bilingual and monolingual students. Then, the results of these analyses are compared.

Course performance measures were gathered from 449 students enrolled in 19 sections of Intermediate Algebra from 10 instructors. The distribution of course grades can be seen in Table 29.

Table 29

\section{Course Grades}

\begin{tabular}{lll}
\hline Course grades & Frequency & Percent
\end{tabular}

\begin{tabular}{lcc}
\hline A & 55 & $12.2 \%$ \\
B & 56 & $12.5 \%$ \\
C & 67 & $14.9 \%$ \\
D & 53 & $11.8 \%$ \\
F & 95 & $21.2 \%$ \\
W or WF & 115 & $25.6 \%$ \\
X & 8 & $1.8 \%$ \\
Total & 449 & $100.1 \%$ \\
\hline
\end{tabular}

Note: Students who did not want their grade recorded or who did not complete the AMAS were not included.

It should be noted that course grades matched the profile for the college with $39.6 \%$ earning course grades of $\mathrm{A}, \mathrm{B}$, or $\mathrm{C}, 33 \%$ earning grades of $\mathrm{D}$ or $\mathrm{F}$, and $25 \%$ 
withdrawing from the course. Course grades were coded with $\mathrm{A}=5, \mathrm{~B}=4, \mathrm{C}=3, \mathrm{D}=2$, $\mathrm{F}=1$ and $\mathrm{W}$ or $\mathrm{WF}=0$. Audits were excluded from the calculations that follow since these students were not receiving course credit. Table 30 describes the summary statistics for the course grades.

Table 30

Course Grade Summary Statistics for All, Bilingual, and Monolingual Participants

\begin{tabular}{lccc}
\hline Statistic & All & Bilingual & Monolingual \\
\hline Frequency & 441 & 181 & 260 \\
Mean & 2.04 & 2.08 & 2.02 \\
Standard deviation & 1.75 & 1.80 & 1.71 \\
\hline Note: Course grade was coded as $0,1,2,3,4$, or $5(0=\mathrm{W}$ or $\mathrm{WF}, 1=\mathrm{F}, 2=\mathrm{D}, 3=\mathrm{C}, 4=\mathrm{B}, 5=\mathrm{A})$.
\end{tabular}

Figure 9 depicts a scatterplot of the AMAS scores and the course grades for all the participants. The plot implied that there was indeed a negative relationship between AMAS scores and course grade.

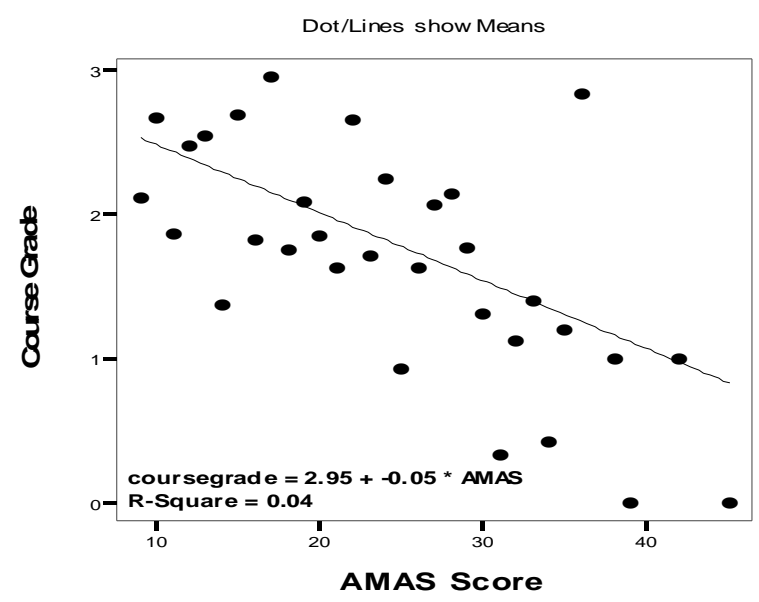

Note: Each dot represents the mean course grade value for each AMAS score.

Figure 9. Scatterplot of AMAS scores and mean course grades. 
Since a negative linear association appeared to describe the data, the researcher continued with correlational analysis. There was a statistically significant negative linear correlation between AMAS scores and course grades for the 441 participants, $r=-.192, p$ $<.0009$. This means that students with high math anxiety tended to earn low course grades.

Next, the data were studied taking into account the bilingual or monolingual status of participants. The distribution of course grades according to bilingual status can be seen in Table 31 .

Table 31

Course Grades by Bilingual and Monolingual Status

\begin{tabular}{lccccc}
\hline & \multicolumn{2}{c}{ Frequency } & & \multicolumn{2}{c}{ Percent } \\
\cline { 2 - 3 } \cline { 5 - 6 } Course grade & Bilingual & Monolingual & & Bilingual & Monolingual \\
\hline A & 25 & 30 & & $13.8 \%$ & $11.5 \%$ \\
B & 26 & 30 & & $14.4 \%$ & $11.5 \%$ \\
C & 22 & 45 & & $12.2 \%$ & $17.3 \%$ \\
D & 23 & 30 & & $12.7 \%$ & $11.5 \%$ \\
F & 36 & 59 & & $19.9 \%$ & $22.7 \%$ \\
W or WF & 49 & 66 & & $27.1 \%$ & $25.4 \%$ \\
Total & 181 & 260 & $100.1 \%$ & $99.9 \%$
\end{tabular}

Note: Students who did not want their grade recorded or who did not supply their ID numbers were recorded as no grade.

Figure 10 shows a scatterplot of the AMAS scores and the course grades for the bilingual participants (indicated by yes) and monolingual participants (indicated by no). The plot implied that there was indeed a minimal negative relationship between AMAS 
scores and course grade for bilingual students. Since a linear model appeared to fit the data, the researcher continued with a correlational analysis. There was a statistically significant negative linear correlation between AMAS scores and course grades for the 181 bilingual participants, $r=-.178, p=.017$. That is, as AMAS scores increased (indicating higher anxiety), final course grades decreased. This addresses the first part of the fourth research question; that is, course grades were related to the AMAS scores for bilingual students.

Next, the researcher studied the results for monolingual students in a similar fashion with the hopes of addressing a comparison with the results for bilingual students. Figure 10 also shows a scatterplot of the AMAS scores and the course grades for the monolingual participants.

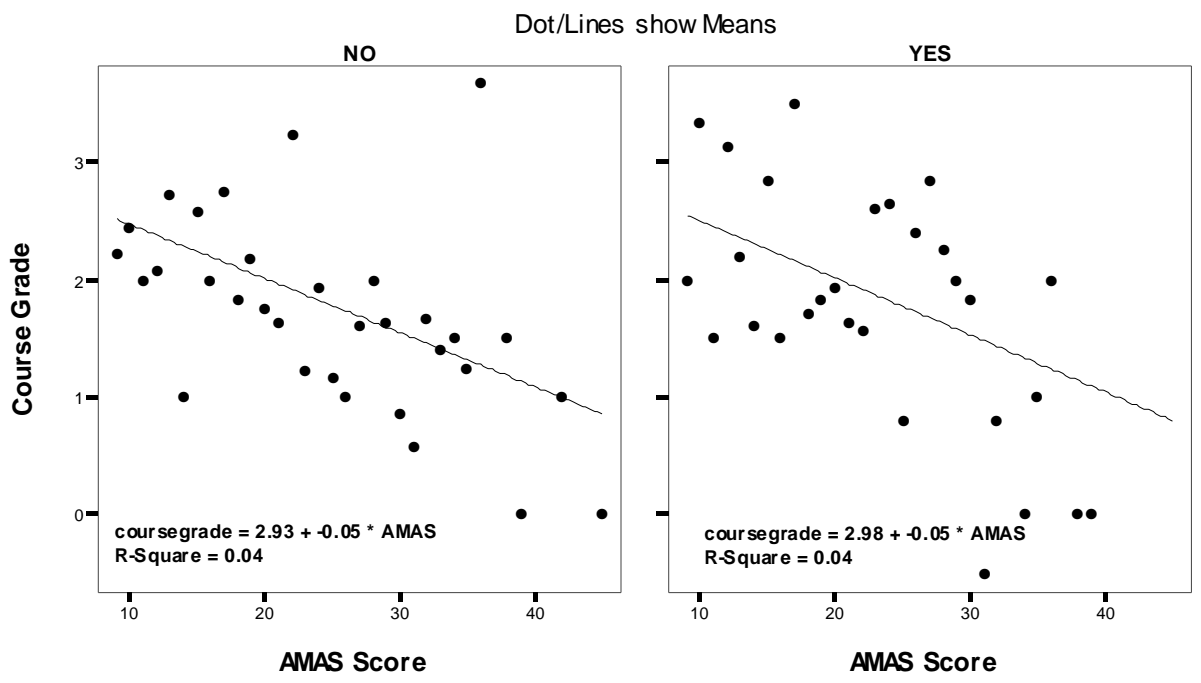

Note: "No" = monolingual participants; "Yes" = bilingual participants.

Figure 10. Scatterplots of AMAS scores and mean course grades for monolingual and bilingual participants. 
The plot implies that there was a negative relationship between AMAS scores and course grades for monolingual students. Since a linear model appeared to fit the data, the researcher continued with correlational analysis. There was a significant linear correlation between AMAS scores and course grades for the 260 monolingual participants, $r=-.203, p=.001$. In other words, the higher the AMAS score (indicating higher anxiety), the lower the course grades. This relationship appeared to mirror the results of the bilingual participants.

Next, the researcher studied whether the relationships between AMAS scores and course scores were different for bilingual students compared to monolingual students. After converting the two $r$ correlations using a Fisher's $r$ to $Z$ transformation, the researcher tested whether the correlation coefficient for the bilingual students was significantly different from the correlation coefficient for the monolingual students. There was no statistically significant difference in strength the linear relationship of the AMAS scores and the course scores between the bilingual participants and monolingual participants, $z=-.2660, p=.79$.

Finally, the researcher studied those predictor variables that were statistically significant predictors of math anxiety classification to see if those same variables were related to course performance in a statistically significant manner. There was a statistically significant difference in the mean course grades between those who took a math preparatory course $(M=1.68)$ and those who did not take a math preparatory course $(M=2.18)$, with $t(440)=2.947$ and $p=.003$. There was not a statistically significant difference in the mean course grades between women $(M=2.00)$ and men $(M=1.98)$, with $t(447)=.912$ and $p=.546$. There was no statistically significant difference in the 
mean course grades between education majors $(M=2.00)$ and non-education majors $(M$ $=1.94)$, with $t(436)=.188$ and $p=.851$.

Since preparatory course was the only variable that was found as a significant predictor of math anxiety classification for bilingual students and the only predictor variable that resulted in statistically different course grades, a regression analysis was conducted to determine the strength of a relationship between anxiety classification of low/middle/high, preparatory course enrollment, and course grades. This analysis was not conducted for monolingual participants since preparatory enrollment was not a significant predictor variable for math anxiety classification for this group. Anxiety classification and preparatory enrollment predicted $10.7 \%$ of the variance of course grades for bilingual participants. The model with these predictor variables formed a significant relationship with course grade for the bilingual students, $F(2,172)=4.45, p<.0009$. However, only anxiety classification was a statistically significant variable in the model with $\beta=-.288$ and $p<.0009$. Preparatory enrollment was not a statistically significant predictor, $\beta=-$ $.116, p=.116$. These results provide additional evidence of the negative relationship between math anxiety and course performance for bilingual students which is similar to the relationship for monolingual

\section{Summary}

This chapter presented the results from the statistical analysis of the data that related to the four research questions posed. Overall, the findings indicated that (a) AMAS measured the same factors of math anxiety for bilingual students and monolingual students (i.e., assessment and learning content), (b) bilingual students and monolingual students reported similar levels of math anxiety, (c) bilingual and monolingual students 
exhibited similar relationships between math anxiety and the independent variables, (d) prior preparatory course enrollment, education major, and business major predicted the low/middle/high math anxiety classification of bilingual students, (e) gender predicted the low/middle/high math anxiety classification of monolingual students, (f) math anxiety scores were not statistically significantly related to the final exam performance of bilingual students but were significantly related for monolingual students, and (g) math anxiety scores were significantly related to the course performance for bilingual students and for monolingual students. Discussion of these results follows in chapter 5. 


\section{CHAPTER V \\ DISCUSSION}

This chapter includes a discussion of the findings of the study. The chapter begins with a summary and overview of the significant findings. Then, the findings are evaluated in light of the current literature. Next, this chapter describes limitations that may affect validity and generalizability, followed by recommendations for practice and further research.

Summary of the Study and Overview of Significant Findings

This study derived its foundation from the prior research of mathematics anxiety, postsecondary math students, and performance. This study compared the reported math anxiety levels and performance outcomes for bilingual and monolingual community college students enrolled in an Intermediate Algebra course on one campus of a culturally diverse urban commuter college during the fall semester of 2008. The participants were enrolled in 19 sections of the course from 10 instructors.

There were four sources of data for this study: a demographic questionnaire, the Abbreviated Math Anxiety Scale (AMAS) by Hopko et al. (2003), final exam grade, and course grade. Participants ( $N=618,250$ men, 368 women; 361 monolingual, 257 bilingual) completed the AMAS and a demographic instrument during the first week of the semester. Final exam grades were provided by the instructors at the end of the semester for 294 (117 bilingual and 172 monolingual) of the 618 participants and course grades were provided by the instructors at the end of the semester for 449 (181 bilingual and 260 monolingual) of the 618 participants. 
The data from 257 bilingual and 361 monolingual participants were analyzed for the first phase of this study. There were 184 participants (29.8\%) who declared that they spoke Spanish fluently and 213 students (34.5\%) who declared themselves of Hispanic ethnicity, 362 students (58.6\%) were non-Hispanic. Of the 472 survey participants who responded, 299 (63.3\%) identified their race as White and 134 (28.4\%) identified their race as Black or African American. The majority of the students who participated in this study were of traditional college age with over $87 \%$ of the participants aged 23 or younger. The income levels of participants varied with $24.6 \%$ earning below $\$ 25,000$, $28.6 \%$ between $\$ 25,000$ and $\$ 49,999,25.5 \%$ between $\$ 50,000$ and $\$ 74,999,11.4 \%$ between $\$ 75,000$ and $\$ 99,999$, and $9.9 \%$ with household incomes $\$ 100,000$ or more. Of the 610 who responded, 265 or $42.9 \%$ had taken the preparatory course in elementary algebra at a state college. Of the 603 who described their major, $7.3 \%$ declared themselves as education majors, $18.4 \%$ as business majors, $16.9 \%$ as health science majors, and $11.9 \%$ as science majors.

Four research questions were addressed. The research questions were addressed using factor analysis, $t$ tests, $z$ tests, ANOVA, and regression analysis.

1. Are bilingual and monolingual students different in their self-reported levels of math anxiety?

2a. What are the variables that predict math anxiety levels?

2b. Are the predictor variables for math anxiety levels different for bilingual students compared to monolingual students?

3a. How are final exam performance and self-reported levels of math anxiety related for bilingual students? 
3b. Is this relationship different from the relationship of final exam performance and self-reported math anxiety levels for monolingual students?

4a. How are course performance and self-reported levels of math anxiety related for bilingual students?

4b. Is this relationship different from the relationship of course performance and self-reported math anxiety levels for monolingual students?

For the first research question, factor analysis (principal component analysis using varimax rotation of the scores on the AMAS) yielded similar two-factor structures for both bilingual and monolingual populations: assessment and learning content. Bilingual and monolingual students showed comparable mean AMAS scores and comparable proportions of participants who declared themselves as math anxious individuals. The mean AMAS score for the bilingual group of 20.6 was comparable to the mean AMAS score for the monolingual group of $20.7, t(596)=.051, p=.96$. There was no statistically significant difference, $z=-0.52, p=.605$, in the proportion of bilingual participants who declared themselves as math anxious individuals (125 out of 250 or $50 \%$ ) and the proportion of monolingual participants who declared themselves as math anxious individuals (168 out of 351 or $48 \%$ ).

For research questions $2 \mathrm{a}$ and $2 \mathrm{~b}$, the 11 independent variables of gender, age, income, race (Black, White), ethnicity (Hispanic, non-Hispanic), U.S. origin, preparatory course enrollment, and major (education, business, health science, and science) were used to discriminate between low, middle, and high levels of math anxiety. Two statistically significant predictor variables for the bilingual participants were the preparatory course variable $(\beta=.236, p=.041)$ with those enrolled in prior preparatory courses scoring 
higher, the education major variable $(\beta=.285, p=.018)$ with education majors scoring higher, and the business major variable $(\beta=.252, p=.032)$ with business majors scoring higher. The model for the monolingual participants included one statistically significant predictor variable, gender with $\beta=-.085$ and $p=.001$ such that females ranked higher in math anxiety classification.

To address the third research question, the relationships between reported math anxiety levels and final exam scores $(N=294)$ for bilingual and monolingual students were analyzed. No statistically significant linear correlation between AMAS scores and final exam grades $(r=-.096, p=.147)$ emerged for bilingual participants. For monolingual participants, there was a statistically significant negative linear correlation between AMAS scores and final exam scores $(r=-.253, p<.0009)$.

The fourth research question addressed relationships between reported math anxiety levels and course grade $(N=449)$ for bilingual and monolingual students. There was a statistically significant negative linear correlation between AMAS scores and course grades for the bilingual participants $(r=-.178, p=.017)$ and for monolingual participants $(r=-.203, p=.001)$. In other words, for both bilingual and monolingual participants, the higher the math anxiety scores, the lower the course grades.

\section{Evaluation of Findings}

The researcher evaluated the findings in light of recent research. First, the findings related to reported levels of math anxiety are evaluated. Second, the findings related to demographic variables and math anxiety are evaluated. Third, the findings related to math anxiety and performance are evaluated. 


\section{Reported Levels of Math Anxiety}

Fifty percent of bilingual and $48 \%$ of monolingual participants reported they were math anxious individuals. Only $21 \%$ of bilingual participants said that they do not experience math anxiety with $63 \%$ of bilingual participants experiencing it sometimes or frequently. About $86 \%$ of monolingual participants claimed that they experience math anxiety with some level of frequency, with $63 \%$ of monolingual participants claiming that they experience it sometimes or frequently. Furthermore, $76.4 \%$ of the bilingual participants experienced math anxiety with some level of intensity and $83.1 \%$ of the monolingual participants experienced math anxiety with some level of intensity. These findings support the findings of high proportions of math anxious individuals of Jackson and Leffingwell (1999), who found that 93\% of college students experienced math anxiety, and Perry (2004) who found that $85 \%$ of the participants claimed to experience math anxiety.

The descriptive statistics for the monolingual and bilingual groups were comparable. There were no statistically significant differences in the proportions of selfdeclared math anxious bilingual students $(50 \%)$ and monolingual students $(48 \%), z=-$ $0.52, p=.605$. The mean AMAS score for the 242 bilingual participants was 20.6 with a standard deviation of 7.5. The mean AMAS score for the monolingual group was 20.7 with a standard deviation of 7.7. The findings from the current study indicated that the mean reported math anxiety scores were the same for bilingual and monolingual populations $t(596)=.051, p=.96$, helping to fill a void in the literature about the math anxiety of bilingual college students. Moreover, the factor structures of the two factors on AMAS (assessment and learning content) were similar for both groups. Furthermore, the 
factor structure in this study was similar to that found by Hopko et al. (2003). These results indicate that the AMAS can be utilized to study the math anxiety levels for bilingual students as well as for monolingual students in future studies.

Based on the finding of no significant difference between the means of the two groups, this study supports that the mean reported math anxiety scores are the same for bilingual and monolingual populations. Moreover, the findings for bilingual college students compared favorably with normative data cited by Hopko et al. (2003) who found that the mean score was 21.1 with a standard deviation of 7.0 for 1,239 undergraduate students. There was no statistically significant difference in the mean AMAS scores between that of the bilingual students in the current study and the mean AMAS scores reported by Hopko et al., $t(1479)=1.00, p=.315$. This is an important finding because Hopko et al. did not specify whether or not their undergraduate students were bilingual or monolingual.

The Relationship between Demographic Variables and Math Anxiety

Demographic variables identified in the literature review were analyzed to discover relationships with the population of this study. Those variables included income, gender, ethnicity (Hispanic, non-Hispanic), race (Black, White), preparatory coursework, age, U.S. origin, major (science, education, business, or health sciences).

Gender. In the current study, there was a statistically significant difference in the mean scores between men and women with $t(596)=2.50, p=.013$. These findings agreed with the results of several studies (Hembree, 1990; Llabre \& Suarez, 1985; Miller \& Bichsel, 2004; Woodward, 2004; and Zettle \& Raines, 2000). However, gender was not a significant predictor variable for math anxiety classification for the bilingual students in 
this study. Miller and Bichsel (2004) emphasized that, even though women reported higher levels of math anxiety compared to men, there were no significant differences in performance measures. In the current study, there also was no statistically significant difference in the mean final exam scores between women $(M=60.8)$ and men $(M=$ 62.3), with $t(303)=-.604$ and $p=.546$ and in the difference in the mean course grades between women $(M=2.00)$ and men $(M=1.98)$, with $t(447)=.912$ and $p=.546$. So, even though women may have reported higher levels of math anxiety than men, it did not necessarily affect their performance. This could be explained by men's discomfort in reporting their anxiety. In fact, Zettle and Houghton (1998) cautioned against using MARS for screening the presence of math anxiety among men. This caution may be valid for AMAS as well, but the present study provided evidence that gender may not be as influential for differing math anxiety levels among bilingual students.

Age. The majority of the students that participated in this study were of traditional college age with over $87 \%$ of the participants aged 23 or younger; therefore, the results according to age must be interpreted with the caution that few participants were in the three older-age categories. Overall, there were no significant findings related to math anxiety and age. Similarly, Woodward (2004) found no significant difference in the math anxiety scores of students categorized as traditional-aged $(<25)$ and nontraditional-aged ( $\geq 25$ ). However, there was the unexpected finding in the current study of a statistically significant difference, $t(23)=-2.202, p=.03798$, in the mean AMAS score for bilingual and monolingual participants in the 30 - 39 age bracket, such that the monolingual group had higher AMAS scores (indicating higher math anxiety). 
Income. Overall, there were no statistically significant differences related to math anxiety and the variable income in the current study. The researcher found no studies related to income in the literature search to corroborate with these results. The findings help fill a void in the literature on the association between income level and math anxiety.

Race. The literature on the relationship between race and math anxiety is sparse. Hembree (1990) found no difference appeared between the math anxiety of White and Black students. In the current study, no statistically significant difference emerged in the mean scores between Black $(M=20.1, n=128)$ and non-Black $(M=20.5, n=330)$ participants, $t(456)=.599, p=.549$. Further, no statistically significant difference emerged in the mean AMAS scores between White $(M=20.8, n=295)$ and non-White $(M=19.6$, $n=163$ ) participants, $t(456)=-1.63, p=.103$. In addition, race (Black vs. White; $\beta=-$ $.028, p=.827$ ) did not emerge as significant predictor variables for low/middle/high math anxiety classification for bilingual students. The findings from the present study are corroborated by Ma (1999) who found that researchers who study participants of varied racial/ethnic backgrounds tended to find a relationship similar to that found by researchers who study participants with homogeneous racial/ethnic backgrounds.

Ethnicity. There was no statistically significant difference between AMAS scores and ethnicity (Hispanic vs. non-Hispanic), $t(556)=-.933, p=.351$. Furthermore, ethnicity did not emerge as a statistically significant predictor of low, middle, or high math anxiety classification $(\beta=-.099, p=.424)$. This contrasts with Hembree's (1990) finding that the Hispanic group in that study seemed more anxious than the other ethnic groups. Although Ferguson (1986) included a large Hispanic group in his study on the factors of math anxiety and Llabre and Suarez (1985) had a 41\% Hispanic composition, neither study 
tested ethnicity as a variable. The findings from current study join the short list of studies that discuss the relationship between ethnicity and math anxiety.

U.S. origin. There was no statistically significant difference between the mean AMAS scores of participants of U.S. origin and non-U.S. origin, $t(604)=.537, p=.591$. Furthermore, U.S. origin did not emerge as a statistically significant predictor of math anxiety classification $(\beta=-.073, p=.519)$. There were no prior studies that were found that included U.S. origin as a variable in the study of math anxiety.

Preparatory course. The variable of prior preparatory course enrollment and its relationship to subsequent math anxiety not been reported in the literature although there were several studies that included preparatory students (Eppler et al., 2003; Green, 1990; Mohr \& Taylor, 2001).The findings of the current study imply that further study of this variable could prove informative. In the current study, there was a statistically significant difference in the mean AMAS scores between those participants who had taken the preparatory course and those who had not, $t(586)=-2.99, p=.003$ with the preparatory enrollees scoring higher as in Hembree (1990). Furthermore, preparatory course enrollment was a significant predictor variable for low, middle, or high math anxiety classification for the bilingual participants, $\beta=.236, p=.041$. Moreover, there was a statistically significant difference in the mean final exam scores between those who took a math preparatory course $(M=55.5)$ and those who did not take a math preparatory course $(M=64.41)$, with $t(300)=3.61$ and $p<.0009$. Anxiety classification and preparatory enrollment predicted $6 \%(R=.245)$ of the final exam scores for bilingual participants. 
The model with these predictor variables formed a statistically significant relationship with final exam score, $F(2,37)=4.45, p=.019$. However, only preparatory course enrollment emerged as a statistically significant variable in the model with $\beta=$ .346 and $p=.025$. Anxiety classification was not significant at the $5 \%$ level, $\beta=-.267$, $p=.079$, although it would be significant at the $10 \%$ level. There was a statistically significant difference in the mean course grades between those who took a math preparatory course $(M=1.68)$ and those who did not take a math preparatory course $(M=$ 2.18 , with $t(440)=2.947$ and $p=.003$. Anxiety classification and preparatory enrollment predicted $10.7 \%$ of the variance of course grades for bilingual participants. The model with these predictor variables formed a significant relationship with course grade, $F(2,172)=4.45, p<.0009$. However, only math anxiety classification was a statistically significant variable in the model with $\beta=-.288$ and $p<.0009$. Preparatory enrollment did not emerge as a statistically significant predictor, $\beta=-.116, p=.116$. These findings demonstrate the possible association that preparatory course enrollment may have with subsequent math anxiety and with subsequent math performance.

Education major. There was a statistically significant difference in the mean AMAS scores of education and non-education majors with $t(581)=-3.68, p<0.0009$. Education majors had higher math anxiety scores than non-education majors. The findings of the current study resonated with Hembree (1990) who found that preservice education majors reported the highest average math anxiety score on MARS as compared to other college majors.

Many studies had been conducted with education majors with samples consisting of high proportions of women (i.e., Bursal \& Paznokas, 2006; Harper \& Daane, 1998; 
Jackson \& Leffingwell, 1999; Sloan et al., 2002; Trujillo \& Hadfield, 1999). The results of the current study suggested that caution must be taken in generalizing those results to students in other fields of studies or in programs with differing gender distributions. Even the findings of Hembree's (1990) meta-analysis must be looked at in light of the high proportion of studies that were conducted with pre-service elementary education majors. In this study, education major emerged as a significant predictor of low, middle, or high math anxiety classification in the model for bilingual students $(\beta=.285, p=.018)$. Furthermore, there was no statistically significant difference in the mean final exam scores between education majors $(M=53.25)$ and non-education majors $(M=61.76)$, with $t(297)=1.78$ and $p=.076$. However, there were only 20 education majors in Phase II of the study. Since the data produced a $p$-value that was close to $5 \%$, perhaps further study with a greater proportion of education majors would yield significant results at the $5 \%$ significance level.

Business major. Overall, no statistically significant differences emerged between math anxiety scores and business major in the current study. In this study, business major emerged as a statistically significant predictor of low/middle/high math anxiety classification in the model for bilingual students $(\beta=.252, p=.032)$. Hembree (1990) found that business majors in his study reported a mean anxiety level that was fairly low as compared to other majors. The findings from the current study add to the knowledge base about the business major variable and math anxiety.

Health sciences major. There was no statistically significant difference in the mean AMAS scores of health science and non-health science majors, $t(581)=1.54$, $p=.124$, even though health science majors had a lower mean AMAS score of 19.6 and 
the mean AMAS score for non-health science majors was 20.9. Pozehl (1996) also found no statistically significant differences even though his sample of 56 nursing students reported higher levels of math anxiety than the non-nursing students. The different directions in these studies could be attributed to the high numbers of women in that study and to the fact that the current study included more than nursing majors. The current findings agree more with Hembree (1990) who found a mean math anxiety score of 187.5 on MARS for the nursing majors, which ranked fifth out of seven majors. The current study found that health science major did not emerge as a significant predictor variable in the model for low/middle/high math anxiety classification for the entire sample or for the bilingual participants.

Science major. There was no statistically significant difference in the mean AMAS scores of science and non-science majors with $t(581)=1.08, p=.282$. Furthermore, science major did not emerge as a significant predictor variable of low, middle, or high math anxiety classification. These finding agree with Hackett and Betz (1989) who did not find that the mathematics anxiety variable contributed significantly to the prediction of college major in science or math. The low mean math anxiety scores also agreed with Hembree (1990) who found that math/science majors reported the lowest mean math anxiety levels.

In summary, the study findings indicated (a) a statistically significant difference in the mean AMAS scores between men and women for both bilingual and monolingual students, (b) a statistically significant difference in the mean AMAS scores between participants who completed a math prep course and those participants who did not for both bilingual and monolingual participants, (c) a statistically significant difference in the 
mean AMAS scores of education and non-education majors for both monolingual and bilingual participants, (d) education major as a significant predictor variable of low, middle, or high math anxiety classification for bilingual participants, (e) preparatory course as a significant predictor variable of low/middle/high math anxiety classification for combined monolingual and bilingual participants, (f) gender as a significant predictor variable of low/middle/high math anxiety classification for combined monolingual and bilingual participants, (g) preparatory course, education, business variables as the statistically significant predictor variables for the bilingual participants, but not for monolingual participants, and (h) gender as a significant predictor variable for monolingual participants, but not for bilingual participants.

\section{The Relationship between Math Anxiety and Performance}

The statistically significant negative linear correlation between AMAS scores and final exam grades for all participants, $r=-.191$, and for monolingual students, $r=-.253$, agreed with the findings from Ma's (1999) meta-analysis which yielded a negative relationship between anxiety toward mathematics and achievement $(r=-.27)$. The current study findings also agreed with the meta-analysis of 58 studies with postsecondary students by Hembree (1990) which found a statistically significant mean correlation of $r=-.31, p<.01$ between math anxiety and math achievement measures. Clute (1984) found that students with a high level of mathematics anxiety had significantly lower achievement; Hackett and Betz (1989) found that those individuals who reported lower levels of math anxiety had higher scores on mathematics performance. Therefore, it would appear that those individuals with higher math anxiety experienced lower levels of math achievement. Even though the present study found a weak negative linear 
relationship between AMAS scores and final exam grades for bilingual participants, the relationship was not statistically significant, $r=-.096, p=.147$.

There was a statistically significant negative linear correlation between AMAS scores and course grades for the 181 bilingual participants, $r=-.178, p=.017$. As AMAS scores increased (indicating higher anxiety), final grades decreased; that is, course grades were related to the AMAS scores for bilingual students. There was a similar statistically significant negative linear correlation between AMAS scores and course grades for the 260 monolingual participants, $r=-.203, p=.001$. However, there was no statistically significant difference in the strength of the linear relationship of the AMAS scores and the course scores between the bilingual participants and monolingual participants, $z=-.2660, p=.79$

The findings for the bilingual students in the current study agreed with Eppler et al. (2003) who conducted a study on remedial math college students and found a statistically significant negative linear relationship between anxiety and the final course grade $(r=-.353)$. Even though the findings for the current study differed in statistical significance with Hembree's (1990) study which found no statistically significant mean correlation $(r=-.27, p>.01)$ between math anxiety and course performance in the 17 studies of postsecondary students, the present study showed a similar negative relationship. Perhaps in the years ahead with an increased focus on the bilingual population, a meta-analysis of math anxiety studies with bilingual students may produce a different, possibly lower, correlation between math anxiety and performance. 


\section{Limitations}

Many of the participants' ID numbers as reported on the completed AMAS surveys did not match the ID numbers supplied by the instructors. In future research, the researcher recommends obtaining data after add/drop week. There could be a unique pattern to the data of individuals who registered for a course during add/drop week or to those who drop within that first week. Moreover, the possible influence of newly acquired knowledge or exposure to pedagogy of the instructors may influence AMAS scores, thus requiring data collection early in the semester.

The AMAS scale itself may have imposed limits to the responses of participants. Several participants included responses of zero to items on the AMAS. In accordance with guidelines for administering and interpreting AMAS, the researcher did not include those responses as valid AMAS scores. However, the researcher believed that participants were trying to indicate that they did not experience math anxiety in the situations suggested on various items on the AMAS. However, the AMAS scale includes a rating of 1 for "low anxiety" as the least possible rating for math anxiety. The instrument prevented the participants from describing their math anxiety in a manner more representative of their true experience.

The demographics question on country of origin resulted in confusing answers on the demographics instrument where some participants indicated several countries. The researcher surmised that they may have listed countries that represented their family genealogy rather than their country of birth, which was the intent of the researcher. This interpretation by the participants may have limited the data for country of origin. 
The researcher asked participating instructors to distinguish between withdrawals that took place, W or WF. However, many of the participating instructors did not provide this information. Mathematics anxiety can trigger the "fight or flight" response; thus information as to when students fled might have provided some additional insights. A large percentage of bilingual students in this study were Spanish speakers (71.6\%). The study findings may be generalizable only to similar populations.

\section{Recommendations}

The limitations must be taken into consideration when making recommendations based on the findings. The researcher believes that the findings have the potential to add value to those who teach mathematics to both bilingual and monolingual college students as well as those who are interested in furthering the research in this field. In this section, the researcher offers recommendations for practice and for research.

\section{Recommendations for Practice}

This section discusses recommendations for college mathematics instructors, administrators, students, textbook authors, and others with an interest in mathematics education. Since the findings showed that bilingual students and monolingual students reported similar levels of math anxiety and showed similar relationships between math anxiety and performance (final exam grade and course grade), instructors may begin by addressing students from both groups similarly. Furthermore, the results from the factor analysis suggest that instructors and student services personnel can utilize the AMAS for identifying math anxious bilingual and monolingual students. Instructors may want to implement techniques that have been found to reduce the math anxiety of monolingual students in an effort to minimize the math anxiety of bilingual students. Instructors may 
want to convene math anxiety reduction sessions or courses or facilitate math anxiety support groups as has been practiced at various institutions (American River College, 2008; Butte, 2008; Carroll, 2009). Instructors may want to include ethnomathematical material to help reduce anxiety as suggested by the results of McGregor, MacMillan, and Old (2005). Instructors may also become motivated to study the effectiveness of further intervention strategies for bilingual students in their classes.

The findings for math students who had previously enrolled in preparatory courses may have the greatest implications for practice. Although not the focus of this study, the finding that there was a statistically significant difference in the mean course grades between those who took a math preparatory course and those who did not take a math preparatory course suggests that college faculty and support services personnel must pay close attention to these students and offer support to ensure their success. College instructors can be encouraged to identify students with high math anxiety (using AMAS) and offer additional support services for both monolingual and bilingual students as they complete their math preparatory programs. Given the ratings on the AMAS related to learning content, and the relationship between bilingual status and course performance, mathematics instructors should take into account the cognitive and affective factors to learning during and subsequent to preparatory course enrollment.

Textbook authors and publishers may want to consider the math anxiety that may be triggered by starting a new chapter in the textbook. The findings of the current study indicated that starting a new chapter aroused math anxiety and was tied to the factor of learning content of the AMAS for both monolingual and bilingual participants. Authors may want to carefully consider math anxiety as they construct the material that introduces 
the chapters. Textbooks may represent the only resource on math anxiety for students. The findings of the current study indicated that preparatory course enrollment was a predictor of low/middle/high math anxiety with preparatory students reporting higher math anxiety. This suggests that authors may want to include material on math anxiety in preparatory math course texts, especially as many of these texts incorporate study skills. Focusing on study skills that can lead to reduced math anxiety could be beneficial for both bilingual and monolingual students who use the textbooks.

Students may use the findings from the current study to improve understanding about their own math anxiety. They can reflect on how their own math anxiety fits in with the findings of the study. In light of the finding that only 38 students categorized their math anxiety as severe and 100 were labeled high anxiety, students may want to consider that they may not be self aware about their level of math anxiety and could benefit from completing the AMAS.

Bilingual students who have completed preparatory math courses may be encouraged to assess their own math anxiety and take steps to ameliorate high anxiety scores, as appropriate. The researcher hopes that the results of this study do not contribute to any stereotype threat for bilingual students. Instead, the researcher hopes that the findings may empower students to discover and share their best practices for coping with math anxiety.

\section{Recommendations for Research}

Follow up studies could include qualitative studies and/or mixed methods studies that allow for in depth exploration of the mathematics anxiety of college students. Case study approaches could explore in more depth the phenomenon of math anxiety of 
bilingual students compared to monolingual students. These factors may then be compared with the factors that have been discovered in other studies and with the factors associated with math anxiety of monolingual students.

A similar factor structure emerged for the AMAS scores of bilingual and monolingual students, which indicates an inherent acceptance of the validity of AMAS for the participants in the present study. Future studies can determine whether the factor structures of math anxiety instruments other than AMAS (i.e., MARS, MAS) are also similar for bilingual students and monolingual students. New factor structures may appear in more complex assessment instruments. Reliable and valid assessment instruments for math anxiety are needed to help professors who teach mathematics improve their instruction and pedagogy to meet the needs of math anxious individuals.

Findings related to the similar factor structures indicate that the AMAS instrument measures the same construct for bilingual students and for monolingual students. The findings of the current research match that of previous research. However, the AMAS may be improved if restructured slightly to reflect trends in math education. The first statement in the instrument, "Having to use the tables in the back of a math book," may be outdated as many textbooks have eliminated tables. Replacement options could include statements, such as "interpreting tables," "interpreting graphs," or "having to use a calculator." New math anxiety instruments may need to be adapted to reflect the increasingly diverse forms of math instruction which include emporium models, computer directed instruction, and distance learning.

The researcher recommends similar studies in other countries to isolate whether the country of study influences math anxiety. Furthermore, the findings from other 
countries could then be compared to similar studies conducted in the United States. This could serve to further identify the impact of the bilingual variable.

To better understand the phenomenon of bilingualism and math anxiety, the researcher recommends further studies with more students who are bilingual in languages other than English and Spanish. For instance, a study with a large Creole and English speaking population might yield different results. Comparisons of math anxiety for students with other languages could isolate specific variables that influence math anxiety for these populations. Additionally, future research could study the variable of primary language. Quite possibly, bilingual students who study math in their primary languages might show differences in math anxiety compared to bilingual students who study math in a second language. There could be different manifestations of math anxiety for these nuances of bilingualism. Other predictor variables could be identified in future studies, such as the number of years of math instruction in English, language of greater fluency, the number of years of fluency in each language spoken, time elapsed since last math course, and parental language skills. Inquiry into past experiences with mathematics such as high school experiences could prove to be insightful since math anxiety often develops during this time (Wigfield \& Meece, 1988).

The findings for the relationship of prior preparatory courses and math anxiety for bilingual students need to be replicated. In this study, those students who enrolled in preparatory math courses reported higher levels of math anxiety similar to the results of Hembree (1990) whose findings, however, were not specific to bilingual preparatory students. Overall, further study on preparatory course enrollment, math anxiety, and math performance is warranted for all college students since the findings of the present study 
indicated a difference in both the math anxiety ratings and final exam scores between those students who took a math preparatory course and those students who did not take a math preparatory course. Future studies could include longitudinal studies that explore students' math anxiety throughout enrollment in preparatory math courses and subsequent college level math courses. In particular, future studies could include whether preparatory course enrollment is associated with subsequent reported math anxiety levels and subsequent performance. Follow up studies could attempt to ascertain the direction of the association between math anxiety and performance at the preparatory course level.

It could be beneficial to conduct similar studies with students at various levels of mathematics so as to extend the knowledge about bilingual students' experiences with math anxiety. Just as experiences with math anxiety change throughout the curriculum in grades 6-12 (Hembree, 1990; Wigfield \& Meece, 1988), the experiences with math anxiety may differ as college students continue through the college curriculum. Even though Woodward (2004) included participants from three different levels of math courses, course level was not included as a variable in that study. The relationship between bilingual and monolingual students' math anxiety, demographic variables, and performance could differ depending on the course level. Hembree (1990) suggested that high levels of math anxiety appeared in remedial mathematics and declined with more advanced courses. A study that included students from introductory to more advanced courses could provide a better understanding of the math anxiety of bilingual and monolingual students. Additionally, tracing the changes in students' math anxiety through the college sequence could provide a more comprehensive understanding of math anxiety for both bilingual and monolingual student populations. 
The findings from this study indicated that math anxiety and math performance are related for community college students. Because the factor analysis of AMAS scores revealed that assessment was an important component of math anxiety, future studies may include questioning the relationship between assessment design and math anxiety. Researchers may want to identify the relationship between monolingual and bilingual students' math anxiety with various types of assessment questions (e.g., multiple choice, word problems, or free response).

Studies on the effectiveness of intervention strategies for college students who experience math anxiety could prove beneficial. Although, the findings from the current study do not suggest different intervention strategies are advisable for bilingual students,,current intervention strategies may result in different influences on the math anxiety and performance for bilingual and monolingual college math students. Future studies may determine which intervention strategies best influence the math anxiety and math performance of bilingual students.

As described in the critique of the literature in chapter 2, statistics anxiety is a separate, but related construct. Because relationships between math anxiety and performance were statistically significant in the current study, researchers could explore the relationships between statistics anxiety and performance for community college students. Further studies could compare the statistics anxiety of bilingual students to the statistics anxiety of monolingual students to verify if similar relationships exist for statistics anxiety as for mathematics anxiety.

The findings indicate that math anxiety is associated with performance for both bilingual and monolingual students. In light of recent research on how math anxiety 
affects working memory (Ashcraft \& Kirk, 2001), the researcher recommends comparing how math anxiety affects the working memory of bilingual and monolingual individuals. With bilingual students, there could be translations that interact with the disruptions that math anxiety triggers in working memory. Also, this study suggests looking at the relationship between working memory and math anxiety for those students enrolled in preparatory courses. Further study on how math anxiety affects the brain processes during math problem solving could ultimately suggest strategies for improving performance for all community college students.

\section{Conclusion}

The research on the math anxiety of students with diverse backgrounds is still in its infancy. This study joins the vast expanse of research on math anxiety. However, this study begins the discussion on the math anxiety of bilingual community college students. Further dialogue is warranted on the causes of math anxiety and on intervention strategies for the math anxiety of bilingual students and monolingual college students alike. Math educators dream of the day when their students can confidently and successfully practice mathematics. This dream will only be realized when the entire educational community strives to prevent, recognize, and treat math anxiety for all students. 


\section{REFERENCES}

Akinsola, M. K. (2008). Relationship of some psychological variables in predicting problem solving ability of in-service mathematics teachers. The Montana Mathematics Enthusiast, 5(1), 79-100.

The American Institute for the Improvement of Mathematics Learning and Instruction. (2005). Mathematics-learning distress. Retrieved March 21, 2009, from http://www.mathsense.org

American River College. (2008). Fall 2008 class schedule: Mathematics. Retrieved March 21, 2009, from http://www.losrios.edu/arc/fall/Mathematics-MATH.htm

Ashcraft, M. H. (2002). Math anxiety: Personal, educational, and cognitive consequences. Current Directions in Psychological Science, 11(5), 181-185.

Ashcraft, M. H., \& Kirk, E. P. (2001). The relationships among working memory, math anxiety and performance. Journal of Experimental Psychology, 130(2), 224-237.

Ashcraft, M. H., \& Ridley, K. S. (2005). Math anxiety and its cognitive consequences: A tutorial review. In J.I.D. Campbell (Ed.), Handbook of mathematical cognition (pp. 315-330). New York: Psychology Press.

Bandalos, D. L., Yates, K., \& Thorndike-Christ T. (1995). Effects of math self-concept, perceived self-efficacy and attributions for failure and success on test anxiety. Journal of Educational Psychology, 87(4), 611-623.

Baylor, A. L., Shen, E., \& Warren, D. (n.d.). Supporting learners with math anxiety: The impact of pedagogical agent emotional and motivational support. Retrieved March 21, 2009, from http://ritl.fsu.edu/papers/W7_baylor_revised.pdf

Beck, A. T., Emery, G., \& Greenberg, R. L. (1985). Anxiety disorders and phobias: A cognitive perspective. New York: Basic Books.

Bessant, K. C. (1995). Factors associated with types of mathematics anxiety in college students. Journal for Research in Mathematics Education, 26(4), 327-345.

Blair, D., Phinney, L., \& Phillippe, K.A. (2001). International programs at community colleges. (Report No. AACC-RB-01-1). Retrieved March 21, 2009, from the American Association of Community Colleges Web site: http://www.aacc.nche.edu/Publications/Briefs/Pages/rb01012001.aspx

Brush, L. R. (1978). A validation study of the Mathematics Anxiety Rating Scale (MARS). Educational and Psychological Measurement, 38(2), 485-499. 
Bursal, M., \& Paznokas, L. (2006). Mathematics anxiety and preservice elementary teachers' confidence to teach mathematics and science. School Science and Mathematics, 106(4), 173-180.

Butte College. (2008). Catalog. Retrieved March 21, 2009, from http://www.butte.edu/departments/curriculum/catalog/

Caniglia, J., \& Duranczyk, I. M. (1999). Understanding mathematics backwards: A qualitative analysis of students' mathematical beliefs through autobiographies. In J. L. Higbee \& P.L. Dwinell (Eds.), Developmental education: An expanded role (pp. 43-55). Morrow, GA: National Association for Developmental Education.

Capraro, M. M., Capraro, R. M., \& Henson, R. K. (2001). Measurement error of scores on the mathematics anxiety rating scale across studies. Educational and Psychological Measurement, 61(3), 373-386.

Carroll, C. (2009). Developing math confidence. University of Florida Counseling Center. Retrieved March 21, 2009, from http://www.counsel.ufl.edu/selfHelpInformation/academicAndCareerConcerns/devel oping_math_confidence.aspx

Cates, G. L., \& Rhymer, K. N. (2003). Examining the relationship between mathematics anxiety and mathematics performance: An instructional hierarchy perspective. Journal of Behavioral Education, 12(1), 23-34.

Chapell, M. S., Blanding, Z. B., Silverstein, M. E., Takahashi, M., Newman, B., Gubi, A., \& McCann, N. (2005). Test anxiety and academic performance in undergraduate and graduate students. Journal of Educational Psychology, 97(2), 268-274.

Clute, P. S. (1984). Mathematics anxiety, instructional method, and achievement in a survey course in college mathematics. Journal for Research in Mathematics Education, 15(1), 50-58.

Dew, K. M. H., Galassi, J. P., \& Galassi, M. D. (1983). Mathematics anxiety: Some basic issues. Journal of Counseling Psychology, 30(3), 443-446.

Donelle, L., Arocha, J. F., \& Hoffman-Goetz, L. (2008). Health literacy and numeracy: Key factors in cancer risk comprehension. Chronic Diseases in Canada, 29(1), 18 .

Dreger, R. M., \& Aiken, L. R. (1957). The identification of number anxiety in a college population. Journal of Educational Psychology, 48, 344-351. 
Eppler, M., Harju, B., Ironsmith, M., \& Marva, J. (2003). Motivation and performance in college students enrolled in self-paced versus lecture-format remedial mathematics courses. Journal of Instructional Psychology, 30(4), 276-284.

Ferguson, R. D. (1986). Abstraction anxiety: A factor of mathematics anxiety. Journal for Research in Mathematics Education, 17(2), 145-150.

Glesne, C. (1999). Becoming qualitative researchers: An introduction ( $2^{\text {nd }}$ ed.). New York: Longman.

Goldberg, R., \& Waxman, J. (2003). A novel approach to curing quantiphobia. Mathematics and Computer Education, 37(1), 39-54.

Green, L. T. (1990). Test anxiety, mathematics anxiety, and teacher comments: Relationships to achievement in mathematics classes. The Journal of Negro Education, 59(3), 320-335.

Hackett, G. (1985). Role of mathematics self-efficacy in the choice of math related majors of college women and men: A path analysis. Journal of Counseling Psychology, 32(1), 47-56.

Hackett, G., \& Betz, N. E. (1989). An exploration of the mathematics selfefficacy/Mathematics performance correspondence. Journal for Research in Mathematics Education, 20(3), 261-273.

Harper, N. W., \& Daane, C. J. (1998). Causes and reduction of math anxiety in preservice elementary teachers. Action in Teacher Education, 19(4), 29-38.

Hembree, R. (1990). The nature, effects, and relief of mathematics anxiety. Journal for Research in Mathematics Education, 21(1), 33-46.

Hilton, P. (1980a). Math anxiety: Some suggested causes and cures: Part 1. The TwoYear Mathematics Journal, 11(3), 174-188.

Hilton, P. (1980b). Math anxiety: Some suggested causes and cures: Part 2. The TwoYear Mathematics Journal, 11(4), 246-251.

Ho, H., Senturk, D., Lam, A. G., Zimmer, J.M., Hong, S., Okamoto, Y., et al. (2000). The affective and cognitive dimensions of math anxiety: A cross-national study. Journal for Research in Mathematics Education, 31(3), 362-379.

Hopko, D. R., Hunt, M. K., \& Armento, M. E. (2005). Attentional task aptitude and performance anxiety. International Journal of Stress Management, 12(4), 389408. 
Hopko, D. R., Mahadevan, R., Bare, R. L., \& Hunt, M. K. (2003) The Abbreviated Math Anxiety Scale (AMAS): Construction, validity, and reliability. Assessment, 10(2), 178-182.

Hunsley, J. (1987). Cognitive processes in mathematics anxiety and test anxiety: The role of appraisals, internal dialogue and attributions. Journal of Educational Psychology, 79(4), 388-392.

Institute of International Education. (2008). Open doors report on international education exchange. Retrieved March 21, 2009, from http://opendoors.iienetwork.org/?p=131531

Jackson, C. D., \& Leffingwell, R. J. (1999). The role of instructors in creating math anxiety in students from kindergarten through college. Mathematics Teacher 92(7), 583-586.

Kazelskis, R., Reeves, C., Kersh, M. E., Bailey, G., Cole, K., Larmon, M., Hall, L., \& Holliday, D. C. (2000). Mathematics anxiety and test anxiety: Separate constructs? The Journal of Experimental Education, 68(2), 137-146.

Liebert, R.. M., \& Morris, L. W. (1967). Cognitive and emotional components of test anxiety: A distinction and some initial data. Psychological Reports, 20, 975-978.

Llabre, M. M., \& Suarez, E. (1985). Predicting math anxiety and course performance in college women and men. Journal of Counseling Psychology, 32(2), 283-287.

Ma, X. (1999). A meta-analysis of the relationship between anxiety toward mathematics and achievement in mathematics. Journal for Research in Mathematics Education, 30(5), 520-540.

Maqsud, M., \& Khalique, C. (1991). Relationships of some socio-personal factors to mathematics achievement of secondary school and university students in Bophuthatswana. Educational Studies in Mathematics, 22(4), 377-390.

McCabe, R. H. (2003). Yes we can! A community college guide for developing America's underprepared. Phoenix, AZ: League for Innovation in the Community College.

McGregor, C., MacMillan, P., \& Old, B. (2005). Ethnomathematics and aboriginal student anxiety. Academic Exchange Quarterly, 9(3), 126-130.

Miller, H., \& Bichsel, J. (2004). Anxiety, working memory, gender, and math performance. Personality and Individual Differences, 37, 591-606.

Mohr, J., \& Taylor, J. A. (2001). Mathematics for math anxious students studying at a distance. Journal of Developmental Education, 25(1), 30-41. 
National Association for Developmental Education (2001). Definition of developmental education. Retrieved March 21, 2009, from http://www.nade.net/aboutDevEd/definition.html

National Center for Education Statistics. (2000). National Postsecondary Aid Study 19992000 (NPSAS:2000). Retrieved March 21, 2009, from http://nces.ed.gov/das/library/tables_listings/show_nedrc.asp?rt=p\&tableID $=208$

Newman, I., Newman, C., Brown, R., \& McNeely, S. (2006). Conceptual statistics for beginners. New York: University Press of America, Inc.

Onwuegbuzie, A. (2004). Academic procrastination and statistics anxiety. Assessment and Evaluation in Higher Education, 29(1), 3 - 19.

Pan, W., \& Tang, M. (2004). Examining the effectiveness of innovative instructional methods on reducing statistics anxiety for graduate students in the social sciences. Journal of Instructional Psychology, 31(2), 149-159.

Pan, W., \& Tang, M. (2005). Students' perceptions on factors of statistics anxiety and instructional strategies. Journal of Instructional Psychology, 32(3), 205-214.

Parsad, B., \& Lewis, L. (2003). Remedial education at degree-granting postsecondary institutions in fall 2000: Statistical analysis report (NCES 2004-010). Washington, DC: U.S. Department of Education, National Center for Education Statistics. Retrieved March 21, 2009, from http://nces.ed.gov/pubs2004/2004010.pdf

Perry, A.B. (2004). Decreasing math anxiety in college students. College Student Journal 38(2), 321-324.

Polkinghorne, D.E. (2005). Language and meaning: Data collection in qualitative research. Journal of Counseling Psychology, 52(2), 137-145.

Pozehl, B. J. (1996). Mathematical calculation ability and mathematical anxiety of baccalaureate nursing students. Journal of Nursing Education, 35, 37-39.

Pries, C., \& Biggs, B. T. (2001). Can instructors help learners overcome mathematics anxiety? American Technical Education Association Journal, 28(4), 6-10.

Resnick, H., Segal, S., \& Viehe, J. (1982). Is math anxiety a local phenomenon? A study of prevalence and dimensionality. Journal of Counseling Psychology, 29(1), 3947.

Richardson, F. C., \& Suinn, R. M. (1972). The mathematics anxiety rating scale: Psychometric data. Journal of Counseling Psychology, 19(6), 551-554. 
Rounds, J. B. Jr., \& Hendel, D. D. (1980). Measurement and dimensionality of mathematics anxiety. Journal of Counseling Psychology, 27(2), 138-149.

Sarason, I. G. (1972). Test anxiety and the model who fails. Journal of Personality and Social Psychology, 22(3), 410-413.

Schwarzer, R. (1997). Anxiety. John D. and Catherine T. MacArthur Research Network on Socioeconomic Status and Health. Retrieved March 21, 2009, from http://www.macses.ucsf.edu/Research/Psychosocial/notebook/anxiety.html

Selden, A., \& Selden, J. (1993). Collegiate mathematics education research: What would that be like? The College Mathematics Journal, 24(5), 431-445.

Sloan, T., Daane, C. J., \& Giesen, J. (2002). Mathematics anxiety and learning styles: What is the relationship in elementary preservice teachers? School Science and Mathematics, 102(2), 84-87.

Spielberger, C. C. (2006). State-Trait anxiety inventory for adults. Retrieved March 21, 2009, from http://www.mindgarden.com/products/staisad.htm

Steele, C. M. (1998). Stereotyping and its threat are real. American Psychologist, 53(6), 680-681.

Steele, C. M., \& Aronson, J. (1995). Stereotype threat and the intellectual test performance of African Americans. Journal of Personality and Social Psychology, 69(5), 797-811.

Student Community College. (2007). Annual institutional research report. Author.

Suinn, R. M., \& Winston, E. H. (2003). The mathematics anxiety rating scale, a brief version: Psychometric data. Psychological Reports, 92,167-173.

Tapia, M., \& Marsh, G.E. (2004). The relationship of math anxiety and gender. Academic Exchange Quarterly, 8(2), 130-134.

Tobias, S. (1978). Overcoming math anxiety. Boston: Houghton Mifflin Company.

Trujillo, K. M., \& Hadfield, O. D. (1999). Tracing the roots of mathematics anxiety through in -depth interviews with preservice elementary teachers. College Student Journal, 33(2), 219-232.

Tryon, G. S. (1980). The measurement and treatment of test anxiety. Review of Educational Research, 50(2), 343-372. 
United States Census Bureau. (2004a). Census 2000: Profile of general demographic characteristics [Table TP2]. Retrieved March 21, 2009, from

$\mathrm{http} / / /$ censtats.census.gov/data/US/01000.pdf

United States Census Bureau. (2004b). Current population survey, annual social and economic supplement, 2004, ethnicity and ancestry statistics branch, population division. Retrieved March 21, 2009, from http://www.census.gov/population/socdemo/hispanic/ASEC2004/2004CPS_tab8. la.html

Wigfield, A., \& Meece, J. L. (1988). Math anxiety in elementary and secondary school students. Journal of Educational Psychology, 80(2), 210-216.

Wine, J.D. (1971). Test anxiety and direction of attention. Psychological Bulletin, 76, 92104.

Woodward, T. (2004). The effects of math anxiety on post-secondary developmental students as related to achievement, gender, and age. Inquiry, 9(1), Retrieved March 21, 2009, from http://www.vccaedu.org/inquiry/inquiry-spring2004/i-91woodard.html

Zanakis, S. H., \& Valenzi, E. R. (1997). Student anxiety and attitudes in business statistics. Journal of Education for Business, 73, 10-16.

Zeidner, M. (1998). Test anxiety: The state of the art. New York: Plenum Press.

Zettle, R. D., \& Houghton, L. L. (1998). The relationship between mathematics anxiety and social desirability as a function of gender. College Student Journal, 32(1), 8186.

Zettle, R. D., \& Raines, S. J. (2000). The relationship of trait and test anxiety with mathematics anxiety. College Student Journal, 34(2), 246-258. 
Appendix A 


\section{IRB Approval}

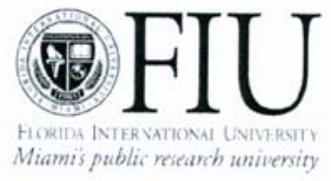

Office of Research Integrity

Research Compliance, MARC 430

\section{MEMORANDUM}

$\begin{array}{ll}\text { To: } & \text { Laura lossi } \\ \text { CC: } & \text { Dr. Ann Nevin } \\ & \text { File } \\ \text { From: } & \text { Chris Grayson, CIM, Asst. Director of Research Compliance } \\ \text { Date: } & \text { April 8,2008 } \\ \text { Proposal Title: } & \text { Bilingual College Students and their Experiences with Mathematics Anxiety. } \\ & \text { Approval \# 040108-00 }\end{array}$

Your study was deemed Exempt by the Institutional Review Board at Florida International University on April 1, 2008.

As a requirement of $I R B$ approval you are required to:

1) Submit a completion report (Form B-2) upon completion of your project in order for the file to be closed.

2) Submit a proposal and receive approval for any additions or changes in the procedures involving human subjects.

3) Provide immediate written notification to the IRB of every serious or unusual or unanticipated adverse event as well as problems with the rights or welfare of the human subjects. You must confirm the receipt of serious AE reports with the IRB office.

Special Conditions: N/A

Please note your approval number is indicated above. For further information, you may contact the IRB Coordinator by email at irbiacue@fiu.edu or visit the OSRA - Human Subjects website at www.osra.fiu.edu. 
Appendix B 


\section{IRB Approval for Revised Research Questions}

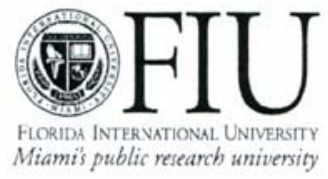

Office of Research Integrity

Research Compliance, MARC 430

\section{MEMORANDUM}
To:
Laura Iossi
CC:
Dr. Ann Nevin

File

From:

Chris Grayson, CIM, Asst. Director of Research Compliance

Date:

October 8, 2008

Proposal Title:

Bilingual College Students and their Expectations with Math Anxiety.

Approval \# 040108-00

The Institutional Review Board has approved the following modification(s):

Two research questions have been deleted and two have been added.

The research method has changed from QUAN-QUAL to QUAN only.

$>$ The data sources have changed. No interviews will be conducted with participants. No math autobiographies will be written by the participants. Performance measures have been added and will be obtained from the professors of the participating students. The final grades will be obtained and will be identified by the last four digets of the student ID.

$>$ A revised cover letter will be distributed to explain the study changes to the students in the classes where the faculty agreed to distribute surveys so that all participants who completed the survey (Phase I) would be informed that grades would be collected.

$>$ Consent forms will no longer be used in this Exempt project.

There are no additional requirements in regards to your study. However, if there are changes in the protocol after you commence your study that may increase the risks that the human subjects are exposed to, then you are required to resubmit your proposal to a Representative of the IRB for review. For further information, you may contact the IRB Coordinator by email at irbiacuc@fiu.edu or visit the ORI - Human Subjects website at http://ori.fiu.edu/IRB.html. 
Appendix C 


\section{Demographic Questionnaire}

Please fill in your responses on this sheet.

Please insert the last four digits of your student ID number:

1. What is your major?

2. Have you taken MAT 0024 or MAT 0020 (Elementary Algebra) at a Florida community college? Yes

No

3. Gender (check one):

Male

Female

4. $\quad$ Age range (check one): Less than 19

19-23

24-29

30-39

40 or over

5. Do you consider yourself bilingual? (For purposes of this study, you are bilingual if you are fluent in two or more languages)? Check one of the following:

Yes

No

6. What languages do you speak fluently? (Check all that apply.)

English

Spanish

Creole

Portuguese 
French

Other:__ Please specify:

7. Which racial category best describes you? (You may check one or more categories, if applicable.)

American Indian or Alaskan Native

Asian
Black or African American
Native Hawaiian or Pacific Islander
White
Other (please specify)

8. Ethnicity.

Hispanic

Non-Hispanic

9. What is your country of origin?

10. What is your estimated household income (check one)?

Below $\$ 25,000$
$\$ 25,000-\$ 49,999$
$\$ 50,000-\$ 74,999$
$\$ 75,000-\$ 99,999$
$\$ 100,000$ or above

11. Do you consider yourself to be a math anxious individual? (Check one.) Yes

No 
12. Select the sentence that best describes your experience. (Check one.)

I do not experience math anxiety.

I rarely experience math anxiety.

I sometimes experience math anxiety.

I frequently experience math anxiety.

13. Select the sentence that best describes your experience. (Check one.)

I do not experience math anxiety. I experience mild math anxiety.

I experience moderate math anxiety.

I experience severe math anxiety.

14. Would you be willing to participate in interviews about your experiences with mathematics?

Yes

No 
Appendix D 
Abbreviated Math Anxiety Scale (AMAS)

Please insert the last four digits of your student ID number:

Please rate each item in terms of how anxious you would feel during the event specified. Use the following scale and record your answer in the space to the left of the item:

Scale:

$1=$ Low Anxiety

$2=$ Some Anxiety

$3=$ Moderate Anxiety

$4=$ Quite a bit of Anxiety

$5=$ High Anxiety

1. Having to use the tables in the back of a math book.

2. Thinking about an upcoming math test one day before.

3. Watching a teacher work an algebraic equation on the blackboard.

4. Taking an examination in a math course.

5. Being given a homework assignment of many difficult problems which is due the next class meeting.

6. Listening to a lecture in math class.

7. Listening to another student explain a math formula.

8. Being given a "pop" quiz in a math class.

9. Starting a new chapter in a math book.

Permission for use received via personal communication (email) with D. R. Hopko on November 12, 2007.

Hopko, D.R., Mahadevan, R., Bare, R.L., \& Hunt, M.K. (2003) The Abbreviated Math Anxiety Scale (AMAS): Construction, validity, and reliability. Assessment, 10(2), 178-182. 
VITA

\title{
LAURA HILLERBRAND IOSSI
}

\author{
Born, Geneva, Switzerland
}

1995

B.S., Mathematics

Florida Atlantic University

Boca Raton, Florida

1997

M. S., Mathematics

Purdue University

West Lafayette, Indiana

2003

B.A., Theatre

Florida Atlantic University

Boca Raton, Florida

1995-1997

1997-1999

1997-1998

1997-2001

1999-2001

2001-2002

2002-2009

Teaching Assistant

Purdue University

West Lafayette, Indiana

Computer Instructor

Pine Crest Preparatory School

Fort Lauderdale, Florida

Drama Instructor

Pine Crest Preparatory School

Fort Lauderdale, Florida

Mathematics Instructor

Pine Crest Preparatory School

Fort Lauderdale, Florida

Adjunct Professor

SCC

Adjunct Professor

Palm Beach Community College

Boca Raton, Florida

Assistant Mathematics Professor

SCC 


\section{PUBLICATIONS AND PRESENTATIONS}

Iossi, L. (2005, February). Using Smarthinking in the classroom. Presentation at Professional Development Day, SCC.

Iossi, L. (2007, February). Strategies for reducing math anxiety. Presentation at Professional Development Day, SCC.

Iossi, L. (2007, March). Strategies for helping students cope with math anxiety. Poster session presented at the National Association for Developmental Education Conference, Nashville, TN.

Iossi, L. (2007, April). Strategies for reducing math anxiety in post-secondary students. In S. M. Nielsen \& M. S. Plakhotnik (Eds.). Proceedings of the Sixth Annual College of Education Research Conference: Urban and International Education Section (pp. 30-39). Miami, FL: Florida International University. Retrieved March 21, 2009, from http://coeweb.fiu.edu/Research_Conference/2007_SUIE_Proceedings_files/Iossi. $\% 20$ FINAL.pdf 